\title{
High Biomass Low Export Regimes in the Southern Ocean
}

Phoebe J. Lam ${ }^{1,2, *}$ and James K.B. Bishop ${ }^{1}$

${ }^{1}$ Earth Sciences Division, Lawrence Berkeley National Laboratory, 1 Cyclotron Road, Berkeley, CA 94720, USA

${ }^{2}$ Department of Earth and Planetary Science, University of California, Berkeley, Berkeley, CA 94720, USA

"now at Department of Marine Chemistry and Geochemistry, Woods Hole Oceanographic Institution, Woods Hole, MA 02543

Submitted January 27, 2006 to Deep Sea Research II: Special Topics in Oceanography (Special volume on The Role of Marine Organic Carbon and Calcite Fluxes in Driving Climate Change, Past and Future)

Revised version accepted June 28, 2006

Keywords: Ballast, remineralization, POC, Twilight Zone, mesopelagic, Southern Ocean, MULVFS, opal, carbonate, phosphorus 


\section{Abstract}

This paper investigates ballasting and remineralization controls of carbon sedimentation in the twilight zone (100-1000 m) of the Southern Ocean. Size-fractionated $(<1 \mu \mathrm{m}, 1-51 \mu \mathrm{m}$, $>51 \mu \mathrm{m})$ suspended particulate matter was collected by large volume in-situ filtration from the upper $1000 \mathrm{~m}$ in the Subantarctic $\left(55^{\circ} \mathrm{S}, 172^{\circ} \mathrm{W}\right)$ and Antarctic $\left(66^{\circ} \mathrm{S}, 172^{\circ} \mathrm{W}\right)$ zones of the Southern Ocean during the Southern Ocean Iron Experiment (SOFeX) in January-February 2002. Particles were analyzed for major chemical constituents (POC, $\mathrm{P}$, biogenic $\mathrm{Si}, \mathrm{CaCO}_{3}$ ), and digital and SEM image analyses of particles were used to aid in the interpretation of the chemical profiles.

Twilight zone waters at $66^{\circ} \mathrm{S}$ in the Antarctic had a steeper decrease in POC with depth than at $55^{\circ} \mathrm{S}$ in the Subantarctic, with lower POC concentrations in all size fractions at $66^{\circ} \mathrm{S}$ than at $55^{\circ} \mathrm{S}$, despite up to an order of magnitude higher POC in surface waters at $66^{\circ} \mathrm{S}$. The decay length scale of $>51 \mu \mathrm{m}$ POC was significantly shorter in the upper twilight zone at $66^{\circ} \mathrm{S}\left(\delta_{\mathrm{e}}=26\right.$ m) compared to $55^{\circ} \mathrm{S}\left(\delta_{\mathrm{e}}=81 \mathrm{~m}\right)$.

Particles in the carbonate-producing $55^{\circ} \mathrm{S}$ did not have higher excess densities than particles from the diatom-dominated $66^{\circ} \mathrm{S}$, indicating that there was no direct ballast effect that accounted for deeper POC penetration at $55^{\circ} \mathrm{S}$. An indirect ballast effect due to differences in particle packaging and porosities cannot be ruled out, however, as aggregate porosities were high $(\sim 97 \%)$ and variable.

Image analyses point to the importance of particle loss rates from zooplankton grazing and remineralization as determining factors for the difference in twilight zone POC 
concentrations at $55^{\circ} \mathrm{S}$ and $66^{\circ} \mathrm{S}$, with stronger and more focused shallow remineralization at $66^{\circ} \mathrm{S}$. At $66^{\circ} \mathrm{S}$, an abundance of large (several mm long) fecal pellets from the surface to $150 \mathrm{~m}$, and almost total removal of large aggregates by $200 \mathrm{~m}$, reflected the actions of a single or few zooplankton species capable of grazing diatoms in the euphotic zone, coupled with a more diverse particle feeding zooplankton community immediately below.

Surface waters with high biomass levels and high proportion of biomass in the large size fraction were associated with low particle loading at depth, with all indications implying conditions of low export. The $66^{\circ} \mathrm{S}$ region exhibits this "High Biomass, Low Export" (HBLE) condition, with very high $>51 \mu \mathrm{m}$ POC concentrations at the surface $(\sim 2.1 \mu \mathrm{M}$ POC), but low concentrations below $200 \mathrm{~m}\left(<0.07 \mu \mathrm{M}\right.$ POC). The $66^{\circ} \mathrm{S}$ region remained HBLE after iron fertilization. Iron addition at $55^{\circ} \mathrm{S}$ caused a ten fold increase in $>51 \mu \mathrm{m}$ biomass concentrations in the euphotic zone, bringing surface POC concentrations to levels found at $66^{\circ} \mathrm{S}(\sim 3.8 \mu \mathrm{M})$, and a concurrent decrease in POC concentrations below $200 \mathrm{~m}$. The $55^{\circ} \mathrm{S}$ region, which began with moderate levels of biomass and stronger particle export, transitioned to being HBLE after iron fertilization. We propose that iron addition to already HBLE waters will not cause mass sedimentation events. The stability of an iron-induced HBLE condition is unknown. Better understanding of biological pump processes in non-HBLE Subantarctic waters is needed. 


\section{Introduction}

The biological carbon pump transfers carbon from the atmosphere to the deep ocean via the settling of particulate organic carbon (POC) from the surface ocean, where it is produced from photosynthesis, to the deep ocean. Because the biological carbon pump partly determines the equilibrium $\mathrm{CO}_{2}$ concentration in the atmosphere (Volk and Hoffert 1985), understanding the controls on its efficiency is important for understanding global carbon cycling.

There exist several models that predict the magnitude of POC export out of the euphotic zone as a function of various surface properties, including primary production (Eppley and Peterson 1979), ecosystem structure (Michaels and Silver 1988), sea surface temperature (Laws et al. 2000), and combinations of the above (Dunne et al. 2005). In the deep sea, the decay of POC export with depth is most commonly modeled as an empirically fit function of shallow export (Martin et al. 1987). The search for a more mechanistic understanding of controls on deep POC flux (> $1000 \mathrm{~m}$ ) has most recently focused on the importance of mineral ballast (Armstrong et al. 2002; François et al. 2002; Klaas and Archer 2002). The idea of ballast minerals being important for the settling of POC to depth arises from the observation that the density of organic matter $\left(\sim 1.05 \mathrm{~g} / \mathrm{cm}^{3}\right)$ is roughly the same as that of seawater $\left(\sim 1.03 \mathrm{~g} / \mathrm{cm}^{3}\right)$, and that particles require a source of weight ("ballast") in order to sink. The most obvious sources of ballast for marine particulates in the open ocean are the biogenic minerals such as calcite $\left(\mathrm{CaCO}_{3}\right)$ and opal (biogenic silica) that form the shells of coccolithophores and diatoms, respectively. Calcite has a density of $2.71 \mathrm{~g} / \mathrm{cm}^{3}$, and diatom Si frustules have a density of 2.0 $\mathrm{g} / \mathrm{cm}^{3}$ (Hurd and Theyer 1977). Particles with a higher fraction of ballast minerals have a greater excess density over seawater, and thus sink faster. 
Global scale analyses of the composition of deep (>1000 m) sediment trap samples have revealed a linear spatial relationship between the flux of POC and the flux of ballast minerals (François et al. 2002; Klaas and Archer 2002). Further, the flux of opal is found to be a poor predictor of the flux of POC, and the flux of $\mathrm{CaCO}_{3}$ alone explains most of the variability in the flux of POC (François et al. 2002; Klaas and Archer 2002). Klaas and Archer (2002) attribute the more important role for $\mathrm{CaCO}_{3}$ to its higher density compared to opal, and thus its greater capacity for providing the excess density needed for sinking. François et al. (2002), on the other hand, conclude that opal's lack of predictive power means that excess density cannot be the mechanism explaining the correlation between POC and ballast minerals. Instead, François et al. (2002) propose that $\mathrm{CaCO}_{3}$ plays an indirect role in POC flux, either by being an indicator for the lability of settling POC (i.e., high carbonate-producing regions export more refractory POC), or by affecting the porosity or packaging of aggregates (i.e., carbonate regions produce tight fecal pellets and diatom regions produce loose and fluffy aggregates).

While there remain many unanswered questions about the controls on both shallow and deep export, even less well understood are the mesopelagic processes that link the two. The largest vertical gradients in both POC flux and concentration are in the mesopelagic region of the ocean between the euphotic zone and about $1000 \mathrm{~m}$, the so-called "Twilight Zone". This region is so named because it is too dark for photosynthesis, but has enough light for visual predation (Burd et al. 2002).

The specific shape of POC flux profiles in the twilight zone varies widely from place to place (Bishop 1989), and reflects a competition between the "survivability" of the organic carbon as it sinks from the euphotic zone, and the extent of its degradation as it is grazed and decomposed by heterotrophs. POC flux profiles that decrease rapidly and have a steep gradient 
mean that most POC produced is remineralized near the surface, returning inorganic carbon to waters that ventilate with the atmosphere on short time scales (seasons to years). POC flux profiles with small gradients mean that POC is being efficiently transferred to depth before being remineralized to inorganic carbon. Deep waters have a much longer timescale of return communication with the atmosphere. These latter flux profiles indicate regions where the biological pump works efficiently to naturally sequester carbon from the atmosphere for decades to centuries.

The loss of large particles through fragmentation and remineralization, both of which are mediated by zooplankton grazing activity, attenuate the flux of POC to depth from settling. Fragmentation is the breakup of large, sinking particles into smaller, suspended particles. Remineralization is the return of carbon from the particulate back to the dissolved form, and is a result of the metabolism of both large and small particles by zooplankton and bacteria. In the absence of these loss terms, POC concentrations at depth would be controlled entirely by the settling rates of particles.

The relationship between particle concentration and particle flux can be illustrated using the Stokes model for spherical particle settling, which is derived from a simple force balance between gravity and viscous drag:

\section{Equation 1}

$$
w_{s}=\frac{g \Delta \rho d^{2}}{18 \eta}
$$

The settling velocity, $w_{s}$, is proportional to the excess density of the particles above seawater, $\Delta \rho$, and to the square of particle size, $d^{2}$, and inversely proportional to the viscosity of the surrounding seawater, $\eta$. More complex formulae exist for the settling behavior of real, non- 
spherical marine particles (Bishop et al. 1986), but the density and viscosity formulations remain the same. The flux of POC can thus be understood as the concentration of POC times the settling velocity of particles.

Given a constant production of sinking particles in the surface layer and an absence of loss from grazing or microbial remineralization or from significant mechanical fragmentation, POC concentrations would slowly but systematically increase with depth due to the combined effects of increasing seawater viscosity and density. If mechanical fragmentation were to occur, the concentrations of smaller sized particles would increase strongly with depth. What is observed universally with POC, however, is that concentrations in all size fractions decrease strongly with depth. Decreasing POC concentration systematics must therefore reflect the dominance of grazing and remineralization losses.

In this paper, we present new $\mathrm{POC}, \mathrm{CaCO}_{3}$, and opal concentration profiles from the SubAntarctic and Antarctic twilight zones of the Southern Ocean. Together with digital and Scanning Electron Microscopy (SEM) images of particles to aid in the interpretation of the chemical data, we examine the relative importance of ballast minerals for sinking compared to loss processes for shaping the POC profiles. We concentrate our discussion on the large (>51 $\mu \mathrm{m})$ size fraction of suspended particles, since this is the fraction that contains particles important to vertical flux. Our high vertical resolution ( 10 depths/1000 m) compared to sediment traps allows us to examine in detail the region of highest vertical gradients in POC.

\section{Methods}

\subsection{Sampling Location}

We collected size-fractionated particulate samples using the Multiple Unit Large Volume in-situ Filtration System (MULVFS) (Bishop et al. 1985) during the Southern Ocean Iron 
Experiment (SOFeX) in January/February 2002. Like other mesoscale iron fertilization experiments, SOFeX involved the addition of iron to iron-limited waters with high levels of nitrate and phosphate. Its uniqueness was to test the differential response to iron in low versus high silicic acid waters (Coale et al. 2004). Two mesoscale iron addition experiments were conducted in the Southern Ocean southeast of New Zealand: in the low silicic acid $(<3 \mu \mathrm{M})$, but high nitrate $(20 \mu \mathrm{M})$ and phosphate $(1.5 \mu \mathrm{M})$ Subantarctic waters north of the Antarctic Polar Front $(\mathrm{APF})$ around $55^{\circ} \mathrm{S}, 172^{\circ} \mathrm{W}$, and in the high silicic acid $(\sim 60 \mu \mathrm{M})$, nitrate $(30 \mu \mathrm{M})$, and phosphate $(2 \mu \mathrm{M})$ Antarctic waters south of the APF around $66^{\circ} \mathrm{S}, 172^{\circ} \mathrm{W}$ (Coale et al. 2004). We sampled "control" and "iron amended" waters at both locations.

Primary productivity prior to iron fertilization was $\sim 15 \mathrm{mmol} \mathrm{C} / \mathrm{m}^{2} / \mathrm{d}$ and $\sim 32 \mathrm{mmol} / \mathrm{m}^{2} / \mathrm{d}$ at $55^{\circ} \mathrm{S}$ and $66^{\circ} \mathrm{S}$, respectively (Coale et al. 2004). Opal-producing diatoms overwhelmingly

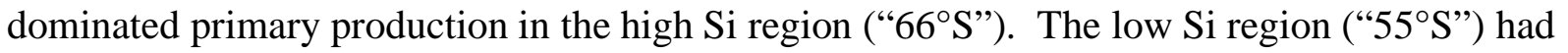
enough silicic acid to support some diatom growth, but also supported a more diverse assemblage, including dinoflagellates and carbonate-producing coccolithophores. These contrasting settings not only provided an interesting comparison for the biological response to iron, but also provided an ideal setting to examine the role of ballasting for shaping vertical POC profiles.

\subsection{Sample Collection}

The MULVFS collects up to 12 size-fractionated samples simultaneously between the surface and $1000 \mathrm{~m}$ during the filtration of up to $12,000 \mathrm{~L}$ of seawater over a four hour period (Bishop et al. 1985). MULVFS samples preserve the morphology of fragile aggregates, and the process of filtration does not induce particle aggregation (Bishop 1988; Bishop et al. 1977). 
The main flow of the MULVFS separates particles into " $<1 \mu \mathrm{m}$ ”, $1-51 \mu \mathrm{m}$, and $>51 \mu \mathrm{m}$ size fractions on a series of paired Whatman quartz fiber (QMA) filters and a polyester prefilter (51 $\mu \mathrm{m}$ mesh size), respectively. Both the $51 \mu \mathrm{m}$ polyester and the paired QMA filters were supported by $149 \mu \mathrm{m}$ polyester mesh to facilitate sample handling, but there was no additional pre-screen upstream of the $51 \mu \mathrm{m}$ polyester prefilter. All filters were of diameter $27.9 \mathrm{~cm}$, but the active particle collection area was of diameter $25.4 \mathrm{~cm}$. The efficiency of trapping by the quartz fiber filters drops sharply for particles below $1 \mu \mathrm{m}$, so the " $<1 \mu \mathrm{m}$ " size fraction is not quantitative, but provides an idea of the systematics of small particles (Bishop and Edmond 1976; Bishop et al. 1977; Bishop et al. 1985). A separate side-arm flow path enabled filtration of up to 50 liters through a $47-\mathrm{mm}$ diameter polycarbonate filter of pore size $0.4 \mu \mathrm{m}$.

A CTD instrument at the end of the MULVFS electromechanical cable recorded temperature and salinity of the water column and provided depth control during MULVFS casts.

We collected "dipped blank" samples, which were the usual MULVFS suite of filters on MULVFS pumps that were deployed identically to other pumps for the duration of the sample collection but whose pump was purposefully disconnected from power and did not have water flowing through. Few or no particles were observed on the filters, thus validating the use of these samples as in-situ blanks. Dipped blank samples were processed identically to all other samples, and are comprehensive blanks for all aspects of sample handling from pre-cruise treatment through deployment through post-cruise analysis.

The MULVFS filters were lightly misted with distilled water under suction to remove excess seawater before being dried in a $60^{\circ} \mathrm{C}$ oven. Each filter is exposed to 5-10 $\mathrm{mL}$ of distilled water during misting. Subsamples of the " $<1 \mu \mathrm{m}$ " and $1-51 \mu \mathrm{m}$ size fractions were isolated from 
distilled water applied during the misting process using sharpened acrylic tubes. These subsamples were stored frozen for later analysis of particulate organic carbon.

Three profiles were collected from the HNLC Southern Ocean in the Subantarctic Pacific $\left(55^{\circ} \mathrm{S}, 172^{\circ} \mathrm{W}\right)$ north of the APF, and five profiles were collected in the Antarctic Pacific $\left(66^{\circ} \mathrm{S}\right.$, $172^{\circ} \mathrm{W}$ ) south of the APF (Table 1; Figure 1). Since each MULVFS profile averages particulate data over the four-hour collection period, we averaged two profiles from each location to approximate a "steady state" profile for each location. For the $55^{\circ} \mathrm{S}$ average, we averaged casts 1 and 2, which were taken within a week of each other. The pumping for cast 2 was initiated inside iron-fertilized waters, but the ship drifted outside of the iron-fertilized patch for much of the pumping. We thus consider cast 2 a non-iron amended station for the purposes of this paper. We did not include the last, iron-amended profile (cast 8) in the $55^{\circ} \mathrm{S}$ average, since it was collected a month after the first two and showed the effects of iron fertilization. For the $66^{\circ} \mathrm{S}$ average, we averaged the two profiles from control, non-iron amended waters (cast 3, 6), which were taken within 10 days of each other.

\subsection{Digital imaging of >51 $\mu \mathrm{m}$ MULVFS filters}

Dried particulate samples on $>51 \mu \mathrm{m}$ filters were photographed using a 5 megapixel Nikon Coolpix 5700 camera. All samples were photographed at a focal length of $67.7 \mathrm{~mm}$ and focal distance of $0.41 \mathrm{~m}$, which corresponded to a field of view of $6.1 \mathrm{~cm} \mathrm{x} 4.1 \mathrm{~cm}$ and represented $\sim 1 / 20$ of the entire MULVFS filter area. All photographs were taken with an aperture of $\mathrm{F}=7.4$ and in identical lighting conditions-samples were illuminated using a $250 \mathrm{~W}$ GE Tungsten professional photography lamp and photographed at night to ensure constant ambient light. Each filter was photographed at three shutter speeds $(1 / 60 \mathrm{~s}, 1 / 125 \mathrm{~s}, 1 / 250 \mathrm{~s})$ in front of a white and black background. 
We photographed an identical, but unused, $51 \mu \mathrm{m}$ polyester filter against the white background at six shutter speeds ranging from $1 / 125 \mathrm{~s}$ to $1 / 4000 \mathrm{~s}$ to provide a conversion of image counts to optical density (OD). Doubling the shutter speed halves the amount of light let in, so the reference filter image series at different shutter speeds functions as a greyscale calibration: $\mathrm{OD}=\log [(1 / 125) /($ speed $)]$. OD at $1 / 125 \mathrm{~s}$ is defined as 0 , so $\mathrm{OD}$ at $1 / 4000 \mathrm{~s}$ was 1.51. This calibration procedure was verified using a Kodak greyscale. We derive a calibration curve relating counts in the green channel to optical density units (ODU) from a polynomial fit to the reference filter image series:

$$
\text { Counts }_{\text {green }}=51.668 * \mathrm{ODU}^{2}-185.02 * \mathrm{ODU}+169.68 \quad \mathrm{R}^{2}=0.999, \mathrm{n}=6
$$

We use the green channel here since it was less noisy and avoided pigment-specific absorption in the blue channel. For optical determination of particle concentration in the samples, we used images taken at 1/125 s against the white background and converted counts in the green channel to ODU. Similar calculations were performed using images of a dipped blank filter. The blank subtracted green optical density anomaly was assumed to originate from particles. We report this measure of particle concentration in optical density units (ODU) normalized by the volume filtered through each filter $\left(\mathrm{ODU} / \mathrm{m}^{3}\right)$.

The optical density of the $>51 \mu \mathrm{m}$ samples reflects the amount of material that is on the filters, and is thus an estimate of the relative particle loadings at each depth, providing an estimate of profile shape. The reflectance-based optical density signal saturates if filters are too heavily loaded, however, since the image does not capture the thickness of material on the filter. Heavily loaded samples were found shallower than $80 \mathrm{~m}$ at $66^{\circ} \mathrm{S}$ and in one sample at $55^{\circ} \mathrm{S}$ (cast $8,45 \mathrm{~m})$. 


\subsection{Chemical composition of particulates}

\subsubsection{Dry Weight of $>51 \mu m$ samples}

MULVFS filters were weighed before and after sample collection to the nearest tenth of a milligram (Bishop et al. 1985). Total dry weight was determined to the nearest tenth of a milligram from the difference, and was typically several hundred milligrams for $>51 \mu \mathrm{m}$ samples in the euphotic zone, and about $100 \mathrm{mg}$ in deep samples (Table 1). An offset in the weights of unused filters weighed before and after sample collection of $0.0032 \pm 0.0016 \mathrm{~g}$ (mean $\pm \mathrm{sd}$; $\mathrm{n}=2$ ) was added to total dry weights.

Subsamples of MULVFS filters were leached in ultrapure $0.6 \mathrm{~N} \mathrm{HCl}$. The leach solution was filtered through a $0.4 \mu \mathrm{m}$ Poretics polycarbonate membrane filter, diluted $\sim 5 \mathrm{x}$ to constant volume, and run on a Finnigan Element II Inductively Coupled Plasma Mass Spectrometer (ICPMS) for major, minor, and trace elements. Elements were normalized to Indium 115 and standardized using mixed element standards and CASS seawater, a coastal seawater standard reference material (National Research Council of Canada).

Total dry weight on the filters comprises the mass of suspended particulate matter and the mass of sea salt. Total salt on the filters has two sources: "MeshSalt" from the drying of residual excess seawater on the polyester mesh filter, and "AggregateSalt", which is salt associated with aggregates from the drying of insterstitial porewater in aggregates ( $c f$. Section 5.4.2.2).

MeshSalt was determined as the difference in total dry weights of dipped blank filters, and was $94.6 \pm 9.0 \mathrm{mg}$ (mean $\pm \mathrm{sd} ; \mathrm{n}=3$ ). MeshSalt was not evenly distributed across the entire filter-it was greatly reduced by distilled water misting over the $25.4 \mathrm{~cm}$-diameter particle

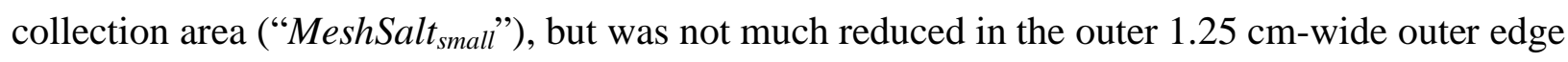


("MeshSalt ring "). We separate the contributions of MeshSalt small $_{\text {and MeshSalt }}$ ring using ICP-MS determined Na. All ICP-MS values were determined from subsamples taken from within and extrapolated to the $25.4 \mathrm{~cm}$-diameter particle collection area, and are thus representative of $\mathrm{Na}$ distributions in this area. We converted $\mathrm{Na}$ to salt using a Salt:Na mass ratio of $3.586 \pm 0.012$, which was determined by weighing the residual solids after $40 \mathrm{~mL}$ of North Atlantic seawater were dried at $60^{\circ} \mathrm{C}$ over several days, typical of the time scales used for drying our samples. The ratio (steady at 3.586 even after three weeks at $60^{\circ} \mathrm{C}$ ) is $\sim 9 \%$ higher than the theoretical dissolved solids to sodium ratio for seawater (3.262; (Pilson 1998)) because significant water of hydration is bound in $\mathrm{Ca}$ and $\mathrm{Mg}$ sulfate salts. MeshSalt small was determined from ICP-MS Na of dipped blanks. MeshSalt ring was determined from the difference between total MeshSalt and MeshSalt $_{\text {small, }}$ and contributed $32.4 \pm 15.2 \mathrm{mg}$ of salt, or $34 \%$ of Total MeshSalt, even though this outer edge contributes only $17 \%$ of the total filter area.

For filters loaded with particles, we also used Na multiplied by the Salt:Na mass ratio above to determine the mass of salt from the particle collection area ("Salt small ), since organisms discriminate preferentially against $\mathrm{Na}$ more than other major cations in seawater (Bishop and Edmond 1976). Since the fractional error in the Salt:Na mass ratio is small, the error in Salt small $_{\text {is }}$ essentially the error of the ICP-MS Na measurement $\left(\% \mathrm{sd}_{\mathrm{Na}}=8.9 \%\right)$, determined from replicate Na measurements on different subsamples of the same filter: $s d_{\text {Salt }_{\text {small }}} \approx \% s d_{N a} \times N a \times S a l t: N a$. ICP-MS Na in samples had three sources: 1) intracellular $\mathrm{Na}$ from biological particles (Na discrimination is not complete); 2) $\mathrm{Na}$ from residual excess seawater on the filter; and 3) $\mathrm{Na}$ from aggregate pore fluids. Salt $t_{\text {small }}$ thus comprises the mass of intracellular fluids scaled to a salt mass, and salt from the mesh (MeshSalt small $_{\text {) }}$ and from aggregates (AggregateSalt). 
The total mass of salt for filters loaded with particles was the sum of MeshSalt ${ }_{\text {ring }}$ and Salt $_{\text {small }}$, and typically accounted for $\sim 60 \%$ and $\sim 80 \%$ of the total dry weight in the euphotic zone and below $100 \mathrm{~m}$, respectively. The mass of suspended particulate material was the salt corrected dry weight of particles (Table 1):

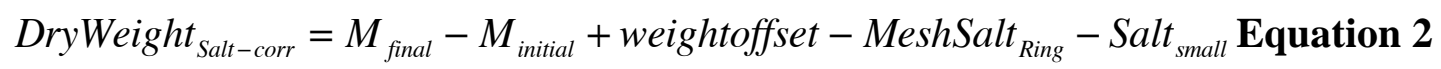

\subsubsection{Sources of $\mathrm{Na}$ in $>51 \mu \mathrm{m}$ samples}

We estimate intracellular Na using ICP-MS determined particulate phosphorus and a molar Na:P of 24.1, which was determined from phytoplankton collected in upwelling waters off the coast of California (Bruland et al. 1991; Martin and Knauer 1973). Intracellular Na accounted for $\sim 50 \%$ of total ICP-MS Na in the diatom-dominated euphotic zone of $66^{\circ} \mathrm{S}$, but less than $\sim 4 \%$

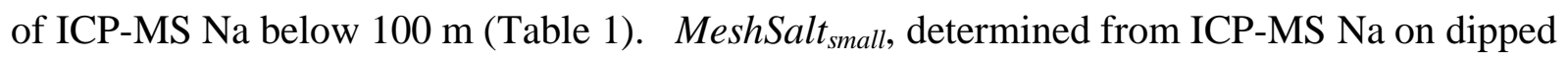
blank samples, was $62.2 \pm 12.3 \mathrm{mg}$ (mean $\pm \mathrm{sd}$; $\mathrm{n}=3$ ), representing $66 \%$ of total MeshSalt and $\sim 25 \%$ and $65 \%$ of ICP-MS Na in the euphotic zone and below $100 \mathrm{~m}$, respectively. Blanks for $\mathrm{Na}$ are negligible in unused filters. Na from AggregateSalt was determined from the difference between ICP-MS Na, intracellular Na, and Na from MeshSalt small. $_{\text {. }}$

\subsection{3 $\mathrm{CaCO}_{3}$ determination}

ICP-MS derived $\mathrm{Ca}$ on the filters is representative of $\mathrm{Ca}$ on the $25.4 \mathrm{~cm}$-diameter particle collection area of the filter, and derives from $\mathrm{Ca}$ from salt, intracellular $\mathrm{Ca}$, and $\mathrm{CaCO}_{3}(\mathrm{Bishop}$ et al. 1977). Salt Ca was determined from the portion of salt Na distributed over the particle

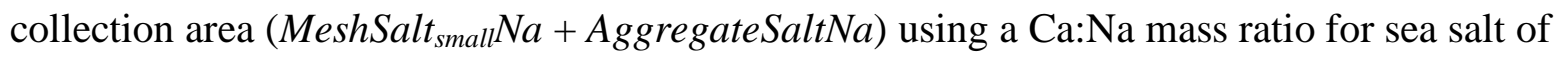
0.0382 (Pilson 1998), and accounted for $\sim 40 \%$ of $1-51 \mu \mathrm{m}$ and $\sim 30 \%$ of $>51 \mu \mathrm{m}$ total Ca at $55^{\circ} \mathrm{S}$, and $\sim 80 \%$ of both $1-51 \mu \mathrm{m}$ and $>51 \mu \mathrm{m}$ total $\mathrm{Ca}$ at $66^{\circ} \mathrm{S}$ (Table 1 ). We use phosphorus 
determined from ICP-MS and a molar $\mathrm{Ca}: \mathrm{P}=0.593$, which is the average $\mathrm{Ca}: \mathrm{P}$ ratio of four diatom species grown in culture (Ho et al. 2003), to estimate and subtract intracellular Ca (Table 1). The remaining $\mathrm{Ca}$ was assumed to come from stoichiometric $\mathrm{CaCO}_{3}$. Since $\mathrm{Na}, \mathrm{Ca}$, and $\mathrm{P}$ are determined simultaneously, the elemental corrections are precise to $3 \%$ for each subsample analyzed.

\subsubsection{Biogenic Silica (Opal) determination}

The 1-51 $\mu \mathrm{m}$ size fraction could not be analyzed directly for biogenic silica because it was collected on a quartz filter. We measured total biogenic silica on the $>0.4 \mu \mathrm{m}$ polycarbonate side-arm filters and on separate MULVFS subsamples from the $>51 \mu \mathrm{m}$ polyester filters.

Estimates of $<51 \mu \mathrm{m}$ opal can be made by difference since there was no prefilter upstream of the polycarbonate filter.

Subsamples were leached overnight in $0.5 \mathrm{~N} \mathrm{NaOH}$ at $60^{\circ} \mathrm{C}$ to recover biogenic silica. $\mathrm{Si}$ was analyzed spectrophotometrically (Bishop et al. 1977). The mass of biogenic silica (opal) was calculated assuming a hydrated form of silica: $\mathrm{SiO}_{2}\left(0.4 \mathrm{H}_{2} \mathrm{O}\right)$ (Mortlock and Froelich 1989).

\subsubsection{POC determination}

Particulate organic carbon (POC) from the small size fractions (“<1 $\mu \mathrm{m}$ ” and 1-51 $\mu \mathrm{m}$ ) was determined directly by combustion (Altabet et al. 1999) after acid fuming overnight with concentrated $\mathrm{HCl}$ in a glass desiccating chamber to remove inorganic carbon. We used the POC determined from combustion and particulate phosphorus determined from ICP-MS analysis to determine the C:P ratio of the 1-51 $\mu \mathrm{m}$ samples (Figure 3c). Blank correction for POC and $\mathrm{P}$ using in-situ dipped blank samples were 0.26 and $3.39 \mu \mathrm{M} \mathrm{POC} / \mathrm{cm}^{2}$ of filter and 2.91 and 4.46 $\mathrm{nM} \mathrm{P} / \mathrm{cm}^{2}$ of filter for the " $<1 \mu \mathrm{m}$ " and 1-51 $\mu \mathrm{m}$ fractions, respectively. 
Because the $>51 \mu \mathrm{m}$ size fraction was collected on a polyester mesh, POC could not be determined directly by combustion. We estimate $>51 \mu \mathrm{m}$ POC using gravimetric determination of organic matter and $>51 \mu \mathrm{m}$ particulate phosphorus profiles determined from ICP-MS. Table 2 summarizes the $>51 \mu \mathrm{m}$ POC terms that are explained below. To derive POC gravimetrically ("POC grav"), particulate organic matter $(\mathrm{POM})$ is determined as the difference between the salt corrected dry weight (Equation 2) and the masses of $\mathrm{CaCO}_{3}$ and biogenic $\mathrm{Si}$ (Bishop and Edmond 1976), and converted to POC using a POM:POC mass ratio of 1.88, based on NMR determinations of the composition of plankton (Hedges et al. 2002):

$$
\mathrm{POC}_{\text {grav }}=\frac{1}{1.88} *\left(\text { DryWeight }_{\text {Salt-corr }}-\mathrm{CaCO}_{3}-\text { Opal }\right) \text { Equation } 3
$$

Lithogenic material has been shown to be very low for samples from this region of the Southern Ocean (Honjo et al. 2000).

We use particulate phosphorus profiles as a crosscheck on $\mathrm{POC}_{\text {grav }}$. We multiply the particulate phosphorus of the $>51 \mu \mathrm{m}$ size fraction determined from ICP-MS by the C:P ratio determined on 1-51 $\mu \mathrm{m}$ samples to get "POC $\mathrm{P}_{\mathrm{P}}$ ". Using a measured $\mathrm{C}: \mathrm{P}$ accounts for the significant deviations from the canonical Redfield ratio that has been observed in the Southern Ocean (Rubin 2003). For casts 1 and 2 at $55^{\circ} \mathrm{S}$ and casts $3-7$ at $66^{\circ} \mathrm{S}$, we multiply by the $55^{\circ} \mathrm{S}$ and $66^{\circ} \mathrm{S}$ average $\mathrm{C}: \mathrm{P}$ ratios, respectively. Because the $\mathrm{C}: \mathrm{P}$ ratio below the euphotic zone for cast 8 at $55^{\circ} \mathrm{S}$ is much lower than for casts 1 and 2 (Figure 3c), we multiply the particulate phosphorus by the $\mathrm{C}: \mathrm{P}$ ratio for cast 8 . While using the measured $\mathrm{C}: \mathrm{P}$ of the small size fraction attempts to account for the higher lability of particulate phosphorus compared to POC, large 
particles have been shown to fractionate to much higher values of $\mathrm{C}: \mathrm{P}$ with depth compared to small particles (Bishop et al. 1977). As a result, we expect $\mathrm{POC}_{\mathrm{P}}$ to underestimate $\mathrm{POC}$ at depth.

The gravimetric estimate of POC, "POC grav", consistently predicts a higher concentration of POC than POC $_{\mathrm{P}}$ (Figure 2d,e; Table 3). At $\sim 40 \mathrm{~m}$, average $\mathrm{POC}_{\text {grav }}$ values are $0.47 \mu \mathrm{M}$ and $3.33 \mu \mathrm{M}$ at $55^{\circ} \mathrm{S}$ and $66^{\circ} \mathrm{S}$, respectively, whereas $\mathrm{POC}_{\mathrm{P}}$ underestimates POC by factors of $\sim 3$ with values of $0.17 \mu \mathrm{M}$ and $0.95 \mu \mathrm{M}$ at $55^{\circ} \mathrm{S}$ and $66^{\circ} \mathrm{S}$ (Table 3). At depth, $\mathrm{POC}_{\text {grav }}$ predicts up to an order of magnitude more $\mathrm{POC}$ below $500 \mathrm{~m}$ than $\mathrm{POC}_{\mathrm{P}} . \mathrm{POC}_{\text {grav }}$ is accurate at high levels of biomass such as in the euphotic zone at $66^{\circ} \mathrm{S}$, but is inaccurate at depth. This is because $\mathrm{POC}_{\text {grav }}$ is estimated by difference between total dry weights measured on the entire filter and the masses of salt, $\mathrm{CaCO}_{3}$, and opal. At depth, the mass of salt is large compared to total dry weight, resulting in high relative uncertainties for $\mathrm{POC}_{\text {grav }}$. We calculate the error associated with $\mathrm{POC}_{\text {grav }}$ estimates as:

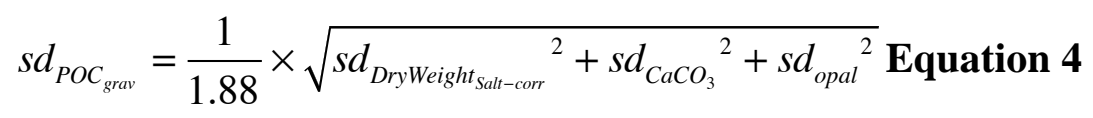

where

$$
s d_{\text {DryWeightsalt-cor }}=\sqrt{s d_{\text {weightoffset }^{2}}+s d_{\text {MeshSalt }_{\text {Ring }}}{ }^{2}+s d_{\text {Salt }_{\text {sall }}}{ }^{2}} \text { Equation } 5
$$

Typical relative errors for each of the components are: $\% s d_{\text {DryWeightsalt-corr }}=37 \%, \% s d_{\mathrm{CaCO}_{3}}=25 \%$, and $\% s d_{\text {opal }}=3 \%$.

The standard deviation of deep (>200 m) POC $_{\text {grav }}$ estimates $(\sim 0.06-0.11 \mu \mathrm{M})$ is greater than the differences in deep POC $\left(\Delta \mathrm{POC}_{\mathrm{P}} \sim 0.001-0.04 \mu \mathrm{M}\right)$ that we are trying to resolve (Figure $2 \mathrm{~d}, \mathrm{e})$. 
While $\mathrm{POC}_{\mathrm{P}}$ likely underestimates $\mathrm{POC}$ at depth, we have several reasons to believe $\mathrm{POC}_{\mathrm{P}}$ systematics are a reasonable representation of the systematics of $>51 \mu \mathrm{m}$ POC. First, digital images taken of the $>51 \mu \mathrm{m}$ MULVFS samples from mid depths ( $465 \mathrm{~m})$ clearly show that the filters at $55^{\circ} \mathrm{S}$ have many more particles than at $66^{\circ} \mathrm{S}$ (Figure 4a,b). Further, the shapes of the green optical density profiles, a photographic proxy for the amount of particles on our filters, mimic the systematics of the $\mathrm{POC}_{\mathrm{P}}$ profiles (Figure $2 \mathrm{f}$ ), notably showing higher particle concentration at $55^{\circ} \mathrm{S}$ than $66^{\circ} \mathrm{S}$ below $150 \mathrm{~m}$ as the $\mathrm{POC}_{\mathrm{P}}$ profiles do.

$\mathrm{POC}_{\text {grav }}$ is accurate in the euphotic zone, especially at $66^{\circ} \mathrm{S}$ where biomass is high and uncertainty is small (Table 3). We therefore use $\mathrm{POC}_{\text {grav }}$ in the euphotic zone at $66^{\circ} \mathrm{S}$ to determine the factor by which $\mathrm{POC}_{\mathrm{P}}$ underestimates POC. At $66^{\circ} \mathrm{S}$ in the upper $50 \mathrm{~m}$, where $\mathrm{POC}_{\text {grav }}$ is most accurate, $\mathrm{POC}_{\text {grav }}: \mathrm{POC}_{\mathrm{P}}$ is $2.6 \pm 0.9$ (mean $\left.\pm \mathrm{sd} ; \mathrm{n}=8\right)$. We scale $\mathrm{POC}_{\mathrm{P}}$ at all

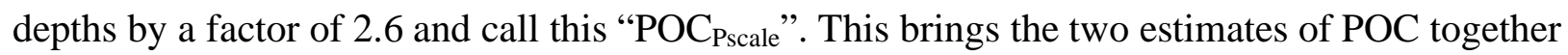
at the surface, while also mimicking the increase of $\mathrm{C}: \mathrm{P}$ with depth for large particles. For the rest of this paper, we use $\mathrm{POC}_{\text {Pscale }}$ in discussions of $>51 \mu \mathrm{m}$ POC, bearing in mind the caveats discussed above.

\section{Results}

\subsection{POC and $P$ profiles in the Twilight Zone}

All size fractions (“<1 $<\mathrm{m}$ ”, 1-51 $\mu \mathrm{m},>51 \mu \mathrm{m}$ ) show that POC concentrations were consistently lower at $66^{\circ} \mathrm{S}$ than $55^{\circ} \mathrm{S}$ below $200 \mathrm{~m}$ with up to 3 -fold lower concentrations at depth, despite higher surface concentrations (Figure 3, Table 3) and productivity at $66^{\circ} \mathrm{S}$. The behaviour of particulate phosphorus in all size fractions yields the same systematic differences (Figure 2a-c), with lower deep concentrations at $66^{\circ} \mathrm{S}$ despite higher surface concentrations 
there. The lower deep concentrations of POC and P are also reflected by such a basic parameter as volume filtered: for roughly the same filtration time, about $20 \%$ more water was filtered through the deep, low particle waters of $66^{\circ} \mathrm{S}$ than $55^{\circ} \mathrm{S}$ (Table 1). $>51 \mu \mathrm{m} \mathrm{POC}_{\text {Pscale }}$ shows a much steeper gradient in concentration at $66^{\circ} \mathrm{S}$ compared to $55^{\circ} \mathrm{S}$ (Figure $3 \mathrm{~d}$ ).

\section{2 $\mathrm{CaCO}_{3}$ and Opal profiles in the Twilight Zone}

The profiles of small $(1-51 \mu \mathrm{m})$ and large $(>51 \mu \mathrm{m})$ size fractions for $\mathrm{CaCO}_{3}$ and total $(>0.4 \mu \mathrm{m})$ and large $(>51 \mu \mathrm{m})$ size fractions for opal from $55^{\circ} \mathrm{S}$ and $66^{\circ} \mathrm{S}$ are presented in Figure 5. Both $1-51 \mu \mathrm{m}$ and $>51 \mu \mathrm{m} \mathrm{CaCO}_{3}$ are far more abundant at $55^{\circ} \mathrm{S}$ than $66^{\circ} \mathrm{S}$ throughout the upper 1000 m (Figure 5a,c).

$>51 \mu \mathrm{m}$ biogenic $\mathrm{Si}$ (opal) concentrations and profile shapes are roughly similar to those of POC at both $55^{\circ} \mathrm{S}$ and $66^{\circ} \mathrm{S}$, except that the gradient is less steep for opal than for POC (Figure 5d, Figure 3d). Opal concentrations at $66^{\circ} \mathrm{S}$ are an order of magnitude higher at the surface than at $55^{\circ} \mathrm{S}$, but decay quickly in the upper $150 \mathrm{~m}$ so that the concentrations below 150 $\mathrm{m}$ are very similar at both locations (Figure 5).

The $55^{\circ} \mathrm{S}$ region has both higher POC penetration to depth and higher $\mathrm{CaCO}_{3}$ concentrations. This observation is consistent with the $\mathrm{POC}-\mathrm{CaCO}_{3}$ correlation from the deep sediment trap studies. The greatest difference in profile shapes between $55^{\circ} \mathrm{S}$ and $66^{\circ} \mathrm{S}$ for all components are in the depth interval 100-200 m immediately below the euphotic zone.

\subsection{Imaging of >51 $\mu \mathrm{m}$ MULVFS filters}

Digital images of profiles of MULVFS filters provide insights on interpreting the trends apparent in the chemical composition of the particulates. Figures 4,6 and 8 show pairs of images taken against a black and a white background. The two backgrounds reveal the relative 
abundance of the more optically transparent particles, which are most visible against the black background, compared to the abundance of darkly pigmented particles, which are visible against the white background.

Comparison of pre iron-fertilized states at $55^{\circ} \mathrm{S}$ (Figure 6a) and $66^{\circ} \mathrm{S}$ (Figure 6c) shows striking differences in the levels of particle concentrations on the filters. Filters from the euphotic zone $(<50 \mathrm{~m})$ from cast 1 at $55^{\circ} \mathrm{S}$ are speckled with discrete aggregates and other material (Figure 6a, Figure 7a), whereas filters from the euphotic zone from cast 3 at $66^{\circ} \mathrm{S}$ are completely covered with a thick layer of material, intermixed with $\sim 4$ mm-long fecal pellets (Figure 6c). SEM images of surface $66^{\circ} \mathrm{S}$ samples reveal that this thick layer of material is composed almost entirely of large diatoms (Figure 7b).

The long fecal pellets are seen to $\sim 150 \mathrm{~m}$ in all profiles at $66^{\circ} \mathrm{S}$, and are absent in deeper waters. These long fecal pellets indicate the presence of large zooplankton consumers such as euphausiids. The abundance and diversity of fecal pellets types increase dramatically just below the euphotic zone (80-150 m) at $66^{\circ} \mathrm{S}$ (Figure $6 \mathrm{c}, \mathrm{d}$, Figure $8 \mathrm{~b}, \mathrm{~d}$ ), indicating an increase in the complexity of the food web. This reflects actions of a single or few zooplankton species capable of grazing the diatoms in the euphotic zone, coupled with a diverse and dependent particle feeding zooplankton community immediately below.

Stepping down the water column, the large fecal material disappears completely by 200 $\mathrm{m}$ in all $66^{\circ} \mathrm{S}$ profiles and the particle loadings of the filters decrease dramatically (Figure $6 \mathrm{c}, \mathrm{d}$ ), even as the volume of water filtered through each increases (Table 1). The disappearance of all large fecal material within $50 \mathrm{~m}$ implies that secondary consumers were very active between 150-200 $\mathrm{m}$ in grazing and remineralizing the large fecal material. Mechanical fragmentation of 
large particles into small particles can be ruled out as a dominating loss process because POC concentrations in the small fraction do not significantly increase with depth (Figure 3a,b).

Evidence of active grazing can be seen in SEM images of smaller aggregates (fecal material) from $66^{\circ} \mathrm{S}$ below $200 \mathrm{~m}$, which show no recognizable structures and suggests that the material within these aggregates has been heavily processed (Figure 7d). In contrast, aggregates from $55^{\circ} \mathrm{S}$ at $459 \mathrm{~m}$ comprise identifiable small diatom frustules and coccoliths (Figure 7c).

Below $200 \mathrm{~m}$, there is clearly more material on filters from $55^{\circ} \mathrm{S}$ than $66^{\circ} \mathrm{S}$ (Figure 6a,c; $>200 \mathrm{~m}$ ). Since the volumes filtered through the pumps were $\sim 20 \%$ less at $55^{\circ} \mathrm{S}$ than $66^{\circ} \mathrm{S}$ (Table 1), this further confirms the higher concentrations of $>51 \mu \mathrm{m}$ POC at depth at $55^{\circ} \mathrm{S}$ from our chemical (Figure 3) and quantitative (OD) profiles from image analyses (Figure 2f).

Examination of images from the post iron-fertilized state at $55^{\circ} \mathrm{S}$ (cast 8) shows an interesting evolution: euphotic zone samples are now nearly covered with a thick layer of material (Figure $6 \mathrm{~b} ; 35 \mathrm{~m}$ ), much like samples from the euphotic zone at $66^{\circ} \mathrm{S}$ (Figure $6 \mathrm{c}, \mathrm{d} ;<50$ m). Moreover, there is a clear decrease in material on filters below $100 \mathrm{~m}$ relative to before iron fertilization (Figure $6 \mathrm{a}, \mathrm{b} ;>100 \mathrm{~m})$. Indeed, all estimates of $>51 \mu \mathrm{m}$ particle concentrations $(\mathrm{P}$, $\mathrm{OD}_{\text {green }}, \mathrm{POC}_{\text {Pscale }}$ ) show that the cast 8 profiles (solid circles) follow the shape of the $66^{\circ} \mathrm{S}$ profiles (triangles) more than the shapes of the earlier $55^{\circ} \mathrm{S}$ profiles (open circles, squares) (Figure 2,3). Autonomous profiling floats that were inside and outside of the Fe fertilized patch at this time show that the $0.8 \mu \mathrm{M}$ POC isolevel remained at around $125 \mathrm{~m}$ outside of the patch, but shoaled to $100 \mathrm{~m}$ inside of the patch (Bishop et al. 2004), confirming that this feature was likely associated with Fe fertilization and not from a general decrease throughout the region.

The most striking differences in particle size distribution between $55^{\circ} \mathrm{S}$ and $66^{\circ} \mathrm{S}$ are in the non iron-amended euphotic zones, with pre iron-fertilized $55^{\circ} \mathrm{S}$ filters comprising discrete 
aggregates $50-150 \mu \mathrm{m}$ in size (Figure 6a), whereas filters from $66^{\circ} \mathrm{S}$ are dominated by a thick layer of diatoms (Figure 6c). In the depth interval immediately below the euphotic zone (80-150 $\mathrm{m})$, the particle size distribution appears shifted towards larger particles at $66^{\circ} \mathrm{S}$ than at $55^{\circ} \mathrm{S}$ (Figure 8). Deeper still, preliminary quantitative image analyses of $>51 \mu \mathrm{m}$ filters not only showed more particles at $55^{\circ} \mathrm{S}$ at $450 \mathrm{~m}$, but that they were generally larger than particles from the same $450 \mathrm{~m}$ depth at $66^{\circ} \mathrm{S}$.

Comparison of digital images of MULVFS filters taken against white and black backgrounds reveal some aggregates that are visible against both white and black backgrounds, but also light-colored aggregates that are only visible against the black background. Lightcolored fecal material likely has a lower density than dark material (Bishop et al. 1986). $55^{\circ} \mathrm{S}$ seems to have more aggregates that are visible against both backgrounds, whereas $66^{\circ} \mathrm{S}$ seems to have more optically transparent aggregates that are visible against the black background only (Figures 4, 6, and 8). Overall, light-colored aggregates dominate numerically at both locations. We postulate that the pigmented particles are more tightly packed fecal pellets, which may be responsible for much of the particle flux, whereas the light-colored particles are looser and less dense aggregates of fecal matter and marine snow.

The assemblage of organisms is more diverse at $55^{\circ} \mathrm{S}$ than at $66^{\circ} \mathrm{S}$, with diatoms, coccolithophores, and dinoflagellates common at $55^{\circ} \mathrm{S}$, whereas diatoms are the predominant organisms at $66^{\circ} \mathrm{S}$. Coccoliths from the coccolithophore Emiliania huxleyi are visible in SEM images of aggregates throughout the water column at $55^{\circ} \mathrm{S}$. 


\section{Discussion}

\subsection{Modeling the decrease in $>51 \mu m$ POC with depth}

Several lines of evidence suggest that the POC profiles at $55^{\circ} \mathrm{S}$ and $66^{\circ} \mathrm{S}$ can be thought of as a 1-D system, with large $(>51 \mu \mathrm{m})$ particles below the euphotic zone deriving from settling from above. Since coccolithophores are known to grow in sub-Antarctic but not in Antarctic waters (Balch et al. 2005), the high $\mathrm{CaCO}_{3}$ concentrations (Figure 5) and the presence of coccoliths in aggregates (Figure $7 \mathrm{c}$ ) throughout the twilight zone at $55^{\circ} \mathrm{S}$ supports the assumption that aggregates at depth derive from the surface sub-Antarctic above, and argues against the hypothesis that subduction of surface polar waters from further south are the dominant source of mid-water particles at $55^{\circ} \mathrm{S}$. In addition, profiling floats deployed at $55^{\circ} \mathrm{S}$ showed little evidence of current shear in the upper kilometer (Bishop et al. 2004). At $66^{\circ} \mathrm{S}$, a profiling float that was parked at $100 \mathrm{~m}$ for $20 \mathrm{hrs} /$ day lost the iron fertilized patch after 10 days, indicating some shear between the surface and subsurface, but the float continued to track high surface biomass and low particle abundance at depth in the surrounding waters for 2 months until the onset of winter (Bishop, in prep), arguing against the horizontal advection of POC-rich surface water from elsewhere over local low particle water. We therefore assume that the $55^{\circ} \mathrm{S}$ and $66^{\circ} \mathrm{S}$ POC profiles can be considered 1-D systems.

With the assumption of a 1-D vertical system at steady state, we can model the decrease in $>51 \mu \mathrm{m}$ POC with depth by equating the divergence of the flux of POC from particle settling in and out of a depth layer to the internal sink of POC due to fragmentation and remineralization (biological metabolism) of large particles: 


$$
\frac{\partial\left(w_{s} C\right)}{\partial z}=-r C \text { Equation } 6
$$

where $C$ is the POC concentration, $z$ is depth, $w_{s}$ is the particle settling velocity, and $r$ is the loss rate due to fragmentation and remineralization. If $w_{s}$ and $r$ are constant with depth, the solution to the differential equation is an exponential function:

$$
C=C_{0} \mathrm{e}^{-\frac{z}{\left(w_{s} / r\right)}} \text { Equation } 7
$$

If either $w_{s}$ or $r$ is dependent with depth $\left(w_{s}=w_{0} z\right.$ or $\left.r=r_{0} / z\right)$, the solution to the differential equation is a power law function:

$$
C=C_{0}\left(\frac{z}{z_{0}}\right)^{-\frac{z_{0}}{\left(w_{0} / r_{0}\right)}} \text { Equation } 8
$$

The decay length scale $(\delta)$ can best be thought of as the ratio of particle settling velocity to remineralization rate $\left(\delta=w_{s} / r\right)$.

The assumptions for the depth-dependent behaviours of the settling and remineralization rates required for the exponential or power law formulations of POC concentration are vast simplifications of actual processes occurring in the water column. The application of exponential or power law models is therefore meant as a physically motivated but simplified empirical description of our observations.

\subsection{Decay length scales of $>51 \mu \mathrm{m} \mathrm{P,POC,} \mathrm{CaCO}_{3}$, and opal in the Twilight Zone of the}

\section{Southern Ocean}

The average profiles from each location for $>51 \mu \mathrm{m}$ particulate phosphorus $(\mathrm{P})$, POC, $\mathrm{CaCO}_{3}$, and opal were used to determine decay length scales for each of these components. The 
$1 \%$ light levels at $55^{\circ} \mathrm{S}$ and $66^{\circ} \mathrm{S}$ shoaled from $83 \mathrm{~m}$ to $32 \mathrm{~m}$ and $58 \mathrm{~m}$ to $23 \mathrm{~m}$, respectively, over the course of the iron addition experiment ( 30 days) (Coale et al. 2004). We chose samples deeper than $80 \mathrm{~m}$ for analysis since they are below the $1 \%$ light level and thus interpretation of profile shape is not complicated by the presence of growing phytoplankton. We report $\delta_{\mathrm{e}, \mathrm{p}}$, the length scale at which the concentrations are reduced by 1/e compared to a reference depth of $90 \mathrm{~m}$ (Table 4).

\subsection{1 $P$ and $P O C$}

Since POC is derived from $\mathrm{P}$, we discuss these two components together. The power law function fits the data for both $\mathrm{P}$ and POC at both $55^{\circ} \mathrm{S}$ and $66^{\circ} \mathrm{S}$ better than the exponential function, especially in the upper twilight zone, which is the location of the highest gradient (Figure 9). The poor fit using an exponential function implies that the simplest assumption of constant sinking and remineralization rates with depth cannot be true.

A single power law function fit the $55^{\circ} \mathrm{S} \mathrm{P}$ and POC profiles very well $\left(\mathrm{R}_{\mathrm{P}}^{2}=0.986\right.$ and $\mathrm{R}_{\text {POC }}^{2}=0.980$ ), capturing both the shape of the highest gradient as well as the values of the concentrations at depth (Figure 9a,c). The shapes of the $66^{\circ} \mathrm{S} \mathrm{P}$ and POC profiles, on the other hand, were not well captured with a single power law function (Figure 9b,d). The residuals to the $66^{\circ} \mathrm{S}$ POC fits show that the data above $200 \mathrm{~m}$ depth behave differently than the data below (Figure 9f). We separate the twilight zone at $66^{\circ} \mathrm{S}$ into an upper regime that spans $80-200 \mathrm{~m}$ and captures the region of the highest concentration gradients, and a lower regime that spans 200$1000 \mathrm{~m}$. The fit to the upper regime captures the steepness of the gradient, but underpredicts $\mathrm{P}$ and POC values below $200 \mathrm{~m}$, and the fit to the lower regime captures deep values but underpredicts shallow P and POC (Figure 9a,c). This suggests that the P and POC loss rates in the upper regime $(80-200 \mathrm{~m})$ are much higher than those in the lower regime $(200-1000 \mathrm{~m})$. The 
upper regime fit captures the quickly decaying $\mathrm{P}$ and $\mathrm{POC}$ fractions, which dominate total $\mathrm{P}$ and POC in this region. The lower regime fit captures slowly decaying $\mathrm{P}$ and POC.

Comparison of the power law decay lengths $\left(\delta_{\mathrm{e}, \mathrm{p}}\right)$ in the region of the highest gradient reveals that $\mathrm{P}$ and $\mathrm{POC}$ at $66^{\circ} \mathrm{S}$ decay more quickly $\left(\delta_{\mathrm{e}, \mathrm{p}(\mathrm{P})}=23 \mathrm{~m}, \delta_{\mathrm{e}, \mathrm{p}(\mathrm{POC})}=26 \mathrm{~m}\right)$ than $\mathrm{P}$ and $\mathrm{POC}$ at $55^{\circ} \mathrm{S}\left(\delta_{\mathrm{e}, \mathrm{p}(\mathrm{P})}=79 \mathrm{~m}, \delta_{\mathrm{e}, \mathrm{p}(\mathrm{POC})}=81 \mathrm{~m}\right)($ Table 4$)$.

These decay length scales are much shorter than remineralization length scales commonly reported from POC flux profiles estimated using ${ }^{234} \mathrm{Th}$ deficits or sediment traps, which are closer to 150-200 m (Equatorial Pacific (Bacon et al. 1996); North Pacific (Martin et al. 1987)). This is because our fits are to POC concentration rather than flux. The conversion from a concentration to a flux profile using particle settling velocities ( $c f$. Equation 1) must take into account the size spectrum of particles, all of which sink at different speeds. The resulting flux profile has a shape and remineralization length scale that is commensurate with what is estimated using sediment traps ( $c f$. Bishop et al. 1986).

\subsection{2 $\mathrm{CaCO}_{3}$ and $\mathrm{Opal}$}

The remineralization of $\mathrm{CaCO}_{3}$ and opal should not necessarily be expected to follow the decay of POC, and yet both minerals do exhibit a decrease in concentration with depth. We fit exponential and power law functions to normalized $\mathrm{CaCO}_{3}$ and opal profiles as a simple way to compare the decay length scales of these biogenic minerals with those of POC.

The $55^{\circ} \mathrm{S} \mathrm{CaCO}_{3}$ profile was better fit with the power law compared to the exponential function (Figure 10a; Table 4). The decay length scale was $155 \mathrm{~m}, \sim 75 \mathrm{~m}$ longer than for POC (Table 4). In this case, the factor of three increase in concentrations of $1-51 \mu \mathrm{m} \mathrm{CaCO}_{3}$ to $300 \mathrm{~m}$ at $55^{\circ} \mathrm{S}$ (Figure 5a) suggests that some coccoliths in aggregates were delivered to the small 
particle fraction through fragmentation. Although the $66^{\circ} \mathrm{S} \mathrm{CaCO}_{3}$ profile was also better fit with a power law compared to the exponential (Figure 10b;Table 4), the levels of $\mathrm{CaCO}_{3}$ are so low that this may not be relevant.

Opal at $55^{\circ} \mathrm{S}$ is well fit with a single exponential $\left(\mathrm{R}^{2}=0.933\right)$ or a single power law $\left(\mathrm{R}^{2}=0.936\right)$ function, but the shape of the profile is better captured with the power law function (Figure 10c). At $66^{\circ} \mathrm{S}$, neither a single power law nor exponential function captures the shape of the opal profile. Similar to the behaviour of POC at this location, the opal gradient can only be captured by fitting the upper regime separately (Figure 10d). The upper regime power law fit to opal at $66^{\circ} \mathrm{S}$ predicts a decay length scale of $\delta_{e, p}=36 \mathrm{~m}$, similar to the upper regime decay halflength of POC $\left(\delta_{e, p}=26 \mathrm{~m}\right)$, and shorter than the opal decay length scale at $55^{\circ} \mathrm{S}\left(\delta_{\mathrm{e}, \mathrm{p}}=186 \mathrm{~m}\right)$.

\subsection{Seasonal and interannual context}

The contrasts in POC profiles that we find between $55^{\circ} \mathrm{S}$ and $66^{\circ} \mathrm{S}$ were also seen in studies in the Australian sector of the Southern Ocean (along $\sim 140^{\circ} \mathrm{E}$ ). The shorter POC decay length scale at $66^{\circ} \mathrm{S}$ is consistent with studies in the Australian sector showing shallower remineralization in the Antarctic compared to the Subantarctic in spring 2001(Cardinal et al. 2005). The pattern of higher export at $55^{\circ} \mathrm{S}$ compared to $66^{\circ} \mathrm{S}$ is also consistent with data from sediment traps at $1000 \mathrm{~m}$ that showed higher maximum and integrated POC flux in the carbonate

producing Subantarctic compared to the diatom dominated Polar Frontal Zone(Trull et al. 2001).

In contrast, previous occupations of our sites along $170^{\circ} \mathrm{W}$ during the US JGOFS program between 1996-1998 showed higher maximum POC fluxes in the Antarctic compared to the Subantarctic at $100 \mathrm{~m}$ (Buesseler et al. 2001) and $1000 \mathrm{~m}$ (Honjo et al. 2000), and similar shallow and deep fluxes at both locations when averaged over the growing season (Buesseler et al. 2003). 
There are several explanations for the differences between the JGOFS conclusions and those from our data and the Australian sector studies. The JGOFS seasonal cycle of POC flux at $1000 \mathrm{~m}$ is a composite of the latter part of the 1996-1997 growing season and the beginning of the 1997-1998 growing season. The Australian sector trap data, which showed higher export in the Subantarctic than in the Polar Frontal Zone, were from a full seasonal cycle in the 1997-1998 growing season. Where the two time series overlap at the beginning of the 1997-1998 growing season (September-January), patterns in deep (1000 m) POC flux in both the Antarctic and Polar Frontal/Antarctic Zones were fairly similar (Honjo et al. 2000; Trull et al. 2001). Based on the early season similarities, it is reasonable to speculate that the rest of the season may have behaved similarly at the JGOFS site, and that the JGOFS conclusion that the Antarctic had higher POC export than the Subantarctic may have been influenced by anomalously high Antarctic flux in the 1996-1997 season. Indeed, the 1000 m POC fluxes were more than a factor of four higher in December 1996 than in December 1997 (Honjo et al. 2000).

The Subantarctic is roughly two weeks ahead of the Antarctic in the seasonal cycle of production and export (Green and Sambrotto 2006; Honjo et al. 2000; Trull et al. 2001), so an alternative hypothesis is that our POC profiles are snapshots of different stages in the seasonal cycles of these systems. However, autonomous profiling floats deployed at both $55^{\circ} \mathrm{S}$ and $66^{\circ} \mathrm{S}$ showed that POC concentrations at mid-depths were consistently higher in the Subantarctic than the Antarctic for a full year following SOFeX, and that the pattern of high surface biomass and low particles at depth was a feature that persisted for the rest of the 2001-2002 growing season, and repeated in the beginning of the 2002-2003 growing season (Bishop et al. in prep).

The final resolution of whether the Subantarctic or the Antarctic is better at transferring POC to depth will have to wait for a longer timeseries. 


\subsection{Can differences in settling velocity account for POC differences?}

Particles with faster settling velocities will have shorter residence times and thus be less susceptible to remineralization in shallow waters. As a result, for a given remineralization rate, regions with faster settling particles will have more POC penetration to depth than regions with slowly settling particles. Here we examine whether differences in settling velocities between $55^{\circ} \mathrm{S}$ and $66^{\circ} \mathrm{S}$ can account for the difference in the decay length scales of POC.

The settling velocity is very sensitive to particle size and geometry (Alldredge and Gotschalk 1988; Bishop et al. 1978), but a rigorous analysis of particle size and shape distribution in the two locations is beyond the scope of this paper. We look instead at how differences in seawater viscosity $(\eta)$ and particle excess density $(\Delta \rho)$ between $55^{\circ} S$ and $66^{\circ} S$ affect the settling rates of particles ( $c f$. Equation 1).

\subsubsection{Effect of viscosity on POC}

Viscosity is a strong function of temperature and salinity. The net result of warmer temperatures and fresher waters at $55^{\circ} \mathrm{S}$ is that viscosities at $55^{\circ} \mathrm{S}$ are $5-21 \%$ lower than at $66^{\circ} \mathrm{S}$ (Figure 11). The difference in viscosities between the two locations is most pronounced at the depth of the subsurface temperature minimum at $66^{\circ} \mathrm{S}$, located between $50-100 \mathrm{~m}$.

Higher viscosity reduces the settling speed of particles. Below $150 \mathrm{~m}$, where POC is lower at $66^{\circ} \mathrm{S}$, the more viscous waters there would retard the settling of particles. To see how much of an effect viscosity plays in the POC profile differences, we compare the $>51 \mu \mathrm{m}$ average POC concentrations at the two locations with the effect of viscosity removed. We pick a reference viscosity $\left(\eta_{\text {ref }}\right)$ of 0.018 poise, which is the viscosity of $66^{\circ} \mathrm{S}$ waters at $300 \mathrm{~m}$, and determine $\eta_{\text {ref }} / \eta_{\text {obs }}$ for each location, where $\eta_{\text {obs }}$ is determined from temperature and salinity 
measurements at $55^{\circ} \mathrm{S}$ and $66^{\circ} \mathrm{S}$. Returning to our earlier Stokes' Law example (Equation 1), the flux of POC can be understood as the concentration of POC multiplied by the settling velocity of particles:

$$
F=C^{*} w_{s}=C * \frac{g \Delta \rho d^{2}}{18 \eta} \text { Equation } 9
$$

It follows that for a given flux, $F$, the concentration of POC, $C$, is proportional to the viscosity, $\eta$. We multiply POC by $\eta_{\text {ref }} / \eta_{\text {obs }}$ to compare the shapes of the resultant viscosity-normalized POC profiles. Comparison of viscosity-normalized profiles shows that differences in viscosity between $55^{\circ} \mathrm{S}$ and $66^{\circ} \mathrm{S}$ shift profiles slightly further apart, but have a negligible effect on the shapes of POC profiles (Figure 12), and the decay length scales for the viscosity-normalized POC $_{\text {Pscale }}$ profiles remain virtually unchanged (Table 4). While the differences in viscosity between Subantarctic and Antarctic waters are generally much less than $20 \%$ and have a negligible effect on POC profile differences, the viscosity of seawater ranges by a factor of two over the globe and becomes an important effect when comparing polar and tropical waters.

\subsubsection{Ballast mineral-induced changes in excess density}

We now turn to how ballast mineral-induced changes in excess density, $\Delta \rho$, affect the settling velocity, $w_{s}$. Ballast minerals may influence the excess densities of particles in two ways: directly, through compositional differences, and indirectly, by influencing the packaging and porosity of aggregates.

\subsubsection{Compositional contribution to excess density}

We first calculated the excess densities of particles based on their compositional differences only. We assume all particles are comprised of three major components: $\mathrm{CaCO}_{3}$, 
opal, and organic matter. We calculate the average density of particulate matter, $\rho_{P M}$, in our samples as:

$$
\rho_{P M}=\frac{m_{P M}}{V_{P M}}=\frac{m_{\mathrm{CaCO}_{3}}+m_{\text {opal }}+m_{\text {org }}}{V_{\mathrm{CaCO}_{3}}+V_{\text {opal }}+V_{\text {org }}}=\frac{m_{\mathrm{CaCO}_{3}}+m_{\text {opal }}+m_{\text {org }}}{\frac{m_{\mathrm{CaCO} O_{3}}}{\rho_{\mathrm{CaCO}}}+\frac{m_{\text {opal }}}{\rho_{\text {opal }}}+\frac{m_{\text {org }}}{\rho_{\text {org }}}} \text { Equation } 10
$$

where $m_{\mathrm{CaCO}_{3}}$ and $m_{\text {opal }}$ are the weights of $\mathrm{CaCO}_{3}$ and opal on the filter, $m_{\text {org }}$ is the weight of

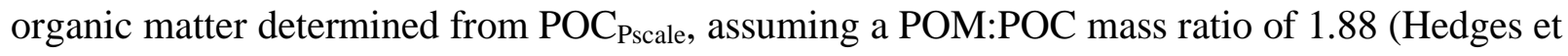
al. 2002), $\rho_{\mathrm{CaCO} 3}=2.71 \mathrm{~g} / \mathrm{cm}^{3}, \rho_{\text {opal }}=2.0 \mathrm{~g} / \mathrm{cm}^{3}$ (Hurd and Theyer 1977), and $\rho_{\text {org }}=1.05 \mathrm{~g} / \mathrm{cm}^{3}$ (Young 1994). The excess density is the density of particulate matter above the density of seawater, which we calculate from temperature and salinity (Millero and Poisson 1981).

The fraction of carbonate that does contribute to ballasting is mostly from coccoliths and partly from fragments of larger carbonate shells. In previous observations of MULVFS samples from the Equatorial Atlantic, whole and fragments of small, juvenile foraminifera contributed $6 \%$ and $1 \%$, respectively, of total suspended carbonate concentrations in the $>53 \mu \mathrm{m}$ size fraction, with the remaining $93 \%$ of the carbonate bound in aggregates as coccoliths (Bishop et al. 1977). Coccoliths also accounted for $>90 \%$ of $>53 \mu \mathrm{m}$ carbonate concentrations in MULVFS samples from the upwelling Southeast Atlantic and Panama Basin (Bé et al. 1985; Bishop et al. 1978). Large, fast-sinking foraminifera are rare in MULVFS samples are not associated with aggregates. In contrast to suspended particles, fast-sinking foraminifera are much more important for sediment trap carbonate flux, with planktonic foraminifera accounting for a quarter to a half of open ocean flux at $100 \mathrm{~m}$ (Schiebel 2002). 
We observed numerous coccoliths within aggregates and occasional small foraminifera and pteropods in SEM images taken of $55^{\circ} \mathrm{S}$ samples. For excess density calculations, we make the simplifying assumption that all $\mathrm{CaCO}_{3}$ and opal measured in our $>51 \mu \mathrm{m}$ samples contribute to ballasting.

Average excess densities ranged from $0.29-0.68 \mathrm{~g} / \mathrm{cm}^{3}$ at $55^{\circ} \mathrm{S}$ and $0.29-0.71 \mathrm{~g} / \mathrm{cm}^{3}$ at $66^{\circ} \mathrm{S}$ (Figure 13), and were significantly different from each other $\left(p(t<T)_{\text {two-tail }}=0.04\right)$. Excess densities increase with depth at both locations as relatively low density organic matter is preferentially remineralized compared to the denser opal and $\mathrm{CaCO}_{3}$ ballast minerals.

Despite the presence of dense calcite at $55^{\circ} \mathrm{S}$ and its near absence at $66^{\circ} \mathrm{S}$, the excess densities of samples from the carbonate producing $55^{\circ} \mathrm{S}$ were lower than the excess densities of the opal dominated $66^{\circ} \mathrm{S}$. This is because $\mathrm{CaCO}_{3}$ was generally only $\sim 10 \%$ by weight even at $55^{\circ} \mathrm{S}$, whereas opal and organic matter together accounted for the rest, with individual component levels as high as $\sim 60 \%$ by weight at $55^{\circ} \mathrm{S}$. The contributions of opal and organic matter to overall density thus swamp out the contribution from $\mathrm{CaCO}_{3}$ at $55^{\circ} \mathrm{S}$. At $66^{\circ} \mathrm{S}$, particulate matter is to first order comprised only of opal and organic matter. The lower excess densities at $55^{\circ} \mathrm{S}$ below $100 \mathrm{~m}$ are driven largely by the higher fraction of low-density organic matter at $55^{\circ} \mathrm{S}$ compared to $66^{\circ} \mathrm{S}$ at depth.

Since the composition-based excess densities of particles at $55^{\circ} \mathrm{S}$ are lower than at $66^{\circ} \mathrm{S}$, ballast mineral composition alone does not explain the greater penetration of $>51 \mu \mathrm{m}$ POC to depth at $55^{\circ} \mathrm{S}$.

\subsubsection{Porosity contributions to excess density}

Since natural marine aggregates such as marine snow can have porosities as high as 99.9\% (Alldredge and Gotschalk 1988), the true excess densities of aggregates must therefore 
take porosity into account. It has been proposed that diatom-dominated aggregates might be less tightly packaged than carbonate-containing aggregates and thus explain why opal does not show much ballasting capacity in deep sediment traps (François et al. 2002).

We estimated the porosity of aggregates using the mass of aggregate-associated salt (“AggregateSalt") on our filters (cf. section 3.4.2). SEM examination of the $>51 \mu \mathrm{m}$ samples revealed that salt crystals are common on the outside of most aggregates (Figure 8c,d). Excess seawater is reduced by misting samples with distilled water immediately after samples are brought on board the ship. We hypothesize that the salt crystals observed in the SEM images are from the evaporation of porewater trapped in the interstitial spaces of the aggregates as the filters are being dried. We account for incomplete rinsing of excess seawater by subtracting the mean

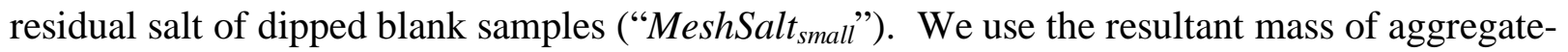
associated salt on our samples and the salinity of seawater as a first order estimate of the pore volume within aggregates:

$$
V_{P W}=\frac{\text { AggregateSalt }}{S} \times \frac{1}{\rho_{S W}} \text { Equation } 11
$$

where $V_{p w}$ is the volume of porewater, AggregateSalt is the mass of aggregate-associated salt on the filter, $S$ is the salinity of seawater, and $\rho_{s w}$ is the density of seawater. The porosity is the volume fraction of pore water in the aggregates, where the total volume of the aggregates was calculated as the sum of the volumes of $\mathrm{CaCO}_{3}$, opal, organic matter, and porewater over the entire filter. The "porous density" of aggregates is then: 


\section{Equation 12}

$$
\rho_{\text {porous }}=\frac{m_{\text {porous }}}{V_{\text {porous }}}=\frac{m_{\mathrm{CaCO}_{3}}+m_{\text {opal }}+m_{\text {org }}+m_{\text {pores }}}{V_{\mathrm{CaCO}_{3}}+V_{\text {opal }}+V_{\text {org }}+V_{P W}}=\frac{m_{\mathrm{CaCO}_{3}}+m_{\text {opal }}+m_{\text {org }}+\rho_{\mathrm{SW}} V_{\mathrm{PW}}}{\frac{m_{\mathrm{CaCO}_{3}}}{\rho_{\mathrm{CaCO}_{3}}}+\frac{m_{\text {opal }}}{\rho_{\text {opal }}}+\frac{m_{\text {org }}}{\rho_{\text {org }}}+V_{P W}}
$$

We estimated uncertainty in the porosity and porous density calculations by propagating errors from the measurement uncertainties in AggregateSalt, $m_{\text {org }}, m_{\mathrm{CaCO} 3}$, and $m_{\text {opal }}$.

Average porosities in the twilight zone estimated from salt were high and ranged from 91\% to $99 \%$ (Figure 14a). Typical relative errors from error propagation for these porosity estimates were $1 \%$. Average porosities at $66^{\circ} \mathrm{S}$ were significantly higher $(p=0.03$ for a onetailed paired-sample t-test) than those at $55^{\circ} \mathrm{S}$ in the upper twilight zone $(80-200 \mathrm{~m})$ (Figure 14a).

Sources of error to this method include underestimation due to premature squeezing out of porewater by aggregate breakage before the filters are dried, or overestimation from incomplete rinsing of the excess external seawater from the surface of aggregates. Since all samples were consistently collected and processed, relative differences should be retained. However, despite the potential uncertainties, the salt-based porosity estimates are quite reasonable compared to previous estimates of the porosity of large (>1 mm) marine snow aggregates, which ranged from 97-99.9\% (Alldredge and Gotschalk 1988).

The salt-based porosities are bulk estimates of overall porosity of all aggregates on the filter, and thus primarily reflect the porosities of the volumetrically dominant light-colored aggregates. Nonetheless, we can still estimate the resulting excess densities after incorporating bulk porosities. Since bulk porosities are similar and very high $(\sim 97 \%)$ in both locations, adding porosity greatly lowers excess densities of aggregates at both $55^{\circ} \mathrm{S}$ and $66^{\circ} \mathrm{S}$ to $<0.04 \mathrm{~g} / \mathrm{cm}^{3}$ 
(Figure 14b), and makes the excess density less sensitive to compositional changes and much

more dependent on porosity differences. Indeed, because of the slightly higher porosities at $66^{\circ} \mathrm{S}$ in the upper twilight zone, the resultant porous excess densities there are now slightly lower $(p=$ 0.05 for a one-tailed paired-sample t-test) than at $55^{\circ} \mathrm{S}$ (Figure $14 \mathrm{~b}$ ).

The photographic images show that $55^{\circ} \mathrm{S}$ samples had more darkly pigmented particles than at $66^{\circ} \mathrm{S}$, suggesting that the $55^{\circ} \mathrm{S}$ region had a higher population of dense fecal pellets. The higher relative abundance of dark particles at $55^{\circ} \mathrm{S}$ may be responsible for most of the particle flux, but the contribution of these particles to excess density and particle flux is obscured in the calculation of bulk porosities.

\subsection{Dominance of biological loss processes in the upper Twilight Zone at $66^{\circ} \mathrm{S}$}

We showed above that the direct effect of ballast mineral composition on excess density goes the wrong way for explaining the differences in POC profile shapes between $55^{\circ} \mathrm{S}$ and $66^{\circ} \mathrm{S}$, but we cannot rule out an indirect ballast effect from a possible correlation between opal producing regions and lower aggregate packaging and porosities, which could lower particle settling rates and thus affect POC profile shape. Since the packaging of particles into aggregates is biologically mediated through zooplankton grazing, our data suggest that biological processes affecting the fragmentation and remineralization of large particles are the most important factors determining the first order shape of POC profiles in the twilight zone. Since we do not find a direct influence of our coccolith-dominated carbonate on POC concentration, we speculate that the correlation between POC flux and $\mathrm{CaCO}_{3}$ flux seen in deep sediment traps (François et al. 2002; Klaas and Archer 2002) is driven primarily by foraminiferal contribution to $\mathrm{CaCO}_{3}$ flux, and reflects the reproductive success of foraminifera in non-diatom dominated regions of high 
food availability (Bé et al. 1985). We recommend a reanalysis of the sediment trap data with foraminifera removed.

The fragmentation of large, sinking particles into smaller, suspended particles, mediated by zooplankton activity, can be inferred from the relatively higher concentration of POC in the small, very slowly-sinking size fraction of particles $(<51 \mu \mathrm{m})$ below the euphotic zone (Bishop et al. 1986). Fragmentation of large aggregates can be further inferred from size-fractionated particulate Ba profiles. Micron-sized barite $\left(\mathrm{BaSO}_{4}\right)$ particles are formed within large aggregates and broken phytoplankton in the near surface, resulting in sometimes high concentrations of particulate $\mathrm{Ba}$ in the $>51 \mu \mathrm{m}$ size fraction in the euphotic zone, but low concentrations in the small, suspended $(1-51 \mu \mathrm{m})$ size fraction (Bishop 1988). Particulate $\mathrm{Ba}$ is transferred from the large to small size fraction when large aggregates are fragmented, releasing barite particles into the suspended size fraction (Bishop 1988). An observed maximum in particulate Ba in the 1-51 $\mu \mathrm{m}$ suspended size fraction below the euphotic zone implies that fragmentation processes are active in this region. The shorter decay length scale for POC at $66^{\circ} \mathrm{S}$ is consistent with particulate 1-51 $\mu \mathrm{m} \mathrm{Ba}$ profiles (Figure 15), which show that the $66^{\circ} \mathrm{S}$ profile has a shallower $\mathrm{Ba}$ maximum $(\sim 150 \mathrm{~m})$ than at $55^{\circ} \mathrm{S}(\sim 200 \mathrm{~m})$. This indicates that biologically mediated fragmentation occurs shallower in the water column at $66^{\circ} \mathrm{S}$. What distinguishes $\mathrm{POC}$ from $\mathrm{Ba}$ is the fact that $\mathrm{Ba}$ particles have no metabolic value and that $\mathrm{Ba}$ is precipitated exclusively in the large particle fraction. This interpretation of particulate $\mathrm{Ba}$ is consistent with more extensive studies of Ba and carbon remineralization in the Southern Ocean (Cardinal et al. 2005).

There are no observations of the depth distribution of zooplankton biomass in this sector of the Southern Ocean. Previous observations of the vertical distribution of zooplankton biomass 
in the Panama Basin have shown that zooplankton biomass is highly correlated with POC flux, with the highest abundance in zooplankton biomass at the depth of the greatest gradient in POC flux (Bishop et al. 1986). This finds confirmation in our observations of the appearance and disappearance of large fecal material in the 100-m depth interval below the euphotic zone, the interval of the highest gradient in POC (Figure 7c,d). The abundance of zooplankton activity high in the twilight zone explains why exponential or power law fits that capture the region of the highest concentration gradient underpredict deep POC fluxes (Armstrong et al. 2002; Lutz et al. 2002), since loss rates are much higher where zooplankton graze.

\subsection{High Biomass Low Export Regions}

Both $55^{\circ} \mathrm{S}$ and $66^{\circ} \mathrm{S}$ are High Nutrient Low Chlorophyll (HNLC) regions. The "Low Chlorophyll" appellation is somewhat misleading, as neither location has particularly low chlorophyll; HNLC regions simply have lower chlorophyll than might be expected given the level of major nutrients available. Indeed, satellite ocean color pictures show relatively high levels of chlorophyll in the Southern Ocean in the summer (Moore and Abbott 2000), especially in comparison to the extremely low levels of chlorophyll characterized by subtropical gyres.

The pre-iron fertilized states of $55^{\circ} \mathrm{S}$ and $66^{\circ} \mathrm{S}$ that we encountered in January 2002 had total surface POC levels of $\sim 2.4 \mu \mathrm{M}$ and $\sim 7.3 \mu \mathrm{M}$ POC, respectively. Both chl a and primary productivity in the surface were twice as high at $66^{\circ} \mathrm{S}$ than at $55^{\circ} \mathrm{S}$, with approximately 0.15 $\mathrm{mg} / \mathrm{m}^{3}$ and $0.3 \mathrm{mg} / \mathrm{m}^{3}$ of chl at $55^{\circ} \mathrm{S}$ and $66^{\circ} \mathrm{S}$, respectively, and $\sim 15 \mathrm{mmol} \mathrm{C} / \mathrm{m}^{2} / \mathrm{d}$ and $\sim 32$ $\mathrm{mmol} \mathrm{C} / \mathrm{m}^{2} / \mathrm{d}$ at $55^{\circ} \mathrm{S}$ and $66^{\circ} \mathrm{S}$, respectively (Coale et al. 2004). Before iron fertilization, the moderate levels of surface biomass at $55^{\circ} \mathrm{S}$ were accompanied by moderate levels of export, as implied by the relatively high levels of POC at depth. The $66^{\circ} \mathrm{S}$ region was characterized by fairly high levels of surface biomass and low levels of export, as implied by the multiple 
indicators of low levels of large particles at depth. Surface waters in the $66^{\circ} \mathrm{S}$ region were further characterized by having an anomalously high proportion of total POC in the large size fraction, with $\sim 60 \%$ of $>1 \mu \mathrm{m}$ POC in the $>51 \mu \mathrm{m}$ size fraction, compared to a more typical $\sim 30 \%$ at $55^{\circ} \mathrm{S}$. We characterize the $66^{\circ} \mathrm{S}$ region, with its high and large surface biomass and low particle loading at depth, as being "High Biomass, Low Export" (HBLE). Twenty eight days after iron fertilization at $55^{\circ} \mathrm{S}$, there was a ten-fold increase in chl a, a nine-fold increase in primary production (Coale et al. 2004), and a four-fold increase in total (>1 $\mu \mathrm{m}$ ) POC, with most of it occurring in the $>51 \mu \mathrm{m}$ size fraction (Table 3 ). The increase in surface biomass and shift to large particles ( $68 \%$ of total POC in the $>51 \mu \mathrm{m}$ size fraction) was associated with an attendant decrease in POC at depth (Figure 3d, Table 3), and the $55^{\circ} \mathrm{S}$ region thus transitioned to being HBLE after iron fertilization.

We propose that regions characterized by high levels of surface biomass with a particularly large size partitioning of particles will result in low levels of export to the twilight zone. This hypothesis is consistent with global deep (> $2000 \mathrm{~m}$ ) sediment trap analyses that find carbonate-dominated, lower productivity surface waters are associated with greater deep POC flux than diatom dominated, highly productive waters (François et al. 2002). Should this hypothesis be borne out by studies from other regions, this suggests that the simplest models of export, which predict an increase in POC flux with increasing surface productivity, should be viewed with caution.

The comparison of the iron-amended $55^{\circ} \mathrm{S}$ profile (cast 8) with the $66^{\circ} \mathrm{S}$ profiles show that the mechanisms preventing export may be quite different even within HBLE regions, however. The persistence of large fecal pellets at $80-150 \mathrm{~m}$ at $66^{\circ} \mathrm{S}$ and their disappearance by 
$200 \mathrm{~m}$ throughout all profiles indicates that the pre-iron amended ecosystem at $66^{\circ} \mathrm{S}$ was already adapted to the presence of large primary producers and had a complex grazing community that prevented the export of large particles by efficiently harvesting them. While primary production increased by two-fold and the surface biomass at $66^{\circ} \mathrm{S}$ increased by three-fold eleven days after iron fertilization (Table 3), we speculate that the grazing community already in place responded quickly to iron-stimulated increases in surface biomass and ramped up its activity in response to increases in surface productivity. This would likely result in moderate increases in export flux commensurate with the increase in food, but would prevent a massive export event. Indeed,

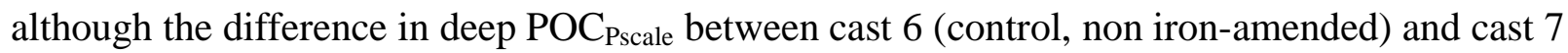
(last iron-amended profile) is negligible, the green optical density profile at $66^{\circ} \mathrm{S}$ from cast 7 shows a factor of 2 increase at depth compared to the non-iron amended profiles (Figure $2 f$ ). Similarly, measurements of shallow export several weeks after iron fertilization show factors of 2-3 increases in particle export relative to non iron-amended waters (Buesseler et al. 2004). In contrast, the ingrowth of surface biomass at $55^{\circ} \mathrm{S}$ after iron fertilization was accompanied by a decrease in large particle concentrations in the twilight zone. The absence of visible fecal pellet production below the euphotic zone suggests the lack of a pre-existing grazing community adapted to feeding on large phytoplankton, preventing a quick consumer response to the iron-stimulated increase in biomass. Rather than settle out, the iron-stimulated surface biomass accumulated in the euphotic zone and starved the twilight zone of particles, at least up until the time of our last MULVFS profile. Robotic observations of POC and export made several weeks later recorded an export event (Bishop et al. 2004), but the specific mechanism triggering this event is unknown. 
Ecosystem differences aside, both $55^{\circ} \mathrm{S}$ after iron fertilization and $66^{\circ} \mathrm{S}$ showed evidence of a High Biomass Low Export condition. Of the role that ballast minerals play in determining the flux of POC to depth, our analysis supports the interpretation made by François et al. (2002) that ballast minerals do not play a direct role in POC flux, but rather are indicators for the state of the ecosystem, which ultimately determines the efficiency of POC flux to depth.

We propose that natural or artificial stimulations of productivity in regions already characterized by an HBLE condition will not lead to mass sedimentation events. Stimulations of productivity in regions that are not HBLE will transition to an HBLE state. The long-term stability of this transitional HBLE state is unknown.

\section{Conclusions}

The carbonate producing sub-Antarctic region had a longer decay length scale for POC in the twilight zone than the diatom dominated Antarctic region. This is evident from the lower gradient in POC concentrations and a deeper and broader maximum in particle fragmentation as evidenced by particulate barium profiles. The $55^{\circ} \mathrm{S}$ sub-Antarctic POC profile was well fit with a single power law function with a decay length scale, $\delta_{\mathrm{e}, \mathrm{p}}$, of $81 \mathrm{~m}$, whereas the $66^{\circ} \mathrm{S}$ Antarctic POC profile required a quickly decaying function for the upper $200 \mathrm{~m}\left(\delta_{\mathrm{e}, \mathrm{p}}=26 \mathrm{~m}\right)$. Opal profiles had a similar behaviour to POC: the $55^{\circ} \mathrm{S}$ opal profile was well fit with a single power law function, and the $66^{\circ} \mathrm{S}$ opal profile had a quickly decaying upper portion on top of a more slowly decaying lower portion. $\mathrm{CaCO}_{3}$ profiles were not well fit with a simple power law or exponential model.

The direct influence of ballast mineral composition on excess density does not explain the differences in POC profile shapes between $55^{\circ} \mathrm{S}$ and $66^{\circ} \mathrm{S}$, but there could be an indirect ballast effect resulting from a correlation between opal producing regions and more loosely- 
packaged aggregates. Our analysis suggests that the correlation between $\mathrm{POC}$ and $\mathrm{CaCO}_{3}$ flux in deep sediment traps is not a result of $\mathrm{CaCO}_{3}$ ballasting of aggregates.

We find abundant large euphausiid fecal pellets just below the euphotic zone at $66^{\circ} \mathrm{S}(80$ $150 \mathrm{~m}$ ), indicators of a much more active grazing ecosystem in the region of higher productivity. This layer of active heterotrophs efficiently consumes POC, preventing the transfer of POC to depth. We conclude that biological processes affecting the fragmentation and remineralization of large particles are the most important factors determining the first order shape of POC profiles in the twilight zone.

We find that surface waters with high biomass levels and a high proportion of biomass in the large size fraction is associated with low POC at depth, and term this a High Biomass Low Export (HBLE) condition. The $66^{\circ} \mathrm{S}$ region is characterized by the HBLE condition, and remains $\mathrm{HBLE}$ after iron fertilization. The $55^{\circ} \mathrm{S}$ region starts off with moderate surface chlorophyll levels, and transitions to the HBLE condition after iron fertilization. However, the long-term stability of the HBLE condition at $55^{\circ} \mathrm{S}$ is unknown. We draw attention to regions equatorward of the polar fronts as locations with likely high but largely unobserved export processes. 


\section{Tables}

Table 1 MULVFS cast information and gravimetric results for the $>51 \mu \mathrm{m}$ size fraction. All masses of $\mathrm{Na}$ and $\mathrm{Ca}$ are for the $\mathbf{2 5 . 4} \mathrm{cm}$-diameter particle collection filter area only. "Xs" Na and Ca are intracellular Na and Ca. Pump start and stop times are

MM/DD/YYYY-time (UTC).

\begin{tabular}{|c|c|c|c|c|c|c|c|c|c|c|c|c|c|c|c|c|}
\hline \multirow[b]{2}{*}{$\begin{array}{l}\mathrm{z} \\
\mathrm{m}\end{array}$} & \multicolumn{8}{|c|}{$1-51 \mu \mathrm{m}$} & \multicolumn{8}{|c|}{$>51 \mu \mathrm{m}$} \\
\hline & $\begin{array}{c}\text { Vol. filt. } \\
\text { L }\end{array}$ & $\begin{array}{l}\text { Vis- } \\
\text { cosity } \\
\text { poise }\end{array}$ & $\begin{array}{l}\text { Tot. } \\
\mathrm{Na} \\
\mathrm{mg}\end{array}$ & $\begin{array}{l}\text { Salt } \\
\mathrm{Na} \\
\mathrm{mg}\end{array}$ & $\begin{array}{l}\mathrm{Xs} \\
\mathrm{Na} \\
\mathrm{mg}\end{array}$ & $\begin{array}{c}\text { Tot. } \\
\mathrm{Ca} \\
\mathrm{mg}\end{array}$ & $\begin{array}{l}\text { Salt } \\
\mathrm{Ca} \\
\mathrm{Mg} \\
\end{array}$ & $\begin{array}{l}\mathrm{Xs} \\
\mathrm{Ca} \\
\mathrm{mg}\end{array}$ & $\begin{array}{l}\text { Tot. } \\
\mathrm{Na} \\
\mathrm{mg}\end{array}$ & $\begin{array}{l}\text { Salt } \\
\mathrm{Na} \\
\mathrm{mg}\end{array}$ & $\begin{array}{l}\text { Xs } \\
\mathrm{Na} \\
\mathrm{mg}\end{array}$ & $\begin{array}{l}\text { Tot. } \\
\mathrm{Ca} \\
\mathrm{mg}\end{array}$ & $\begin{array}{l}\text { Salt } \\
\text { Ca } \\
\mathrm{mg}\end{array}$ & $\begin{array}{l}\text { Xs } \\
\mathrm{Ca} \\
\mathrm{mg} \\
\end{array}$ & $\begin{array}{c}\text { Total } \\
\text { Dry } \\
\mathrm{Wt} \\
\mathrm{mg} \\
\end{array}$ & $\begin{array}{c}\text { Salt- } \\
\text { corr } \\
\text { Dry Wt } \\
\text { mg } \\
\end{array}$ \\
\hline \multicolumn{17}{|c|}{ 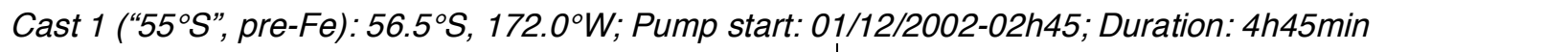 } \\
\hline 15 & 3412 & 0.0154 & 177.1 & 150.9 & 26.2 & 11.7 & 5.8 & 1.5 & 58.2 & 54.2 & 4.1 & 3.3 & 2.1 & 0.2 & 281.9 & 40.2 \\
\hline 40 & 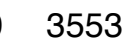 & 6 & & & 27.1 & 10.5 & 5.3 & 31.2 & & 38.7 & 8.4 & 8.0 & 1.5 & 0.4 & $2 \varepsilon$ & 87.3 \\
\hline 89 & 434 & 1 & & 1 & 1 & 10 & 5.7 & 0.6 & & 3 & 7.0 & 6.0 & 1.5 & 3 & 2 & \\
\hline 138 & 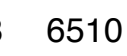 & 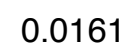 & & & 12.9 & 14 & 6.6 & 0.6 & & 3 & 5.4 & 5.7 & 1.5 & 2 & 2 & .0 \\
\hline 188 & 7593 & & & & 1 & 17 & 7.0 & 0.4 & & 3 & 2.7 & 4.1 & 1.2 & 1 & 2 & 65.5 \\
\hline 237 & & 5 & & & & & 8.4 & 0.4 & & & 5 & 4.6 & 8 & 1 & & \\
\hline 311 & 87 & 7 & & & 9.6 & 23 & 7.5 & 0.4 & & & 0.9 & 3.1 & 1.2 & 0 & & .6 \\
\hline 4 & & & & & & & .7 & 0.4 & & & & 2.6 & 7 & 0 & & \\
\hline 6 & 5 & & & & & 2 & 7.5 & 0.3 & & & & 1.7 & 7 & 0 & & .3 \\
\hline & & & & & & & & & & & & & & & & \\
\hline 904 & - 10844 & 0.0 & 22 & 213.6 & 6.7 & 27.2 & 8.2 & 0.3 & & 17.4 & 0.4 & 1.6 & 0.7 & 0 & & 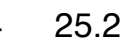 \\
\hline \multicolumn{17}{|c|}{ 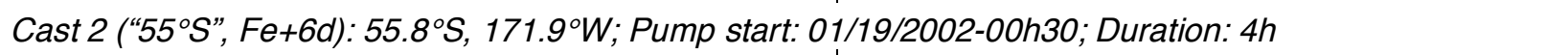 } \\
\hline 35 & 3046 & 0.0154 & & 144.4 & 22.0 & 11.0 & 5.5 & 1.3 & & 19.7 & 1.4 & 2.3 & 0.8 & 1 & & 50.0 \\
\hline 8 & 8 & & & 12 & 1 & & 4.9 & 0.6 & & 2 & 5.1 & 13.3 & 0.9 & 2 & & 129.3 \\
\hline 136 & 9 & & & 20 & 12.7 & 13.8 & 7.9 & 0.5 & & 22 & 2.5 & 3.5 & 0.9 & 1 & & 80.5 \\
\hline 23 & & & & & 10.1 & & 8.3 & 0.4 & & $2 \varepsilon$ & & 3 & & & & \\
\hline 3 & 8 & 3 & & 22 & 9 & 2 & 8.5 & 0.4 & & 2 & 5 & 3.3 & 0 & 1 & & 5.9 \\
\hline & & & & & & 22 & 7.2 & 0.3 & & & & 2.4 & 9 & 0 & & \\
\hline & & & & & & 22 & 6.6 & 0.2 & & 2 & & 2.3 & & 0 & & \\
\hline 916 & 10004 & 0.0173 & 201.2 & 195.9 & 5.3 & 22.8 & 7.5 & 0.2 & 25.1 & 24.8 & 0.3 & 2.5 & 0.9 & 0.0 & & \\
\hline \multicolumn{17}{|c|}{ Cast 3 ("66.' ${ }^{\circ}$ ", pre-Fe): $66.4^{\circ} \mathrm{S}, 171.5^{\circ} \mathrm{W}$; Pump start: 01/23/2002-20h20; Duration: 3h45min } \\
\hline 10 & 1990 & 0.0191 & & & 42.2 & 11.8 & 8.6 & 1.8 & 44.0 & 23.2 & 20.8 & 1.8 & 0.9 & 0.9 & 3.9 & 213.3 \\
\hline & & & & & 45.2 & & 7.9 & 3.3 & & 61.9 & 23.2 & 3.5 & & & & 1808 \\
\hline 136 & 924 & 2 & & 23 & 10.7 & 10.5 & 8.9 & 0.5 & & 48.7 & 2.9 & 2.6 & .9 & .1 & 2 & \\
\hline & & 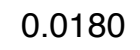 & & & & & 8.0 & 0.4 & & 3 & & 1.7 & 2 & & & \\
\hline 2 & 10790 & & & & & & 8.4 & 0.2 & & & 6 & 1.0 & .8 & 0 & & \\
\hline & 10748 & & & & & & 7.4 & 0.2 & & 45.7 & 4 & 1.7 & 1.7 & 0 & & 8 \\
\hline 666 & 11465 & & & 21 & 4.2 & & 8.1 & 0.2 & & 25 & 0.5 & 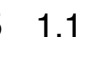 & .0 & 0 & & \\
\hline 817 & 11670 & 2 & $23 \varepsilon$ & 234 & 3.9 & 10.2 & 9.0 & 0.2 & 19.7 & 19.5 & 0.2 & 0.9 & 0.7 & 0.0 & 123.5 & 19.9 \\
\hline 918 & 12076 & 0.0182 & 239.9 & 236.3 & 3.7 & 10.4 & 9.0 & 0.2 & 13.2 & 17.4 & 0.2 & 0.6 & 0.7 & 0.0 & 90.1 & \\
\hline
\end{tabular}




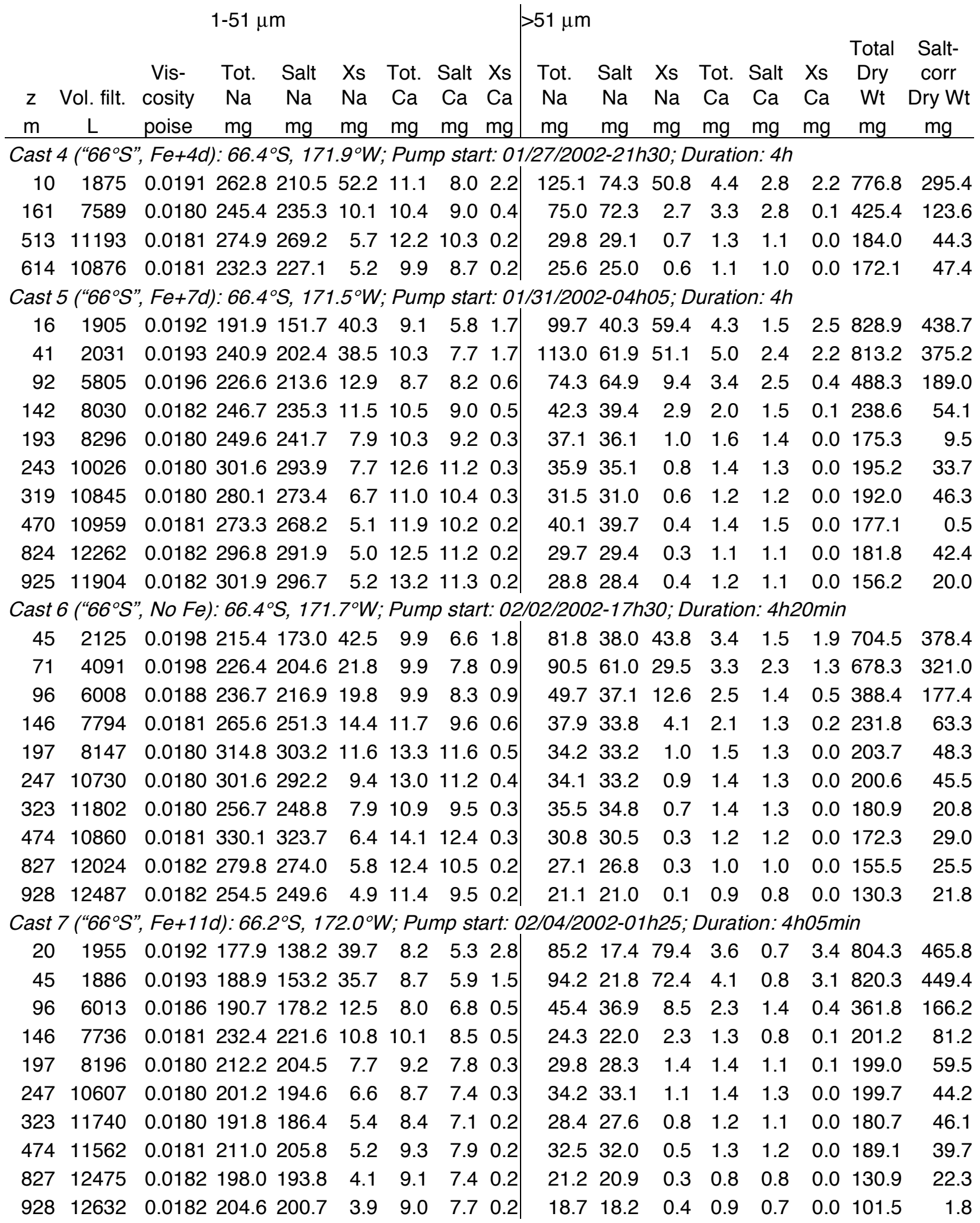




\begin{tabular}{|c|c|c|c|c|c|c|c|c|c|c|c|c|c|c|c|c|}
\hline \multirow[b]{2}{*}{$\begin{array}{l}\mathrm{z} \\
\mathrm{m}\end{array}$} & \multicolumn{8}{|c|}{$1-51 \mu \mathrm{m}$} & \multicolumn{8}{|c|}{$>51 \mu \mathrm{m}$} \\
\hline & $\begin{array}{c}\text { Vol. filt. } \\
\text { L }\end{array}$ & $\begin{array}{l}\text { Vis- } \\
\text { cosity } \\
\text { poise }\end{array}$ & $\begin{array}{l}\text { Tot. } \\
\mathrm{Na} \\
\mathrm{mg}\end{array}$ & $\begin{array}{l}\text { Salt } \\
\mathrm{Na} \\
\mathrm{mg}\end{array}$ & $\begin{array}{l}\mathrm{Xs} \\
\mathrm{Na} \\
\mathrm{mg}\end{array}$ & $\begin{array}{l}\text { Tot. } \\
\mathrm{Ca} \\
\mathrm{mg}\end{array}$ & $\begin{array}{l}\text { Salt } \\
\mathrm{Ca} \\
\mathrm{mg}\end{array}$ & $\begin{array}{l}\mathrm{Xs} \\
\mathrm{Ca} \\
\mathrm{mg}\end{array}$ & $\begin{array}{l}\text { Tot. } \\
\mathrm{Na} \\
\mathrm{mg}\end{array}$ & $\begin{array}{l}\text { Salt } \\
\mathrm{Na} \\
\mathrm{mg}\end{array}$ & $\begin{array}{l}\mathrm{Xs} \\
\mathrm{Na} \\
\mathrm{mg}\end{array}$ & $\begin{array}{l}\text { Tot. } \\
\mathrm{Ca} \\
\mathrm{mg}\end{array}$ & $\begin{array}{l}\text { Salt } \\
\mathrm{Ca} \\
\mathrm{mg}\end{array}$ & $\begin{array}{l}\mathrm{Xs} \\
\mathrm{Ca} \\
\mathrm{mg}\end{array}$ & $\begin{array}{c}\text { Total } \\
\text { Dry } \\
\text { Wt } \\
\text { mg }\end{array}$ & $\begin{array}{c}\text { Salt- } \\
\text { corr } \\
\text { Dry Wt } \\
\text { mg }\end{array}$ \\
\hline \multicolumn{17}{|c|}{ 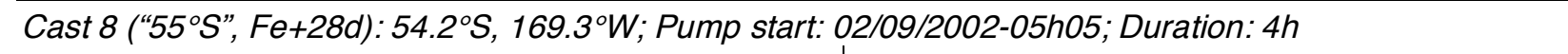 } \\
\hline 35 & 3033 & 0.0150 & 175.1 & 153.7 & 21.4 & 14.1 & 5.9 & 0.9 & 77.8 & 56.5 & 21.4 & 6.9 & 2.2 & 0.9 & 438.2 & 126.2 \\
\hline 85 & 4445 & 0161 & 186.2 & 168.0 & 18.2 & 13.3 & 6.4 & 0.8 & 24.2 & 21.2 & 3.0 & 5.0 & 0.8 & 0.1 & 170.5 & 50.9 \\
\hline 134 & 5491 & 0.0165 & 221 & 205.9 & 15.8 & 16.9 & 7.9 & 0.7 & 25.6 & 24.1 & 1.6 & 2.4 & 0.9 & 0.1 & 152.9 & 28.2 \\
\hline 184 & 8369 & 0.0 & 2 & 231.3 & 12.4 & 19.5 & 8.8 & 0.5 & 23.2 & 21.5 & 1.7 & 2.5 & 0.8 & 0.1 & 162.8 & 46.7 \\
\hline 234 & 8940 & 0.0167 & 250.8 & 239.2 & 11.7 & 23.7 & 9.1 & 0.5 & 28.7 & 27.3 & 1.3 & 2.8 & 1.0 & 0.1 & 191.4 & 55.8 \\
\hline 308 & 8336 & 0.0166 & 241.7 & 230.5 & 11.2 & 27.5 & 8.8 & 0.5 & 20.7 & 19.9 & 0.8 & 2.0 & 0.8 & 0.0 & 148.8 & 41.7 \\
\hline 656 & 11008 & 0.0170 & 232.2 & 223.5 & 8.8 & 26.5 & 8.5 & 0.4 & 23.9 & 22.9 & 0.9 & 2.3 & 0.9 & 0.0 & 140.2 & 21.7 \\
\hline 905 & 11927 & 0.0173 & 209.3 & 202.6 & 6.7 & 26.2 & 7.7 & 0.3 & 16.9 & 17.4 & 0.3 & 2.2 & 0.7 & 0.0 & 114.4 & 21.1 \\
\hline
\end{tabular}

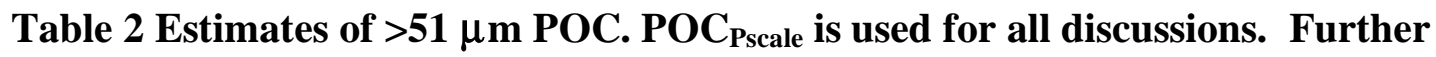
explanation in the text.

\begin{tabular}{|c|c|c|}
\hline POC term & What it is & How it is calculated \\
\hline $\mathrm{POC}_{\text {grav }}$ & Gravimetrically determined & $P O C_{\text {grav }}=\frac{1}{1.88} *\left(\right.$ DryWeight $\left._{\text {Salt }- \text { corr }}-\mathrm{CaCO}_{3}-\mathrm{Opal}\right)$ \\
\hline $\mathrm{POC}_{\mathrm{P}}$ & $\begin{array}{l}\text { POC from }>51 \mu \mathrm{m} \\
\text { particulate phosphorus and } \\
1-51 \mu \mathrm{m} \text { C:P ratios }\end{array}$ & $\mathrm{POC}_{\mathrm{P}}=\mathrm{P}_{>51_{\mu} \mathrm{m}} *(\mathrm{C}: \mathrm{P})_{1-51_{\mu} \mathrm{m}}$ \\
\hline POC $_{\text {Pscale }}$ & $\begin{array}{l}P_{P} \text { scaled to } P_{\text {OC }} \text { grav in } \\
\text { the euphotic zone }\end{array}$ & $\mathrm{POC}_{\text {Pscale }}=\mathrm{POC}_{\mathrm{P}} * 2.6$ \\
\hline
\end{tabular}


Table 3 Chemical composition of size fractionated MULVFS particles. " $<1 \mu \mathrm{m}$ " and 1-51 $\mu \mathrm{m}$ POC values are determined by combustion. $>51 \mu \mathrm{m}$ POC are determined gravimetrically $\left(\mathrm{POC}_{\text {grav }}\right)$ and estimated from phosphorus $\left(\mathrm{POC}_{\mathbf{P}}=(\mathrm{C}: \mathrm{P}) * \mathrm{P}\right) . \mathbf{P}$ is determined by ICP-MS. $\mathrm{Ca}_{\text {corr }}$ is corrected for salt-Ca and dipped-blank. $\mathrm{CaCO}_{3}$ is derived from $\mathrm{Ca}_{\text {corr }}$ that has been corrected for excess Ca. For $\mathrm{POC}_{\text {grav }}$, propagated standard deviations ( $\left(\mathrm{SPOC}_{\text {grav }}\right)$ are reported in parentheses. Means and standard errors of the mean (in parentheses) reported for $55^{\circ} \mathrm{S}$ and $66^{\circ} \mathrm{S}$ averaged data.

\begin{tabular}{|c|c|c|c|c|c|c|c|c|c|c|c|c|c|}
\hline \multirow[b]{3}{*}{$\mathrm{m}$} & \multirow{3}{*}{$\left|\begin{array}{r}<1 \mu \mathrm{m} " \\
\mathrm{POC} \\
\mu \mathrm{M}\end{array}\right|$} & \multirow{3}{*}{$\begin{array}{c}1-51 \mu \mathrm{m} \\
\mathrm{POC} \\
\mu \mathrm{M}\end{array}$} & \multicolumn{5}{|c|}{$|>0.4 \mu \mathrm{m}|>51 \mu \mathrm{m}$} & \multirow{2}{*}{\multicolumn{2}{|c|}{$\mathrm{POC}_{\mathrm{P}} \mathrm{POC}_{\text {Pscale }}$}} & \multirow{2}{*}{\multicolumn{2}{|c|}{$\mathrm{PCaCO}_{3}$}} & \multirow{3}{*}{$\begin{array}{l}\mathrm{Si} \\
\mu \mathrm{M}\end{array}$} & \multirow{3}{*}{$\begin{array}{r}\mathrm{OD}_{\text {green }} \\
\mathrm{ODU} / \mathrm{m}^{3}\end{array}$} \\
\hline & & & \multicolumn{2}{|c|}{$\mathrm{PCaCO}_{3}$} & \multirow{2}{*}{\multicolumn{2}{|c|}{\begin{tabular}{r|r}
$\mathrm{Si}_{\text {grav }}$ & $\mathrm{POC}$ \\
$\mathrm{M}$ & $\mu \mathrm{M}$ \\
\end{tabular}}} & \multirow{2}{*}{$\begin{array}{r}\text { sdPOC } \\
\text { grav } \\
\mu \mathrm{M} \\
\end{array}$} & & & & & & \\
\hline & & & $\mathrm{nM}$ & $\mathrm{nM}$ & & & & \multirow{2}{*}{\multicolumn{5}{|c|}{$\frac{\mu \mathrm{M}}{\text { 12/2002-02h45; Duration: } 4 \text { h45min }}$}} & \\
\hline \multicolumn{9}{|c|}{ 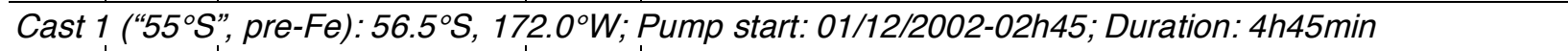 } & & & & & \\
\hline 15 & 0.470 & 1.114 & 13.87 & 23.60 & 0.372 & & $(0.315)$ & 0.174 & 0.375 & . & 8.02 & & \\
\hline 40 & & & & 3.75 & & & & & & & & & \\
\hline 89 & 317 & 364 & & 19.72 & & & & & & & & & \\
\hline 138 & 13 & 170 & 58 & 28.87 & & & & & & & & & \\
\hline 188 & & & & & & & & & & & & & \\
\hline 237 & 79 & & & 34.83 & & & & & & & & & \\
\hline & & & & 74 & & & & & & & & & \\
\hline 4 & 06 & & & & & & & & & & & & \\
\hline & 049 & & & 34 & & & & & & & & & \\
\hline & & & & & & & & & & & & & \\
\hline 904 & $\int 28 \mid$ & & & 43.09 & & & & & & & & & \\
\hline \multicolumn{14}{|c|}{ 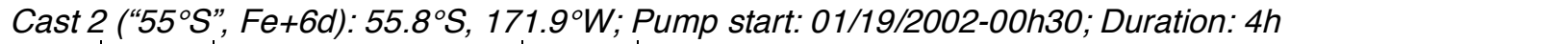 } \\
\hline 35 & 0.471 & 1.047 & & 24.04 & 0391 & 17רי & & & & 080 & & & \\
\hline 86 & 7 & & & & & & & & & & & & \\
\hline 136 & & & & & & & & & & & & & \\
\hline & 58 & & 2 & & & & & & & & & & \\
\hline & 599 & & & & & & & & & & & & \\
\hline & 39 & & & & & & & & & & & & \\
\hline & & & & & & & & & & & & & \\
\hline 916 & .019 & 0.096 & 0.96 & 37.55 & 1 & & & 0.008 & & 0.4 & & & \\
\hline \multicolumn{14}{|c|}{ ast 3 ("66 $6^{\circ}$ ", pre-Fe): $66.4^{\circ} \mathrm{S}, 171.5^{\circ} \mathrm{W}$; Pump start: 01/23/2002-20h20; Duration: 3h45min } \\
\hline 10 & .890 & & & 17. & & & & & & & & & \\
\hline 35 & 962 & & & -8.0 & & & & & & & & & \\
\hline 36 & .082 & & & & & & & & & & & & 55 \\
\hline & 057 & 242 & & 3.18 & 124 & & & & & & & & 022 \\
\hline & 0.022 & 9 & & 10 & & & & & & & & & \\
\hline & & & & & & & & & & & & & \\
\hline 00 & 023 & 16 & & & & & & & & & & & \\
\hline & 015 & & & & & & & & & & & & 007 \\
\hline 918 & .014 & 0.073 & 0.55 & 2.46 & 0.036 & 0.019 & $(0.059)$ & 0.003 & 0.006 & 0.02 & -0.11 & 0.006 & 0.0000 \\
\hline
\end{tabular}




\begin{tabular}{|c|c|c|c|c|c|c|c|c|c|c|c|c|c|}
\hline \multirow[b]{3}{*}{$\mathrm{m}$} & \multirow{3}{*}{$\left|\begin{array}{r}<1 \mu \mathrm{m} " \\
\mathrm{POC} \\
\mu \mathrm{M}\end{array}\right|$} & \multirow{3}{*}{$\begin{array}{c}1-51 \mu \mathrm{m} \\
\mathrm{POC} \\
\mu \mathrm{M}\end{array}$} & \multicolumn{5}{|c|}{$>0.4 \mu \mathrm{m} \mid>51 \mu \mathrm{m}$} & \multirow{2}{*}{\multicolumn{2}{|c|}{$\mathrm{POC}_{\mathrm{P}} \mathrm{POC}_{\text {Pscale }}$}} & \multirow{2}{*}{\multicolumn{2}{|c|}{$\mathrm{PCaCO}_{3}$}} & \multirow{3}{*}{$\begin{array}{r}\mathrm{Si} \\
\mu \mathrm{M}\end{array}$} & \multirow{3}{*}{$\begin{array}{l}\text { OD }{ }_{\text {green }} \\
\text { ODU } / \mathrm{m}^{3}\end{array}$} \\
\hline & & & \multicolumn{2}{|c|}{$\mathrm{PCaCO}_{3}$} & \multirow{2}{*}{\multicolumn{2}{|c|}{\begin{tabular}{l|l}
$\mathrm{Si}$ & $\mathrm{POC}$ \\
$\mathrm{grav}$ \\
$\mathrm{MM}$ & $\mu \mathrm{M}$ \\
\end{tabular}}} & \multirow{2}{*}{$\begin{array}{r}\text { sdPOC } \\
\text { grav } \\
\mu \mathrm{M}\end{array}$} & & & & & & \\
\hline & & & $\mathrm{nM}$ & $\mathrm{nM}$ & & & & $\mu \mathrm{M}$ & $\mu \mathrm{M}$ & $\mathrm{nM}$ & $\mathrm{nM}$ & & \\
\hline \multicolumn{14}{|c|}{ 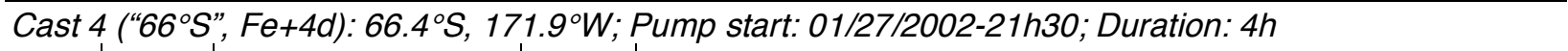 } \\
\hline 10 & 0.968 & 1.470 & 50.33 & 11.23 & 1.518 & 3.691 & $(1.018)$ & 2.500 & 5.400 & 48.94 & -8.47 & & 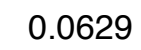 \\
\hline 161 & 0.063 & 0.239 & 2.41 & 3.06 & 0.135 & & & & & & & & \\
\hline 513 & 0.022 & 0.073 & .92 & 3.77 & 0.058 & 0.086 & & & & & & & \\
\hline 614 & 0.016 & 0.160 & 0.86 & 2.24 & 0.081 & 0.1 & & & & & & & \\
\hline \multicolumn{14}{|c|}{ ast 5 ("66 ${ }^{\circ} \mathrm{S}$ ", $\mathrm{Fe}+7 \mathrm{~d}$ ): $66.4^{\circ} \mathrm{S}, 171.5^{\circ} \mathrm{W}$; Pump start: 01/31/2002-04h05; Duration: $4 \mathrm{~h}$} \\
\hline 16 & 1.084 & 1.941 & 38.17 & 20.69 & 1.074 & 5.927 & $(0.835)$ & 2875 & 6.210 & 56.28 & 26 & & \\
\hline 41 & 0.991 & & 34. & .27 & 1.000 & 4 & & & & & & & \\
\hline 92 & 0.174 & 0.433 & 4.02 & 0.17 & 0.267 & 0 & & & & & & & \\
\hline 142 & 0.068 & 0.234 & .58 & 3.25 & 0.147 & 0.079 & & & & & & & 550 \\
\hline 193 & .059 & 0.240 & 1.7 & 2.26 & 0.200 & & & & & & & & 024 \\
\hline 243 & 034 & & 1. & 2.65 & & & & & & & & & \\
\hline 319 & 047 & 0 & 1.1 & 0.73 & D11 & & & & & & & & \\
\hline 470 & 24 & & .8 & 38 & & & & & & & & & \\
\hline 824 & 016 & 2 & 7 & 2.33 & 0.046 & 0. & & & & & & & \\
\hline 925 & 0.026 & 0.069 & 0.79 & 3.38 & 0.051 & 0.0 & & & & & & & \\
\hline \multicolumn{14}{|c|}{ Cast 6 ("66.' ${ }^{\circ}$ ", No Fe): $66.4^{\circ} \mathrm{S}, 171.7^{\circ} \mathrm{W}$; Pump start: 02/02/2002-17h30; Duration: 4h20min } \\
\hline 45 & 0.662 & 0.860 & 36.10 & 17.64 & 1.197 & & & & & - & & & \\
\hline 71 & 0.272 & & 9.6 & 98 & 76 & & & & & & & & \\
\hline 96 & 143 & 34 & 5.96 & 19 & 0.302 & 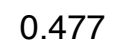 & & & & & & & \\
\hline 146 & 067 & & 3 & 4.70 & 30 & & & & & & & & \\
\hline 197 & 051 & & 2.56 & 3.85 & & & & & & & & & 334 \\
\hline 247 & 0.035 & & & 3.34 & 0.159 & & & & & & & & 025 \\
\hline 323 & 049 & & & 15 & 69 & & & & & & & & \\
\hline 474 & 0.027 & 6 & 6 & .37 & 0.070 & 0 & & & & & & & \\
\hline 827 & .013 & 0.068 & 0.87 & 3.40 & 0.039 & 0.0 & & & & & & & \\
\hline 928 & 0.015 & 0.067 & 0.71 & 3.27 & 0.045 & 0.044 & $(0.060)$ & 0.002 & 0.005 & 0.02 & & 0.011 & \\
\hline \multicolumn{14}{|c|}{ Cast 7 ("66 $\left.{ }^{\circ} \mathrm{S}^{\prime}, \mathrm{Fe}+11 \mathrm{~d}\right): 66.2^{\circ} \mathrm{S}, 172.0^{\circ} \mathrm{W}$; Pump start: 02/04/2002-01h25; Duration: 4h05min } \\
\hline 20 & 0.849 & & & 0.61 & & 5.67 & & & & & & & \\
\hline 45 & 0.045 & 2.572 & 34.23 & 17.25 & 1.499 & 5.381 & & & & & & & 217 \\
\hline 96 & 0.120 & 0.332 & 3.77 & 2.70 & 0.264 & 0.545 & & & & & & & 218 \\
\hline 146 & 0.054 & 0.219 & 2.5 & 77 & 0.188 & 0.1 & & & & & & & 055 \\
\hline 81 & 0.055 & & 1. & & 0.166 & & & & & & & & \\
\hline 247 & 0.026 & & 1.1 & C.टO & INalv & 0.0 & & & & & & & \\
\hline 323 & 0.019 & 0.095 & 0.8 & 2.13 & 0.176 & 0.043 & & & & & & & 026 \\
\hline 474 & 0.023 & 0.091 & 0.81 & 2.62 & 0.080 & 0.078 & & 0.0 & & 07 & & 25 & 0.0025 \\
\hline 27 & 0.009 & 0.065 & 0.6 & 3.08 & 0.062 & 0.028 & & 0. & 10 & 4 & & & .0017 \\
\hline 928 & 0.006 & 0.058 & 0.56 & 2.37 & 0.033 & 0.021 & $(0.058)$ & 0.0 & 0.014 & 0.06 & 0.31 & 0.009 & 0.0015 \\
\hline
\end{tabular}




\begin{tabular}{|c|c|c|c|c|c|c|c|c|c|c|c|c|c|}
\hline \multirow{3}{*}{$\omega_{1}$} & \multirow{3}{*}{$\begin{array}{r}<1 \mu \mathrm{m} " \\
\mathrm{POC} \\
\mu \mathrm{M}\end{array}$} & \multirow{3}{*}{$\begin{array}{c}1-51 \mu \mathrm{m} \\
\mathrm{POC} \\
\mu \mathrm{M}\end{array}$} & \multirow{2}{*}{\multicolumn{2}{|c|}{$\mathrm{PCaCO}_{3}$}} & \multicolumn{3}{|c|}{$|>0.4 \mu \mathrm{m}|>51 \mu \mathrm{m}$} & \multirow{2}{*}{\multicolumn{2}{|c|}{$\mathrm{POC}_{\mathrm{P}} \mathrm{POC}_{\text {Pscale }}^{\mathrm{C}}$}} & \multirow{2}{*}{\multicolumn{2}{|c|}{$\mathrm{PCaCO}_{3}$}} & \multirow{3}{*}{$\begin{array}{r}\mathrm{Si} \\
\mu \mathrm{M}\end{array}$} & \multirow{3}{*}{$\begin{array}{l}\text { OD } D_{\text {green }} \\
\text { ODU } / \mathrm{m}^{3}\end{array}$} \\
\hline & & & & & \multirow{2}{*}{\multicolumn{2}{|c|}{\begin{tabular}{c|r}
$\mathrm{Si}_{\text {grav }}$ & $\mathrm{POC}$ \\
$\mu \mathrm{M}$ & $\mu \mathrm{M}$ \\
\end{tabular}}} & \multirow{2}{*}{$\begin{array}{r}\text { sdPOC } \\
\text { grav } \\
\mu \mathrm{M} \\
\end{array}$} & & & & & & \\
\hline & & & $\mathrm{nM}$ & $\mathrm{nM}$ & & & & $\mu \mathrm{M}$ & $\mu \mathrm{M}$ & $\mathrm{nM}$ & $\mathrm{nM}$ & & \\
\hline \multicolumn{14}{|c|}{ ast 8 (“55 ${ }^{\circ}$ ", Fe+28d): $54.2^{\circ} \mathrm{S}, 169.3^{\circ} \mathrm{W}$; Pump start: 02/09/2002-05h05; Duration: $4 \mathrm{~h}$} \\
\hline 35 & 0.348 & 1.7871 & 12.77 & 60.36 & | $0.207 \mid$ & 0.963 & $(0.429)$ & 1.782 & 3.848 & 12.73 & 31.20 & & 9 \\
\hline 8 & 221 & 0.736 & 7.38 & 28 & & & & & & & & & \\
\hline 13 & 0 & 65 & .19 & 38.19 & 60 & 32 & & & & & & & \\
\hline & & & & & & & & & & & & & \\
\hline 2 & 036 & 96 & 36 & 4 & 36 & & & & & & & & \\
\hline 3 & 032 & 208 & .43 & 50 & & 25 & & & & & & & \\
\hline 6 & 0.015 & 0.111 & 1.44 & 39.95 & 79 & 39 & & & & & & & \\
\hline 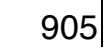 & 0.007 & 0.083 & .01 & 37 & & 37 & & & & & & & \\
\hline \multicolumn{14}{|c|}{$55^{\circ} \mathrm{S}$ average (casts 1,2$)$} \\
\hline 15 & 0.470 & 1.1141 & 13.87 & 2 & 372 & 92 & & & & 16 & 2 & & 014 \\
\hline . & & -- & & & & -- & & . & -- & . & -- & . & . \\
\hline 38 & 0.498 & 0.9101 & 13.40 & 26.40 & 0.288 & 0.475 & & 73 & 74 & 2.54 & .83 & 05 & 053 \\
\hline (2.5) & $(0.027)$ & $(0.138)(($ & $(0.36)$ & (2.35) & $(0.103)$ & $(0.00)$ & & $(0.119)$ & $.256)$ & 74) & (22.3) & 36) & 23) \\
\hline 88 & 0.337 & 0.763 & 6.00 & 24.47 & 0.129 & 0.561 & & 13 & 0.676 & 2.40 & .99 & & 098 \\
\hline (1.5) & $(0.020)$ & $(0.099)($ & (1.37) & $(4.75)$ & $(0.014)$ & $(0.27)$ & & () & 1) & 8) & 4.5) & & 12 \\
\hline 137 & 0.196 & 0.481 & 4.46 & 29.87 & 0.231 & 0.315 & & 0.142 & 07 & 1.27 & 13 & 09 & 099 \\
\hline (1.0) & $(0.058)$ & $(0.011)$ & (0.88) & $(1.00)$ & $(0.057)$ & $(0.11)$ & & $.024)$ & 53) & 22) & $(0.40)$ & & 12 \\
\hline 188 & 0.118 & 209 & 2.41 & 34.02 & 22 & 0.173 & & 56 & 21 & 65 & 98 & 57 & 054 \\
\hline- & & -- & -- & & & -- & & -- & -- & -- & -- & -- & - \\
\hline 237 & 0.069 & 0.216 & 2.17 & 34.28 & 0.212 & 0.088 & & 053 & 14 & 0.52 & .11 & 052 & 20 \\
\hline (0.0) & $(0.011)$ & $(0.024)($ & (0.23) & $(0.55)$ & $(0.049)$ & $(0.07)$ & & $(0.000)$ & $(0.000)$ & (0.00) & $(0.68)$ & 4) & )$(0$. \\
\hline 312 & 0.071 & 0.283 & 2.32 & 50.02 & $\mathrm{aN}$ & 0.033 & & 035 & 76 & 0.29 & .79 & 37 & 039 \\
\hline (0.5) & $(0.012)$ & $(0.048)$ & $0)$ & (2.29) & $(\mathrm{NaN})$ & $(0.03)$ & & $(0.011)$ & $(0.024)$ & $(0.09)$ & (1.45) & & $001)$ \\
\hline 459 & 0.068 & 0.297 & 2.12 & 48.14 & 0.104 & 0.135 & & 27 & 57 & 19 & .92 & 39 & 032 \\
\hline- & & -- & -- & & & -- & & - & - & -- & - & - & - \\
\hline 661 & 0.044 & 0.202 & 1.40 & 36.27 & 0.085 & 0.074 & & & 21 & .07 & 36 & 20 & 18 \\
\hline (4.0) & $(0.005)$ & $(0.036)$ & (0.08) & $(1.44)$ & $(0.000)$ & $(0.04)$ & & $(0.001)$ & $(0.001)$ & $(0.00)$ & $(0.80)$ & $(0.002)$ & $(0.0001)$ \\
\hline 811 & 0.021 & 0.106 & 0.93 & 38.96 & 0.084 & 0.046 & & 0.008 & 0.018 & 0.07 & 3.93 & .016 & $6 \quad 0.0013$ \\
\hline (5.5) & $(0.005)$ & $(0.015)$ & (0.03) & $(1.22)$ & $(0.010)$ & $(0.05)$ & & $(0.002)$ & $(0.004)$ & $(0.02)$ & $(0.67)$ & )$(0$. & D01) \\
\hline 910 & 0.024 & 0.111 & 1.04 & 40.32 & 0.070 & 0.024 & & 0.007 & 0.016 & 0.07 & 3.01 & 0.013 & 0.0015 \\
\hline (6.0) & $(0.005)$ & $0.015)$ & .08) & $(2.77)$ & $|(0.013)|$ & $(0.02)$ & & (0.001) & $(0.001)$ & (0.01) & (1.32) & $(0.002)$ & $001)$ \\
\hline
\end{tabular}




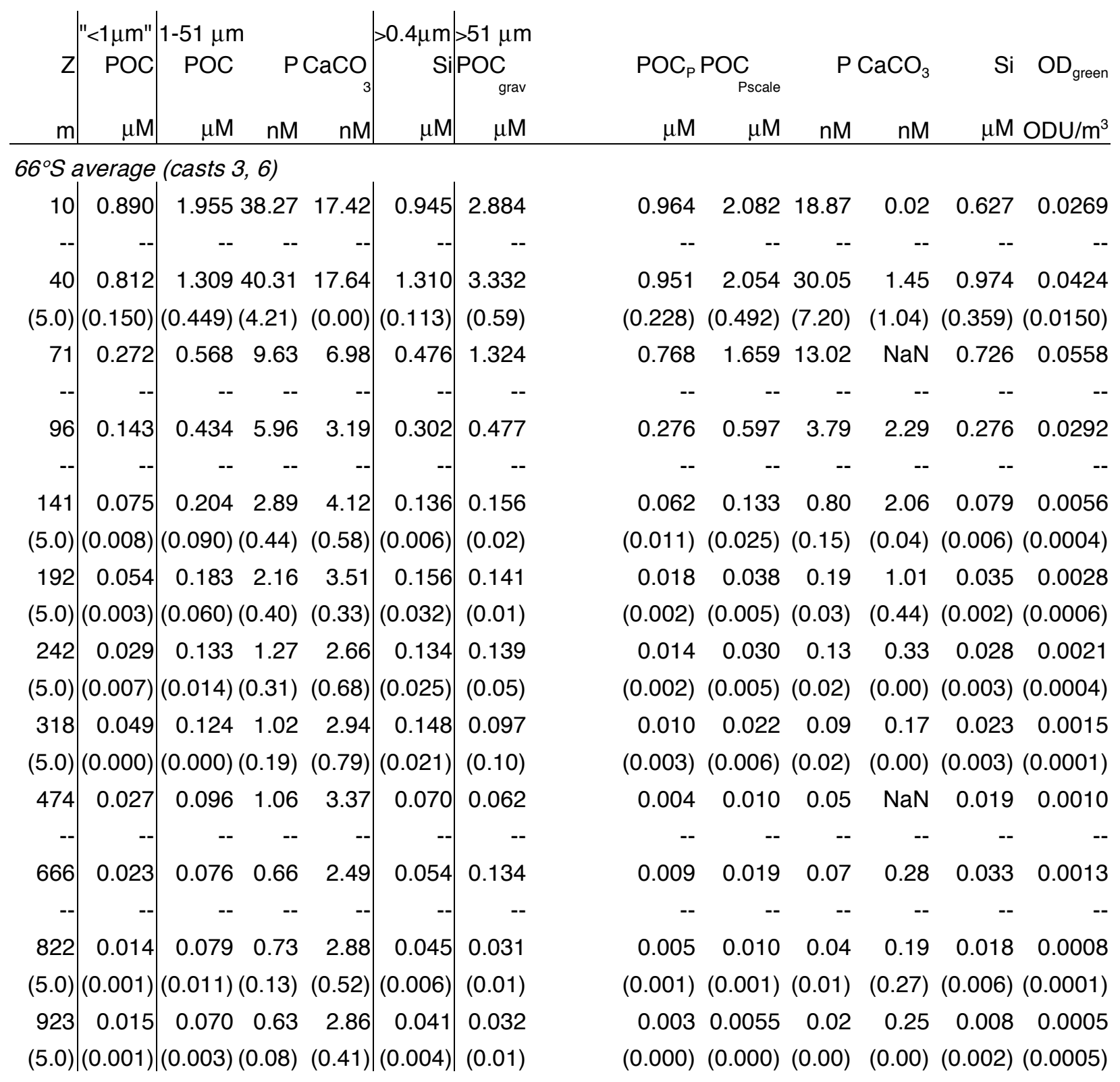


Table 4 Decay Length Scales $(\delta)$ of $\mathrm{P}, \mathrm{POC}$, viscosity-normalized $\mathrm{POC}, \mathrm{CaCO}_{3}$, and opal from fits to the entire twilight zone $(80-1000 \mathrm{~m})$. All decay length scales are the distance with which the concentrations decay by $1 / \mathrm{e}$ relative to concentrations at the reference depth $\left(\mathrm{z}_{\mathrm{ref}}=90 \mathrm{~m}\right)$. All fits were using a linear model to ln-transformed data. Power law fits to upper regime $(80-200 \mathrm{~m})$, and the lower regime $(200-1000 \mathrm{~m})$ of the twilight zone at $66^{\circ} \mathrm{S}$ also reported for $\mathbf{P}$ and POC. Only fits significant at the $95 \%$ levels are reported.

\begin{tabular}{|c|c|c|c|c|c|c|c|}
\hline \multirow{2}{*}{$\begin{array}{l}\text { Component } \\
\text { (X) }\end{array}$} & \multirow[b]{2}{*}{$\begin{array}{l}\text { Depth } \\
\text { Range }\end{array}$} & & \multicolumn{2}{|c|}{ Exponential Function } & \multicolumn{3}{|c|}{ Power Law Function } \\
\hline & & & $\delta_{\mathrm{e}}^{a}(\mathrm{~m})$ & $\mathrm{R}^{2 b}$ & $\mathrm{~b}^{c}$ & $\begin{array}{l}\delta_{\mathrm{e}, \mathrm{p}}{ }^{d} \\
(\mathrm{~m})\end{array}$ & $\mathrm{R}^{2 e}$ \\
\hline \multirow[t]{4}{*}{$\mathrm{P}$} & $80-1000 \mathrm{~m}$ & $55^{\circ} \mathrm{S}$ & 245 & 0.888 & -1.594 & 79 & 0.986 \\
\hline & $80-1000 \mathrm{~m}$ & $66^{\circ} \mathrm{S}$ & 238 & 0.652 & -1.837 & 65 & 0.849 \\
\hline & $80-200 \mathrm{~m}$ & $66^{\circ} \mathrm{S}$ & 32 & 0.997 & -4.317 & 23 & 0.998 \\
\hline & $200-1000 \mathrm{~m}$ & $66^{\circ} \mathrm{S}$ & 510 & 0.765 & -0.992 & $*$ & 0.745 \\
\hline \multirow[t]{4}{*}{ POC $_{\text {Pscale }}$} & $80-1000 \mathrm{~m}$ & $55^{\circ} \mathrm{S}$ & 251 & 0.882 & -1.560 & 81 & 0.980 \\
\hline & $80-1000 \mathrm{~m}$ & $66^{\circ} \mathrm{S}$ & 263 & 0.647 & -1.656 & 75 & 0.840 \\
\hline & $80-200 \mathrm{~m}$ & $66^{\circ} \mathrm{S}$ & & & -3.973 & 26 & 0.9998 \\
\hline & $200-1000 \mathrm{~m}$ & $66^{\circ} \mathrm{S}$ & 535 & 0.670 & -0.960 & $*$ & 0.671 \\
\hline \multirow{4}{*}{$\begin{array}{l}\text { POC } \\
\text { (viscale } \\
\text { (viscosity } \\
\text { normalized) }\end{array}$} & $80-1000 \mathrm{~m}$ & $55^{\circ} \mathrm{S}$ & 246 & 0.884 & -1.590 & 78 & 0.981 \\
\hline & $80-1000 \mathrm{~m}$ & $66^{\circ} \mathrm{S}$ & 264 & 0.653 & -1.649 & 75 & 0.844 \\
\hline & $80-200 \mathrm{~m}$ & $66^{\circ} \mathrm{S}$ & & & -3.907 & 26 & 0.9997 \\
\hline & $200-1000 \mathrm{~m}$ & $66^{\circ} \mathrm{S}$ & 529 & 0.675 & -0.971 & $*$ & 0.677 \\
\hline \multirow[t]{2}{*}{$\mathrm{CaCO}_{3}$} & $80-1000 \mathrm{~m}$ & $55^{\circ} \mathrm{S}$ & 421 & 0.677 & -0.999 & 155 & 0.872 \\
\hline & $80-1000 \mathrm{~m}$ & $66^{\circ} \mathrm{S}$ & 436 & 0.505 & -1.049 & 144 & 0.704 \\
\hline \multirow[t]{3}{*}{ Opal } & $80-1000 \mathrm{~m}$ & $55^{\circ} \mathrm{S}$ & 416 & 0.933 & -0.893 & 186 & 0.936 \\
\hline & $80-1000 \mathrm{~m}$ & $66^{\circ} \mathrm{S}$ & 407 & 0.570 & -1.071 & 139 & 0.739 \\
\hline & $80-200 \mathrm{~m}$ & $66^{\circ} \mathrm{S}$ & & & -2.990 & 36 & 0.997 \\
\hline
\end{tabular}

${ }^{a} \delta_{\mathrm{e}}=\mathrm{e}$-folding length scale for an exponential fit

${ }^{b} \mathrm{R}^{2}$ for the linear fit for $\ln (\mathrm{X})=\ln \left(\mathrm{X}_{\mathrm{ref}}\right)-\left(1 / \delta_{\mathrm{e}}\right) * \mathrm{z}$

${ }^{c} \mathrm{~b}$ is the Martin-like coefficient for a power law function: $\mathrm{X}=\mathrm{X}_{\mathrm{ref}} *\left(\mathrm{z} / \mathrm{Z}_{\mathrm{ref}}\right)^{\mathrm{b}}$

${ }^{d} \delta_{\mathrm{e}, \mathrm{p}}=$ distance for concentrations to decrease by $1 / \mathrm{e}$ relative to $\mathrm{Z}_{\mathrm{ref}}$ for power law fit

${ }^{e} \mathrm{R}^{2}$ for the linear fit for $\ln (\mathrm{X})=\ln \left(\mathrm{X}_{\mathrm{ref}}\right)+\mathrm{b} * \ln \left(\mathrm{z} / \mathrm{z}_{\mathrm{ref}}\right)$

$* \delta_{\mathrm{e}, \mathrm{p}}$ not meaningful for lower twilight zone fits 


\section{Figure Legends}

Figure 1. Timeline of MULVFS casts and iron additions for $55^{\circ} \mathrm{S}$ (top) and $66^{\circ} \mathrm{S}$ (bottom). Grey bars indicate times of iron addition. Black bars indicate times of MULVFS casts. Numbers next to bars indicate cast number. Casts 1,3 , and 6 were in non Fe-amended waters; cast 2 was at the edge of the Fe-fertilized patch; casts 4, 5, 7, and 8 were in Fe-fertilized waters.

Figure 2. Constraints for determining $>51 \mu \mathrm{m}$ POC at $55^{\circ} \mathrm{S}$ (circles, squares) and $66^{\circ} \mathrm{S}$ (triangles). (a) " $<1 \mu \mathrm{m}$ ” particulate phosphorus (P); (b) 1-51 $\mu \mathrm{m} \mathrm{P}$; (c) $>51 \mu \mathrm{m} \mathrm{P}$; (d) $\mathrm{POC}_{\text {grav }}$, determined gravimetrically; error calculated using Equation 4; (e) $\mathrm{POC}_{\mathrm{P}}$, determined from >51 $\mu \mathrm{m}$ P and 1-51 $\mu \mathrm{m} \mathrm{C:P;} \mathrm{(f)} \mathrm{OD}_{\text {green, }}$ green optical density. Symbols show individual casts at $55^{\circ} \mathrm{S}$ (circles, squares) and $66^{\circ} \mathrm{S}$ (triangles). Open symbols are from control stations; filled symbols are from iron-amended stations. Lines are averages of control stations (open symbols) at $55^{\circ} \mathrm{S}$ (thick line) or $66^{\circ} \mathrm{S}$ (thin line).

Figure 3. Profiles of POC in the (a) " $<1 \mu \mathrm{m}$ " and (b) $1-51 \mu \mathrm{m}$ size fractions; (c) profiles of C:P ratio of 1-51 $\mu \mathrm{m}$ particulates; and (d) profiles of $\mathrm{POC}_{\text {Pscale }}$ in the $>51 \mu \mathrm{m}$ size fractions, which is POC estimated from particulate $\mathrm{P}$ and C:P, scaled by surface $\mathrm{POC}_{\text {grav }}$ (POC determined gravimetrically) from the twilight zone at $55^{\circ} \mathrm{S}$ and $66^{\circ} \mathrm{S}$. Symbols as for Figure 2.

Figure 4. Digital pictures of $>51 \mu \mathrm{m}$ MULVFS filters against white $(\mathrm{a}, \mathrm{b})$ and black $(\mathrm{c}, \mathrm{d})$ backgrounds showing higher particle loading at twilight zone mid-depths at $55^{\circ} \mathrm{S}$ compared to $66^{\circ} \mathrm{S}$. Samples are (a,c) $55^{\circ} \mathrm{S}$, cast $1,459 \mathrm{~m}, 8000 \mathrm{~L}$ filtered; and (b,d) $66^{\circ} \mathrm{S}$, cast $5,470 \mathrm{~m}$, $10959 \mathrm{~L}$ filtered. The dimensions of each rectangle are $6.1 \mathrm{~cm} \times 4.1 \mathrm{~cm}$, representing $1 / 20^{\text {th }}$ of a MULVFS filter. Photographs were adjusted for contrast and sharpened in Photoshop using the Unsharp Mask feature, with settings of 300\% (amount), radius=0.4 pixels, threshold=0 levels. 
Figure 5. Profiles of $(\mathrm{a}, \mathrm{c}) \mathrm{CaCO}_{3}$, and (b,c) biogenic $\mathrm{Si}$ (opal) in the twilight zone at $55^{\circ} \mathrm{S}$ and $66^{\circ} \mathrm{S}$. $>0.4 \mu \mathrm{m}$ biogenic $\mathrm{Si}(\mathrm{c})$ was not prefiltered, and includes large particles. $\mathrm{CaCO}_{3}$ is much higher at $55^{\circ} \mathrm{S}$ in both size fractions than at $66^{\circ} \mathrm{S} . \mathrm{CaCO}_{3}$ at $66^{\circ} \mathrm{S}$ was often not detectable (zero or negative numbers do not plot in log coordinates). Biogenic Si was $\sim 10 \mathrm{x}$ higher at $66^{\circ} \mathrm{S}$ than at $55^{\circ} \mathrm{S}$ at the surface, but was similar or lower at depth. Symbols as for Figure 2.

Figure 6. Digital images of $>51 \mu \mathrm{m}$ MULVFS filters at $55^{\circ} \mathrm{S}$. (a) cast 1 , -Fe (01/12/2002); (b) cast $8,+\mathrm{Fe}(02 / 09 / 2002)$. After Fe fertilization (b), particle loading is much higher in the euphotic zone (compare Figure 7a, $40 \mathrm{~m}$ with Figure 7b, $35 \mathrm{~m}$ ), but lower below $50 \mathrm{~m}$. (c) cast 3, -Fe $(01 / 23 / 2002) ;$ (d) cast $7,+\mathrm{Fe}(02 / 04 / 2002)$. Images show a thick layer of material in euphotic zones (Figure 7c,d; $<50 \mathrm{~m}$ ), and fecal pellets several $\mathrm{mm}$ long abundant from surface to $150 \mathrm{~m}$ (especially Figure 7c; $136 \mathrm{~m}$ ), indicating the presence of large zooplankton consumers such as euphausiids. The complete disappearance of these fecal pellets by $200 \mathrm{~m}$ and low particle loading at depth (Figure 7c,d; >150 m) indicate active remineralization between 150-200 m. Picture settings as for Figure 5.

Figure 7. Scanning electron microscope (SEM) images of dried aggregates from cast $1,55^{\circ} \mathrm{S}$ $(\mathrm{a}, \mathrm{c})$ and cast $6,66^{\circ} \mathrm{S}(\mathrm{b}, \mathrm{d})$. (a) filter from $40 \mathrm{~m}$ at $55^{\circ} \mathrm{S}$ showing discrete aggregates and large dinoflagellates. The polyester mesh filter with $51 \mu \mathrm{m}$ openings is visible in the background. (b) filter from $45 \mathrm{~m}$ at $66^{\circ} \mathrm{S}$ showing a thick cake of diatoms. (c) aggregate from $459 \mathrm{~m}$ at $55^{\circ} \mathrm{S}$ showing a melange of coccoliths $\left(\mathrm{CaCO}_{3}\right)$ and partially and fully intact diatom frustules (opal) in upper and lower right; salt crystals are the large, geometric shapes in the lower right quadrant of the image. (d) aggregate from $323 \mathrm{~m}$ at $66^{\circ} \mathrm{S}$ showing cubic salt crystals encrusting the outside of the aggregate on the left and right; inset: higher magnification image of same aggregate showing highly processed opal fragments. 
Figure 8. Digital pictures of $>51 \mu \mathrm{m}$ MULVFS filters against white $(\mathrm{a}, \mathrm{b})$ and black $(\mathrm{c}, \mathrm{d})$ backgrounds showing predominance of white fluffy aggregates (long fecal pellets) at $66^{\circ} \mathrm{S}$ in the upper twilight zone. Samples are (a,c) $55^{\circ} \mathrm{S}$, cast $1,138 \mathrm{~m}, 6510 \mathrm{~L}$ filtered; and (b,d) $66^{\circ} \mathrm{S}$, cast 3, $136 \mathrm{~m}, 7924 \mathrm{~L}$ filtered. The dimensions of each rectangle are $6.1 \mathrm{~cm} \mathrm{x} 4.1 \mathrm{~cm}$, representing $1 / 20^{\text {th }}$ of a MULVFS filter. Large square grid pattern is due to flow interruption by a grid of 1.27 $\mathrm{cm}$ spacing used to support the prefilter. Picture settings as for Figure 5.

Figure 9. Power law (black) and exponential (grey) fits to $>51 \mu \mathrm{m}$ particulate $\mathrm{P}(\mathrm{a}, \mathrm{b})$ and $\mathrm{POC}_{\text {Pscale }}(\mathrm{c}, \mathrm{d})$ and residuals from whole profile fits (f,g) to POC profiles from $55^{\circ} \mathrm{S}(\mathrm{a}, \mathrm{c}, \mathrm{e})$ and $66^{\circ} \mathrm{S}(\mathrm{b}, \mathrm{d}, \mathrm{f})$.

Figure 10. Power law (black) and exponential (grey) fits to $>51 \mu \mathrm{m} \mathrm{CaCO}_{3}$ (a,b) and opal (c,d) profiles from $(\mathrm{a}, \mathrm{c}) 55^{\circ} \mathrm{S}$ and $(\mathrm{b}, \mathrm{d}) 66^{\circ} \mathrm{S}$. Whole profile fits are not good at capturing the gradient. Figure 11. Profiles of seawater (a) temperature, (b) salinity, (c) density, and (d) viscosity at $55^{\circ} \mathrm{S}$ (solid lines) and $66^{\circ} \mathrm{S}$ (dashed lines). Colder temperatures at $66^{\circ} \mathrm{S}$ result in higher seawater density and viscosity.

Figure 12. Average POC and viscosity-normalized POC. Accounting for the differences in seawater viscosity at $55^{\circ} \mathrm{S}$ and $66^{\circ} \mathrm{S}$ does not significantly affect the shape of POC profiles. Figure 13. Excess densities for aggregates at $55^{\circ} \mathrm{S}$ and $66^{\circ} \mathrm{S}$. Composition-based excess densities of aggregates are slightly lower in the carbonate producing $55^{\circ} \mathrm{S}$. Symbols as for Figure 2. Error bars are the standard error of the mean.

Figure 14. (a) Porosities and (b) excess densities with porosity for aggregates at $55^{\circ} \mathrm{S}$ and $66^{\circ} \mathrm{S}$. Uncertainties in porosities and porous excess densities are propagated from measurement uncertainties in the masses of salt, organic matter, $\mathrm{CaCO}_{3}$, and opal. Aggregate porosities are slightly higher at $66^{\circ} \mathrm{S}$ than at $55^{\circ} \mathrm{S}$, especially in the $80-200 \mathrm{~m}$ depth range, lowering the porous 
excess densities of $66^{\circ} \mathrm{S}$ aggregates below those at $55^{\circ} \mathrm{S}$. Symbols as for Figure 13. Anomalous $55^{\circ} \mathrm{S}$ point at $459 \mathrm{~m}$ omitted from average because of large uncertainty in measurement $(85 \%$ relative error).

Figure 15. Profiles of (a) $1-51 \mu \mathrm{m}$ and (b) $>51 \mu \mathrm{m}$ particulate $\mathrm{Ba}$ at $55^{\circ} \mathrm{S}$ and $66^{\circ} \mathrm{S}$. The $1-51$ $\mu \mathrm{m}$ size fraction (a) shows a shallower Ba maximum at $66^{\circ} \mathrm{S}$, implying shallower biologicallymediated fragmentation processes than at $55^{\circ} \mathrm{S}$. Symbols as for Figure 2. 
9 Figures

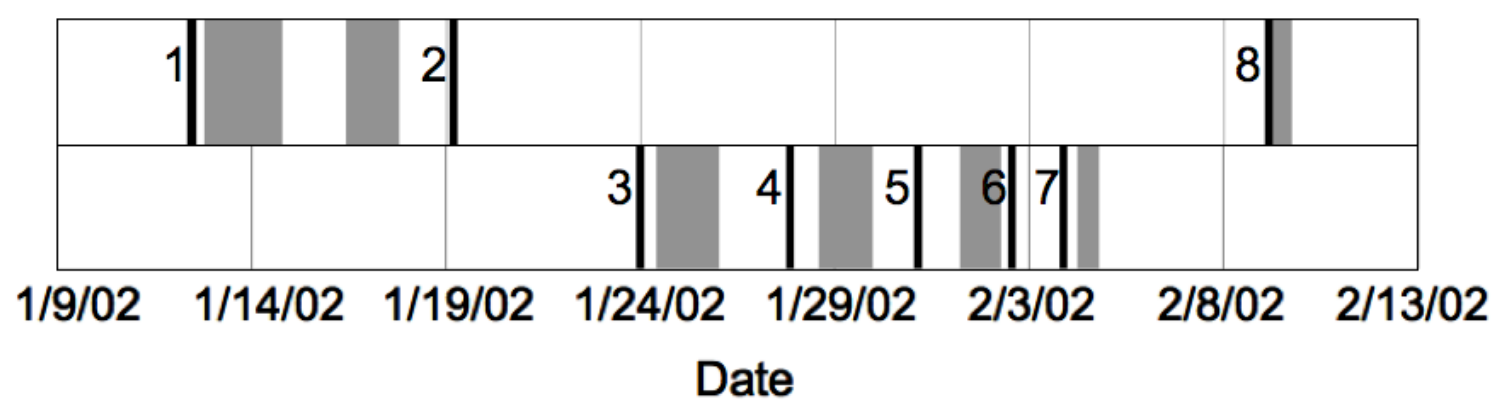

Figure 1 

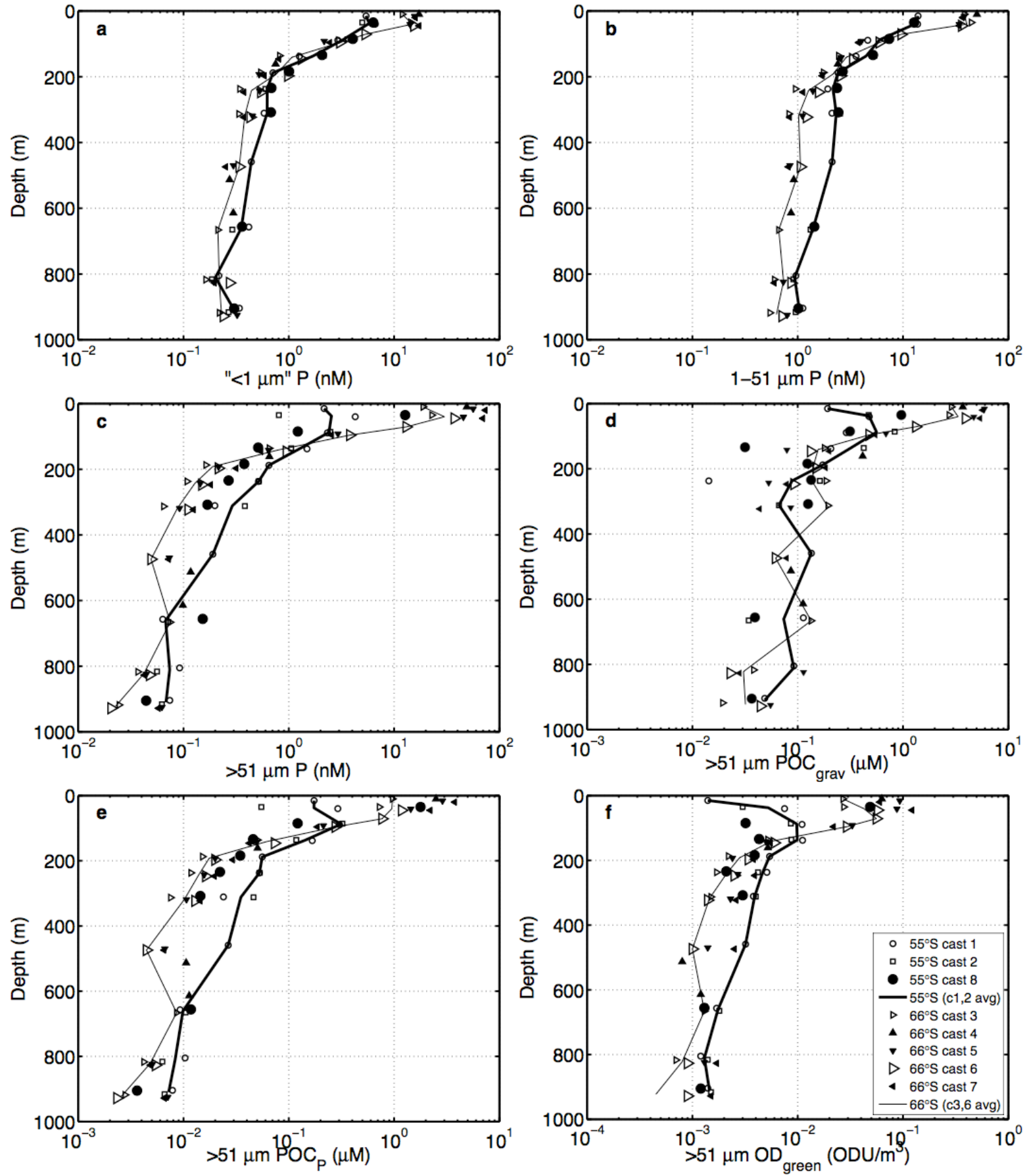

Figure 2 

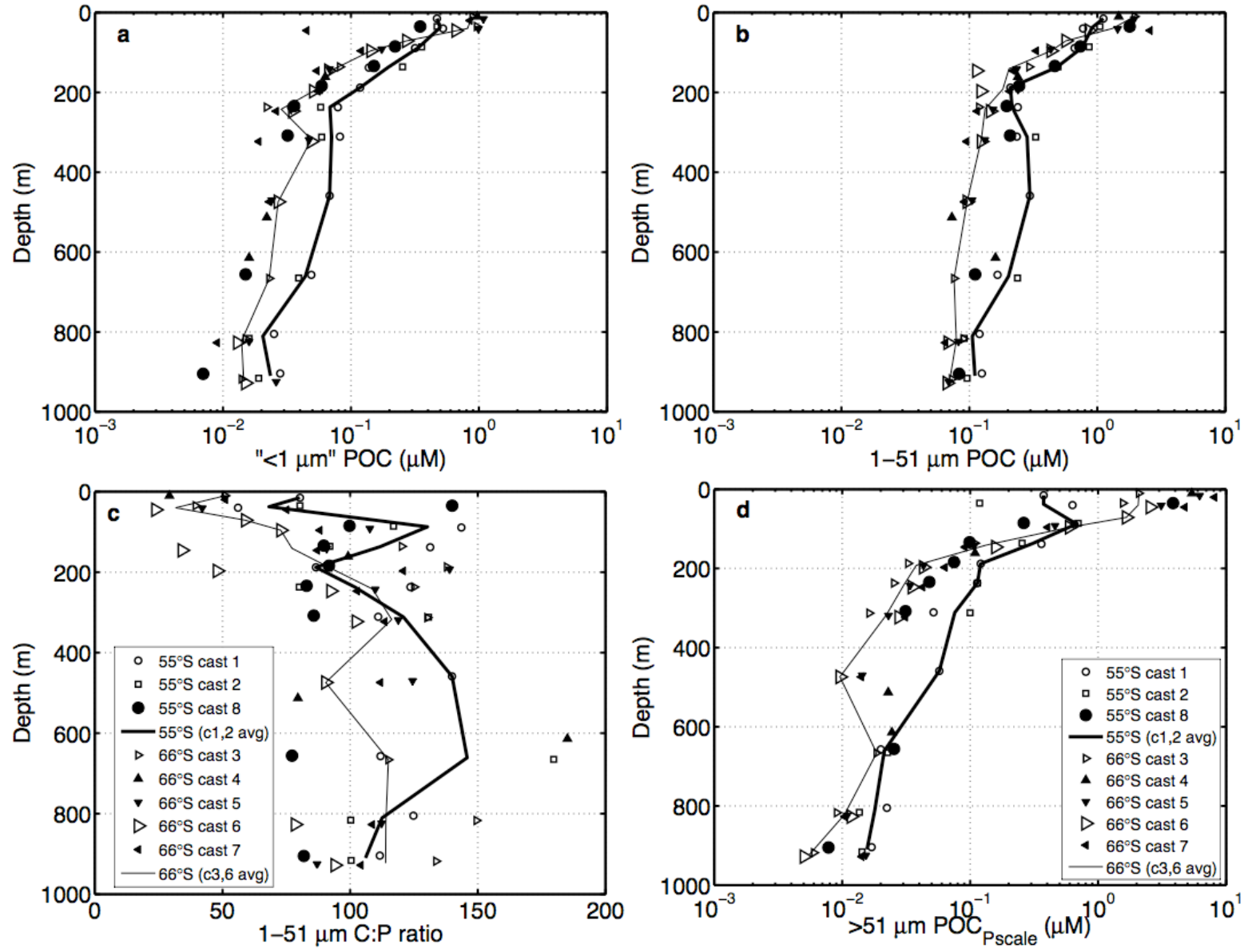

Figure 3 
$55^{\circ} \mathrm{S}$

a

b

$66^{\circ} \mathrm{S}$

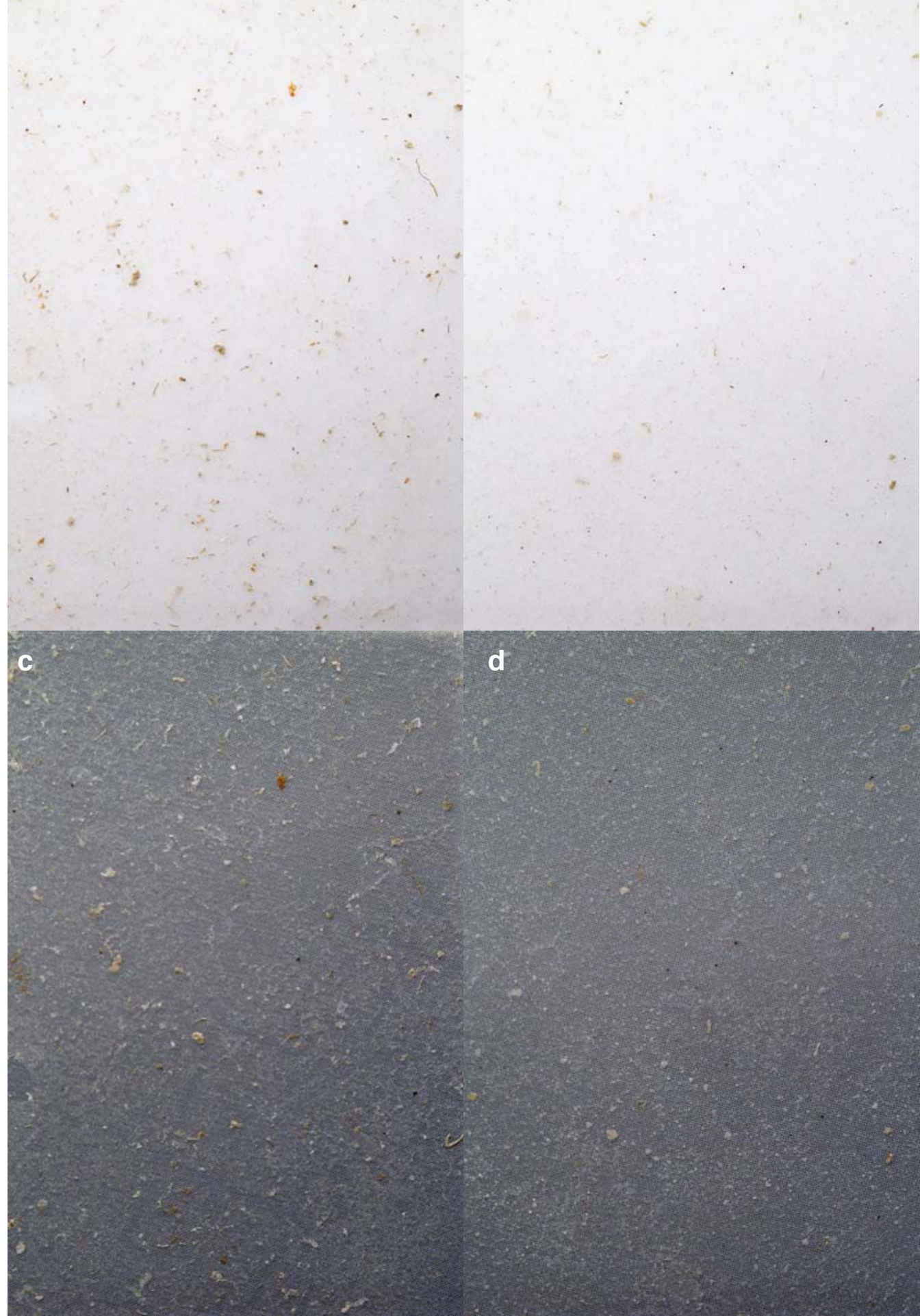

Figure 4 

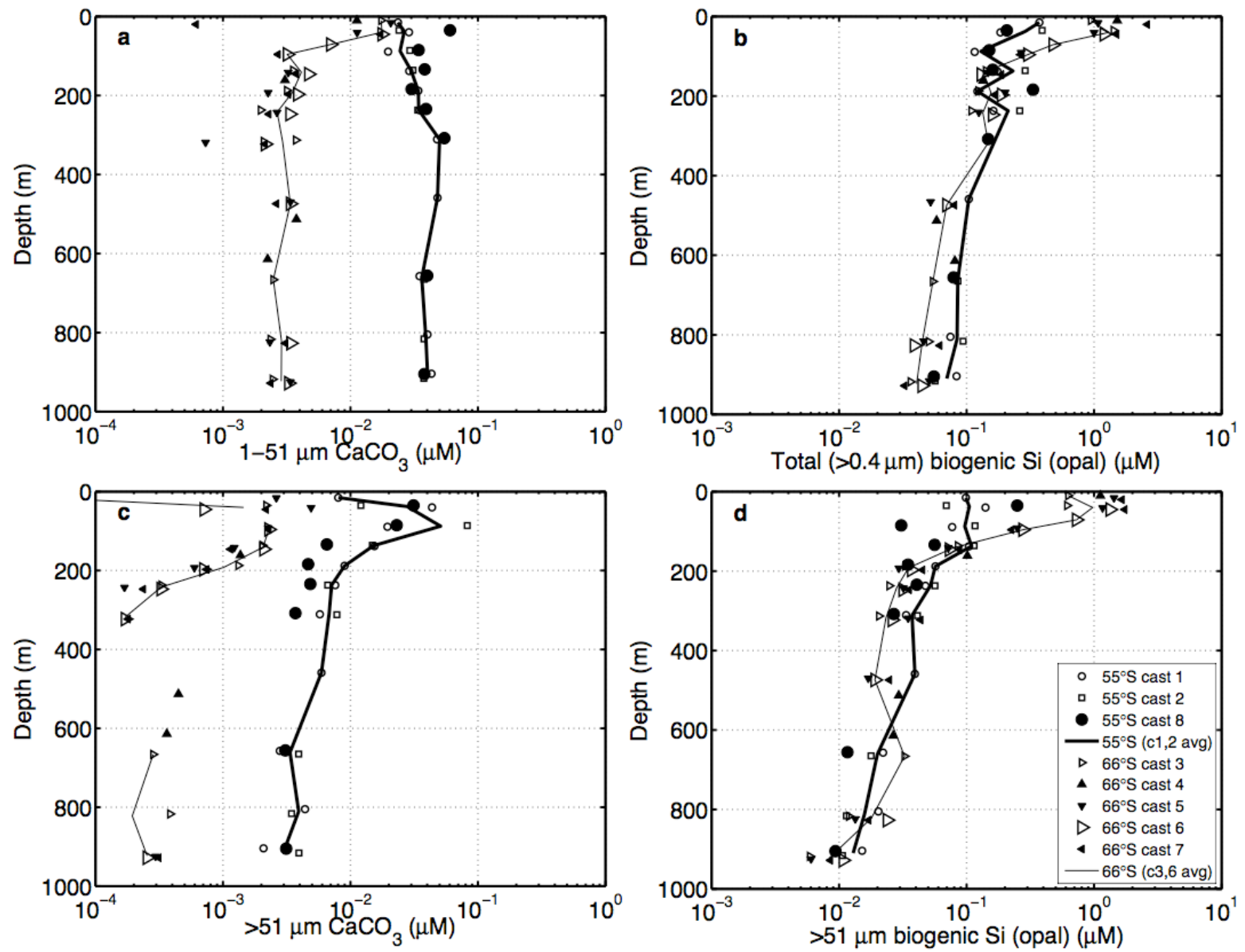

Figure 5 
$55^{\circ} \mathrm{S}-\mathrm{Fe}$

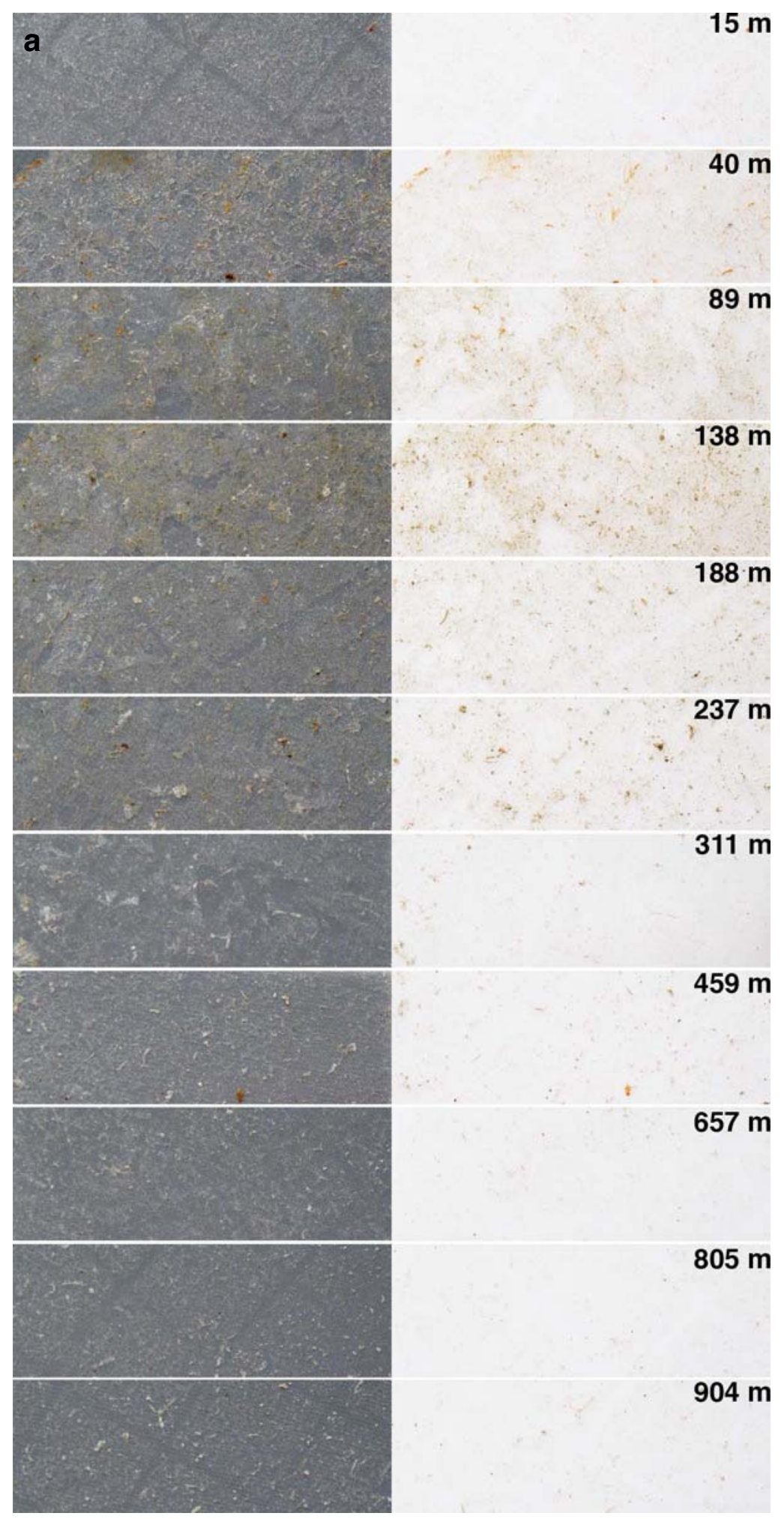

Figure 6a 


\section{$55^{\circ} \mathrm{S}+\mathrm{Fe}$}

b
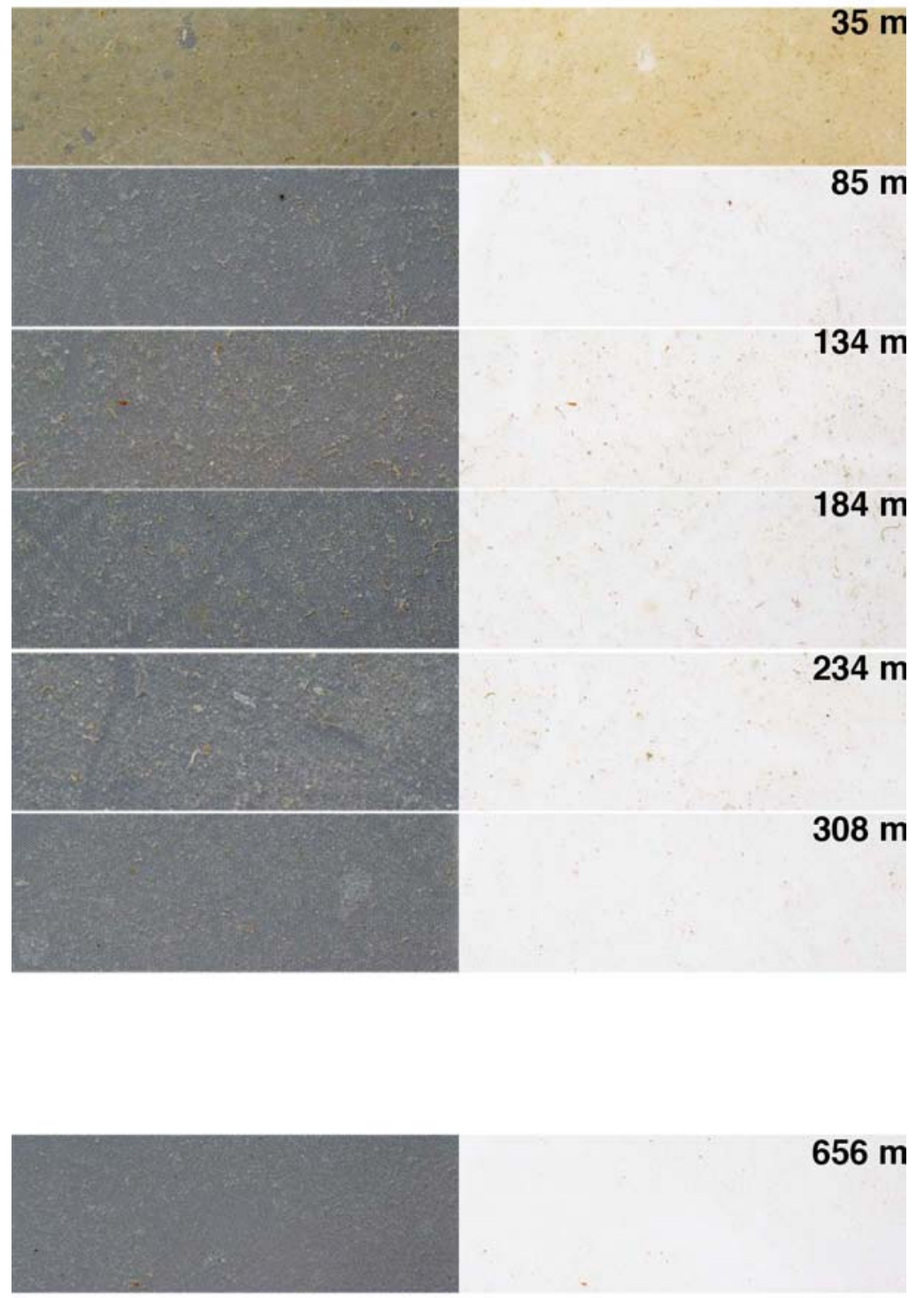

$656 \mathrm{~m}$

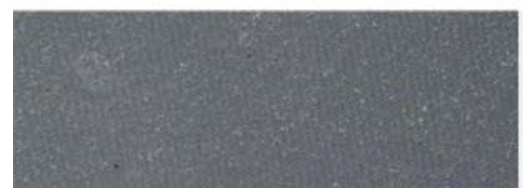

$905 \mathrm{~m}$

Figure 6b. 
$66^{\circ} \mathrm{S}-\mathrm{Fe}$
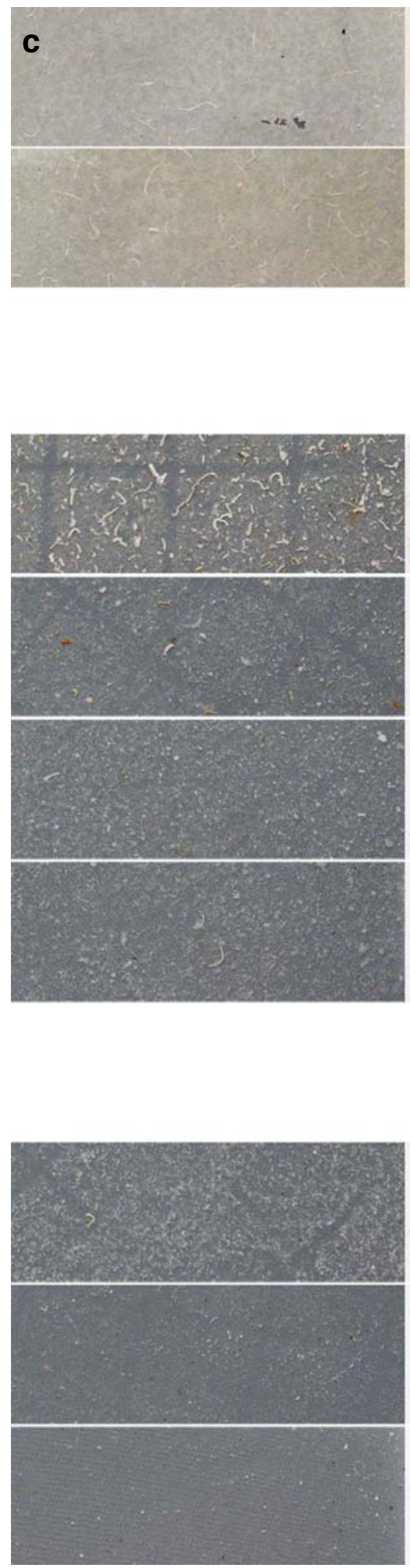

$666 \mathrm{~m}$

Figure 6c.
$35 \mathrm{~m}$

$136 \mathrm{~m}$

$313 \mathrm{~m}$

$10 \mathrm{~m}$

$187 \mathrm{~m}$

$237 \mathrm{~m}$
$918 \mathrm{~m}$

817 m 
$66^{\circ} \mathrm{S}+\mathrm{Fe}$
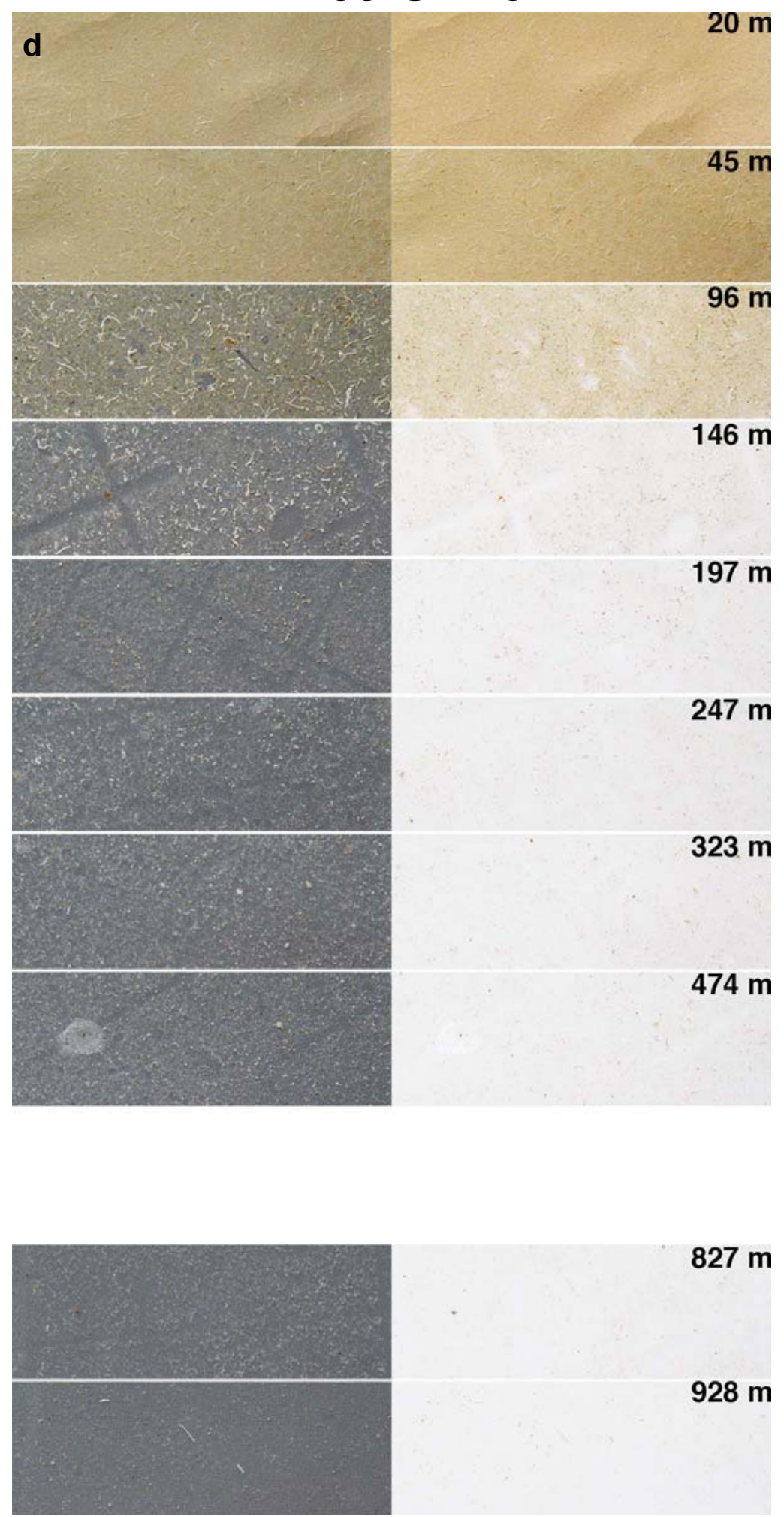

827 m

928 m

Figure 6d. 


\section{$55^{\circ} \mathrm{S}$}
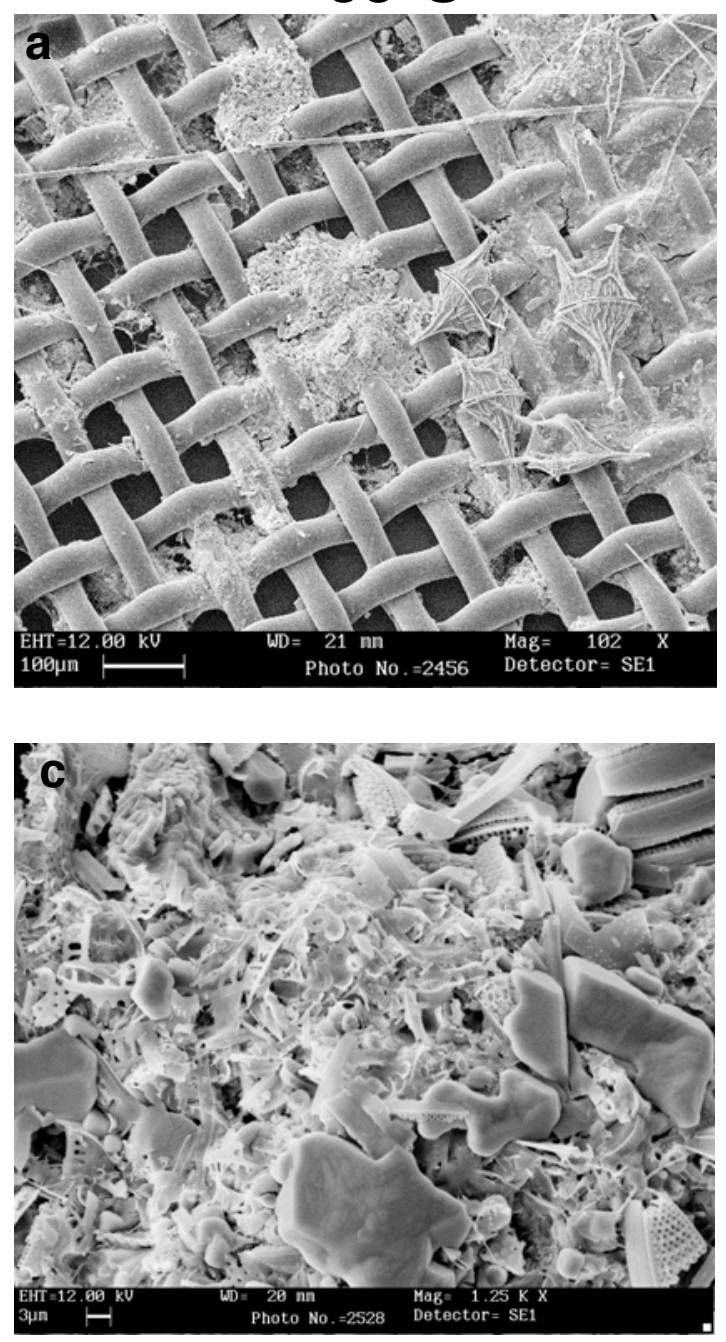

$66^{\circ} \mathrm{S}$
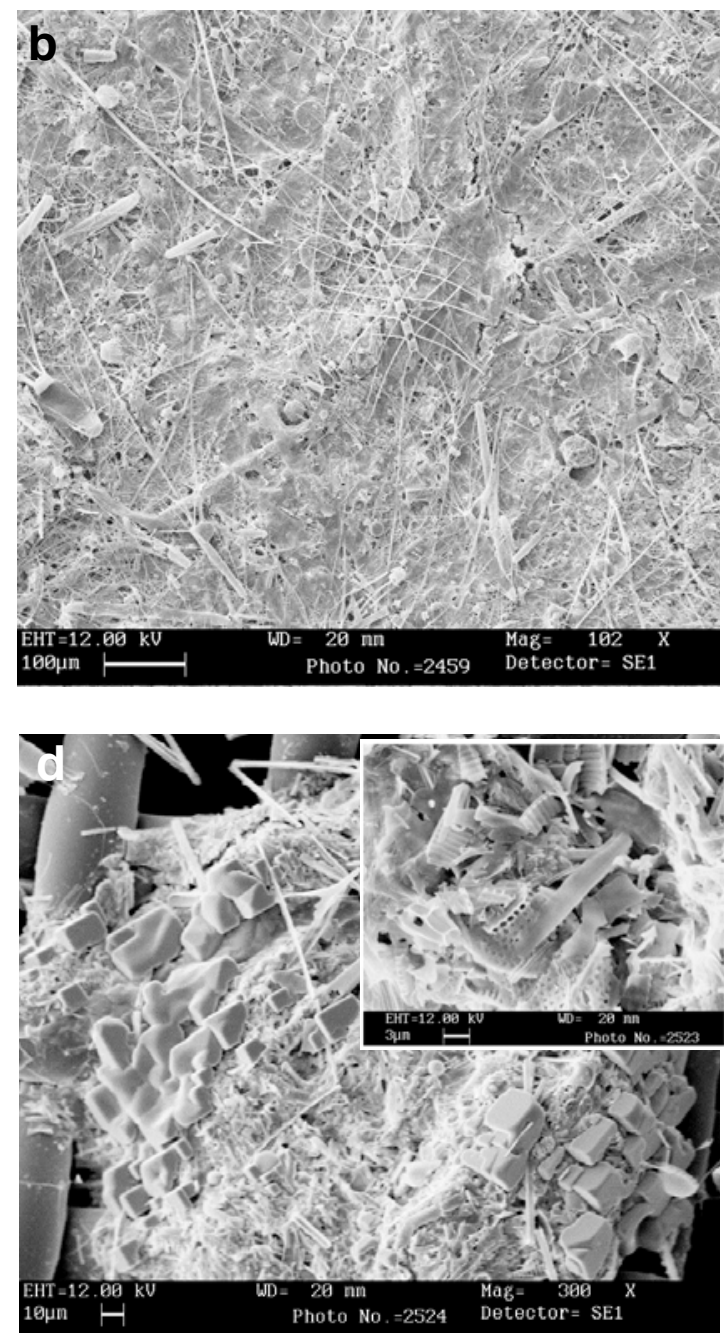

Figure 7 


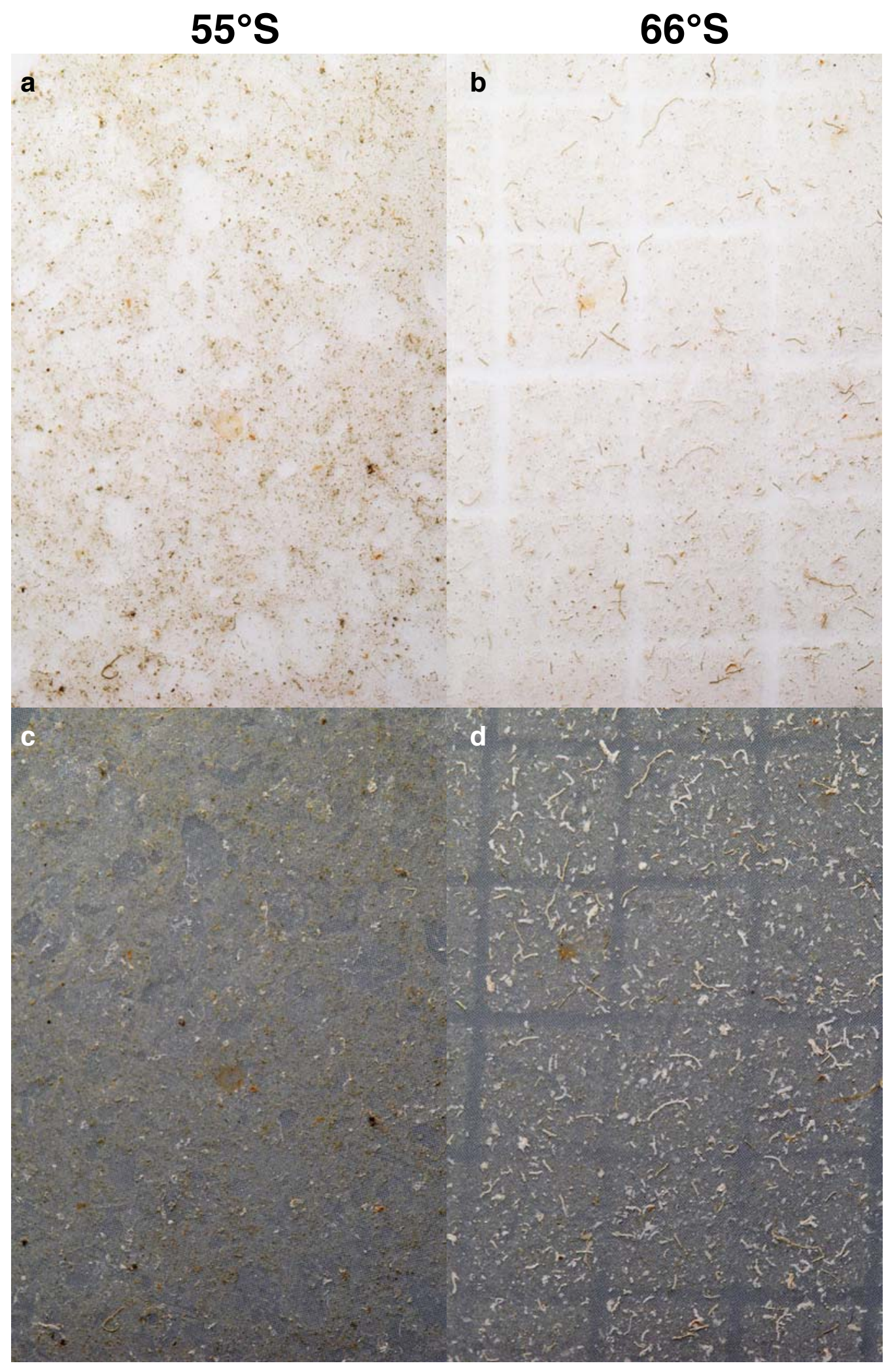

Figure 8 

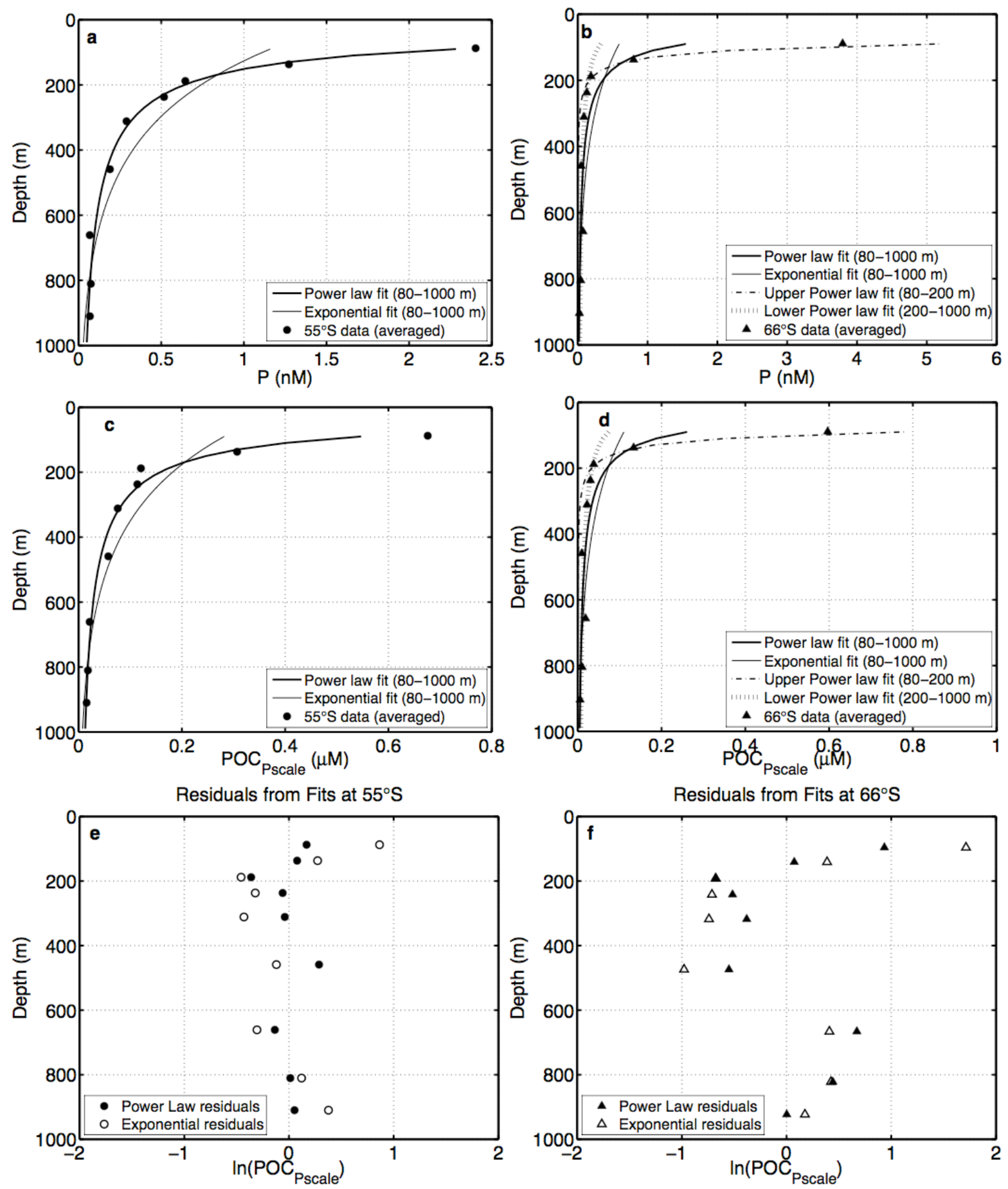

Figure 9 

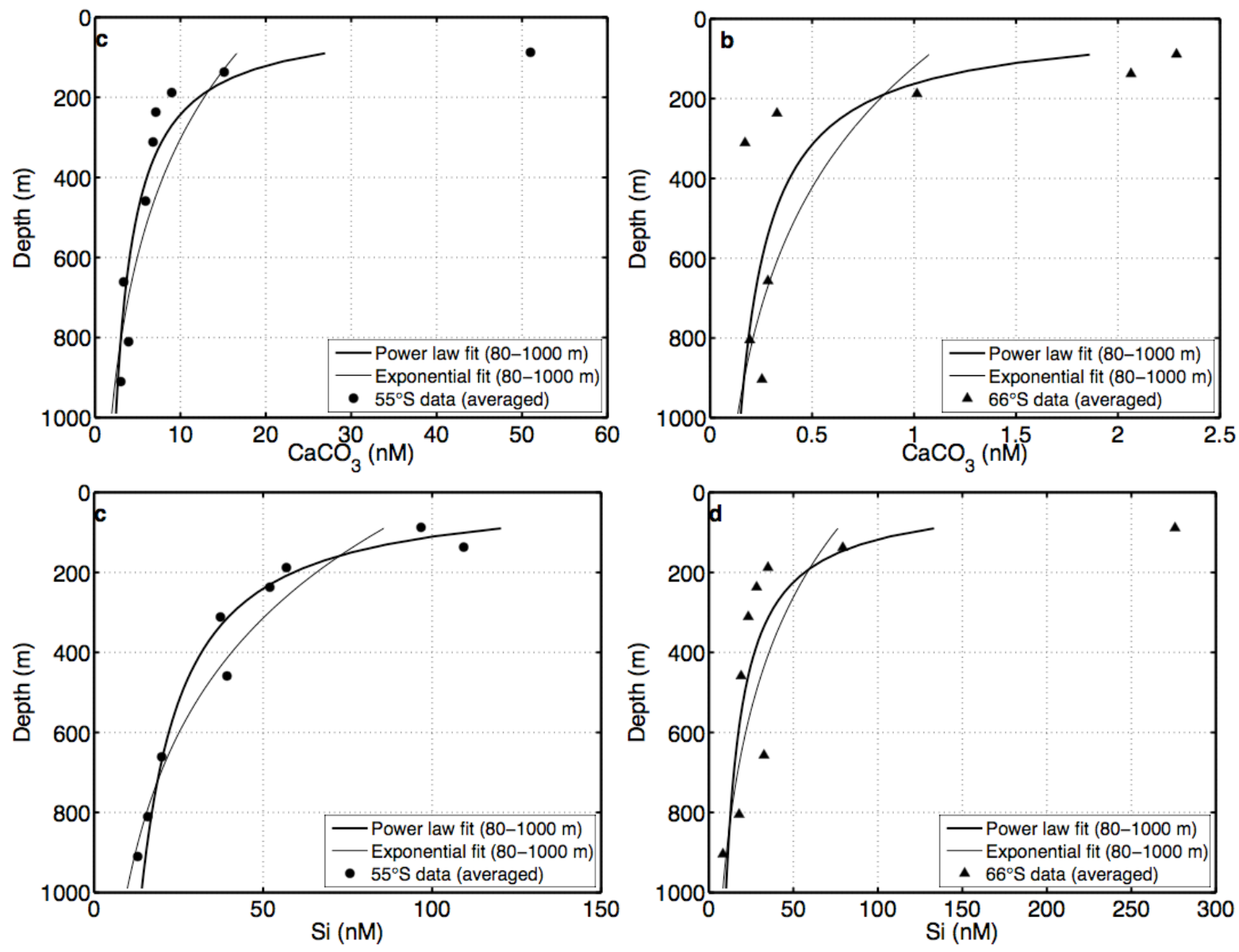

Figure 10 

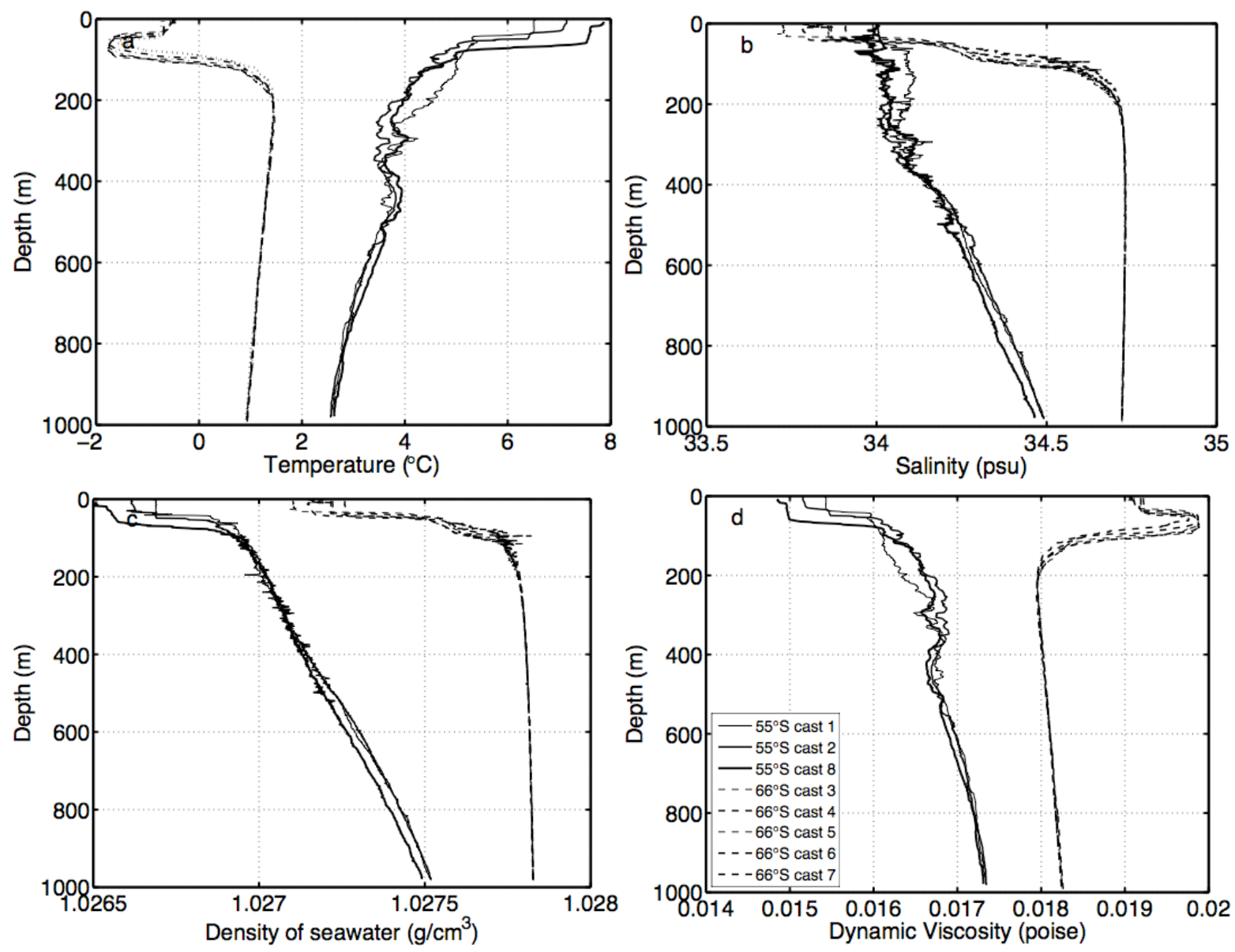

Figure 11 


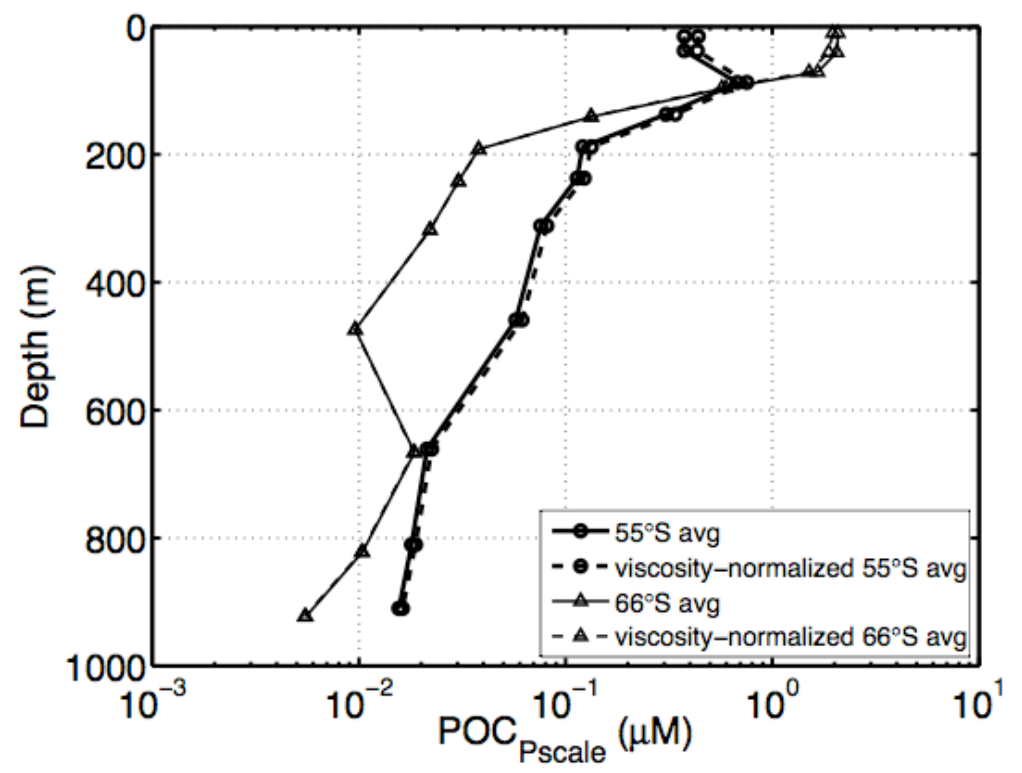

Figure 12 


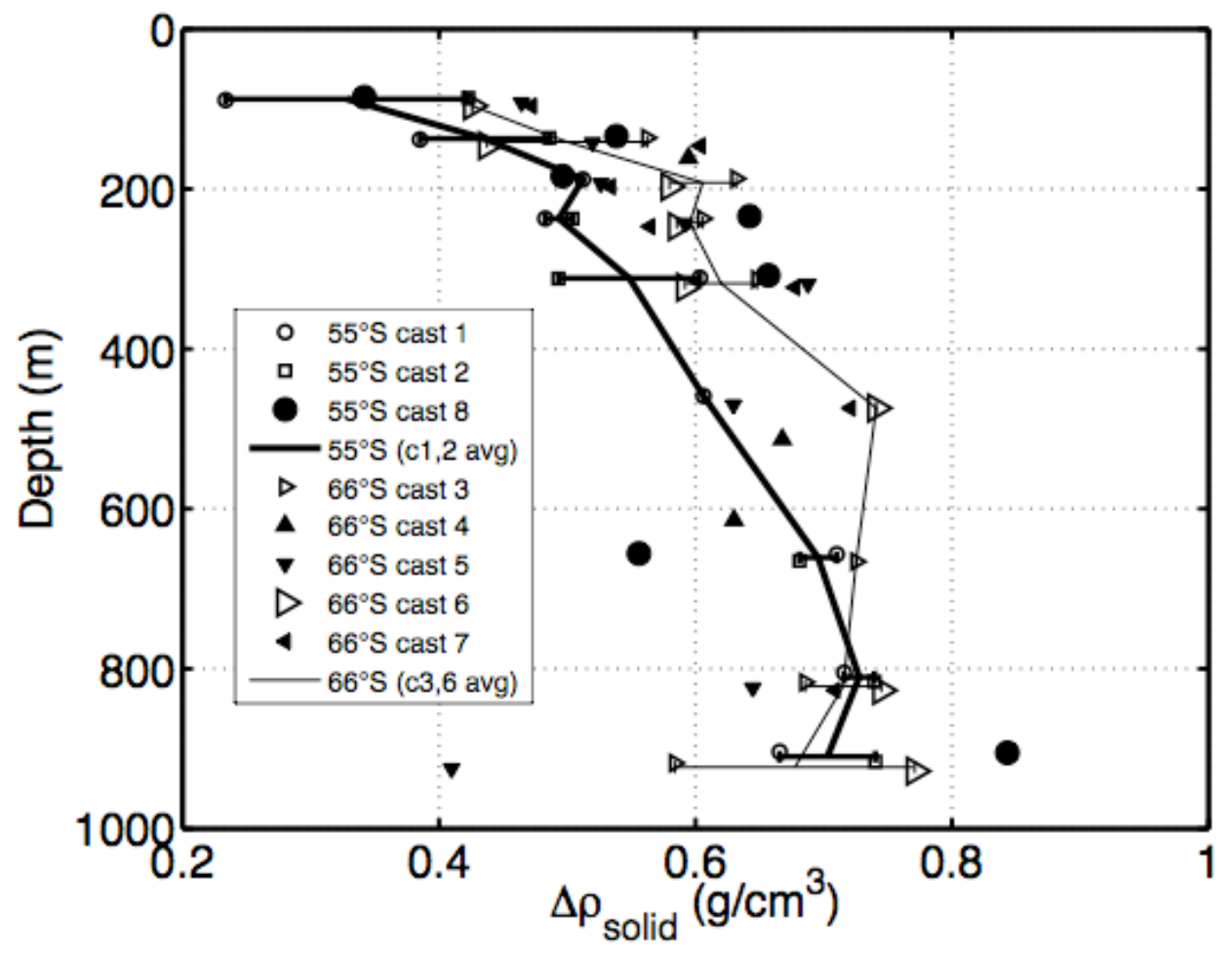

Figure 13 

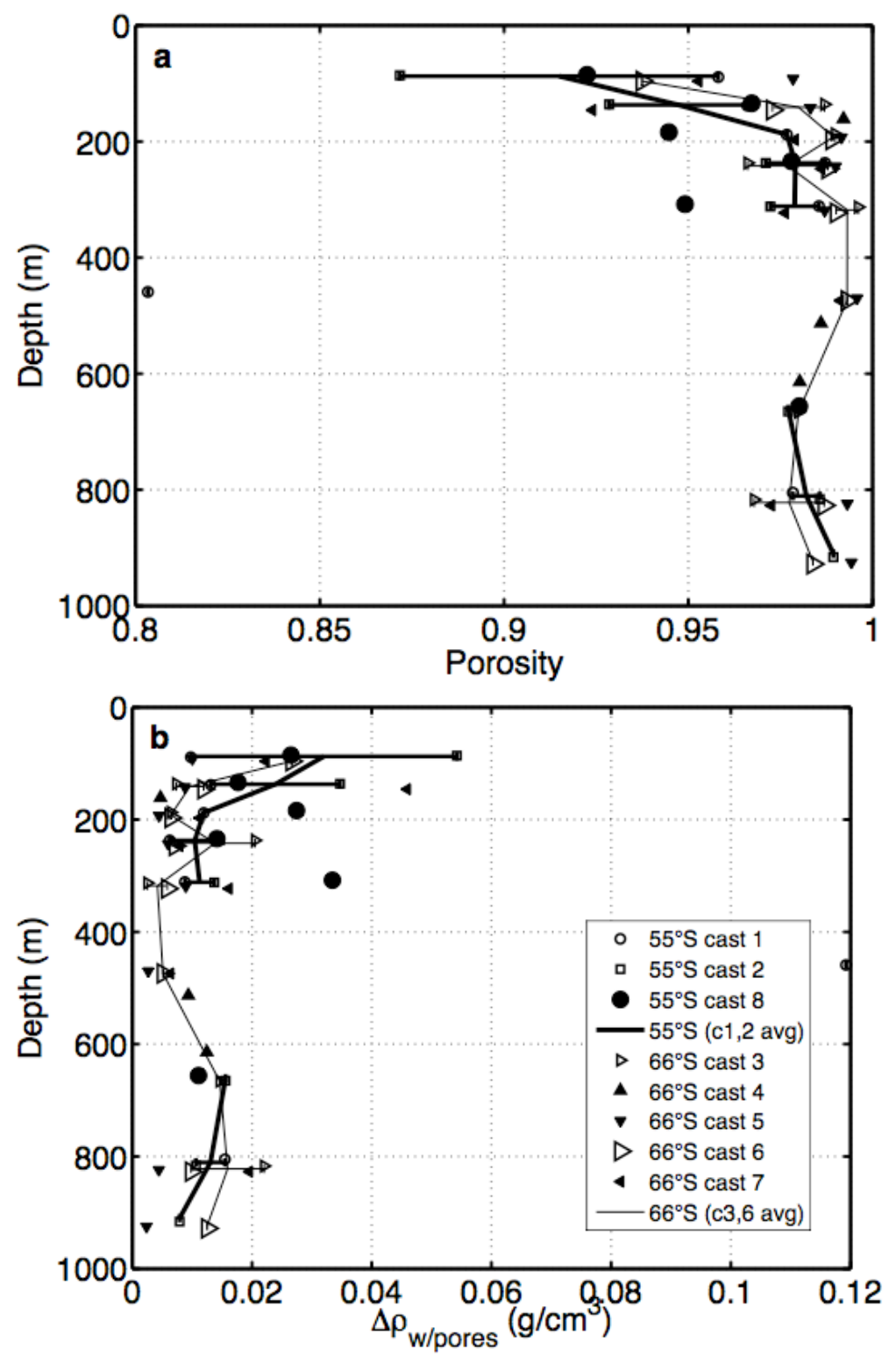

Figure 14 

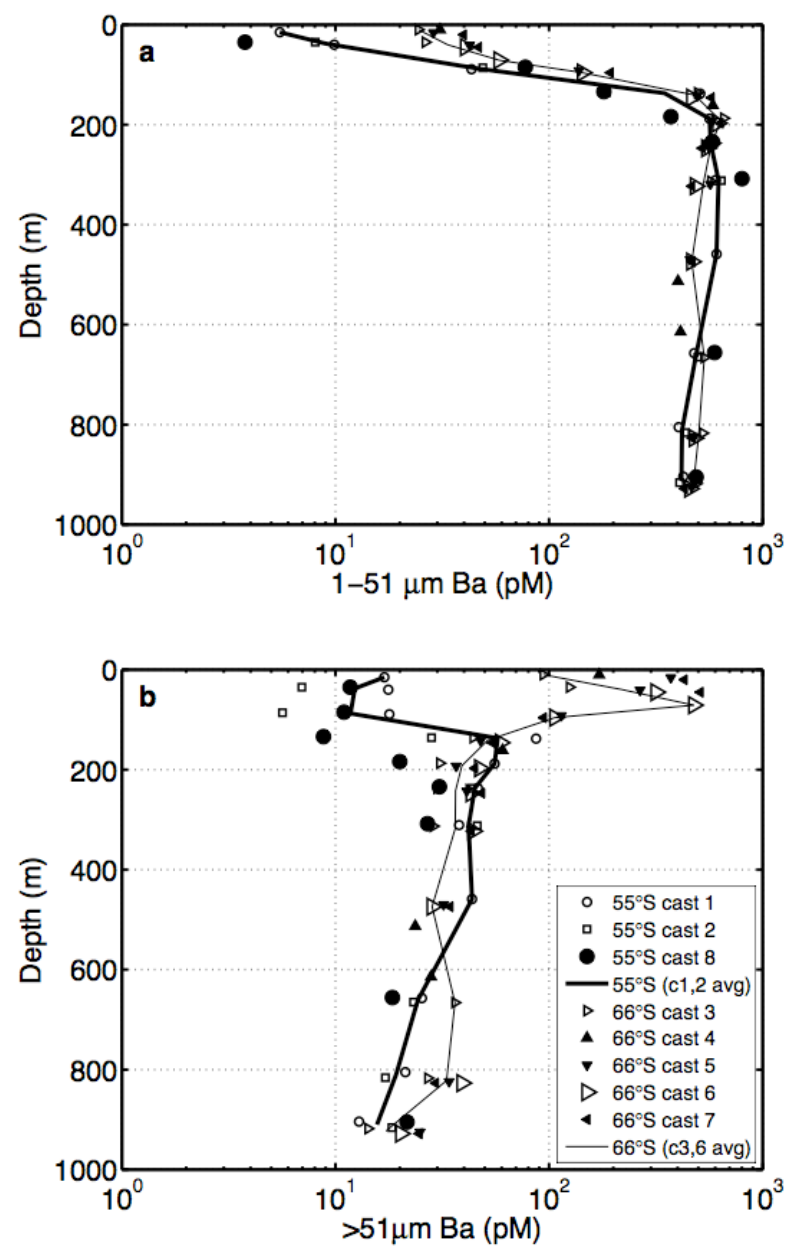

Figure 15 


\section{Acknowledgements}

This paper benefited tremendously from numerous stimulating discussions with Inez Fung and

Cara Henning, as well as helpful comments from two anonymous reviewers. Thanks to Todd

Wood for salt drying experiments and for help on the ICP-MS and at sea, David Timothy and

Mark Altabet for POC analyses of the " $<1 \mu \mathrm{m}$ " and 1-51 $\mu \mathrm{m}$ size fractions, Chief Scientist Ken

Johnson, the SOFeX group, and the captain and ship's crew of the R/V Roger Revelle. This

work was supported by the DOE Office of Science, Biological and Environmental Research

Program. Shiptime for SOFeX was funded by NSF.

\section{References}

Alldredge, A.L., Gotschalk, C., 1988. In situ settling behavior of marine snow. Limnology and Oceanography 33 (3) 339-351.

Altabet, M.A., Pilskaln, C., Thunell, R., Pride, C., Sigman, D., Chavez, F., Francois, R., 1999. The nitrogen isotope biogeochemistry of sinking particles from the margin of the Eastern North Pacific. Deep-Sea Research Part I-Oceanographic Research Papers 46 (4) 655-679.

Armstrong, R.A., Lee, C., Hedges, J.I., Honjo, S., Wakeham, S.G., 2002. A new, mechanistic model for organic carbon fluxes in the ocean based on the quantitative association of POC with ballast minerals. Deep-Sea Research Part Ii-Topical Studies in Oceanography 49 (1-3) 219-236.

Bacon, M.P., Cochran, J.K., Hirschberg, D., Hammar, T.R., Fleer, A.P., 1996. Export flux of carbon at the equator during the EqPac time-series cruises estimated from Th-234 measurements. Deep-Sea Research Part Ii-Topical Studies in Oceanography 43 (4-6) 1133-1153.

Balch, W.M., Gordon, H.R., Bowler, B.C., Drapeau, D.T., Booth, E.S., 2005. Calcium carbonate measurements in the surface global ocean based on Moderate-Resolution Imaging Spectroradiometer data. Journal of Geophysical Research-Oceans 110 (C7).

Bé, A.W.H., Bishop, J.K.B., Sverdlove, M.S., Gardner, W.D., 1985. Standing Stock, VerticalDistribution and Flux of Planktonic-Foraminifera in the Panama Basin. Marine Micropaleontology 9 (4) 307-333.

Bishop, J.K.B., 1988. The Barite-Opal-Organic Carbon Association in Oceanic Particulate Matter. Nature 332 (6162) 341-343.

Bishop, J.K.B., 1989. Regional Extremes in Particulate Matter Composition and Flux: Effects on the Chemistry of the Ocean Interior. In: W. H. Berger, V. Smetacek and D. Wefer [Eds.], Productivity of the Ocean: Present and Past. Life Sciences Research Reports. John Wiley \& Sons, New York, pp. 117-137.

Bishop, J.K.B., Edmond, J.M., 1976. New Large Volume Filtration System for Sampling of Oceanic Particulate Matter. Journal of Marine Research 34 (2) 181-198. 
Bishop, J.K.B., Edmond, J.M., Ketten, D.R., Bacon, M.P., Silker, W.B., 1977. Chemistry, Biology, and Vertical Flux of Particulate Matter from Upper $400 \mathrm{M}$ of Equatorial Atlantic Ocean. Deep-Sea Research 24 (6) 511-548.

Bishop, J.K.B., Ketten, D.R., Edmond, J.M., 1978. Chemistry, Biology and Vertical Flux of Particulate Matter from the Upper 400m of the Cape Basin in the Southeast Atlantic Ocean. Deep-Sea Research 25 (12) 1121-1161.

Bishop, J.K.B., Schupack, D., Sherrell, R.M., Conte, M., 1985. A Multiple-Unit Large-Volume In-situ Filtration System for Sampling Oceanic Particulate Matter in Mesoscale Environments. Advances in Chemistry Series (209) 155-175.

Bishop, J.K.B., Stepien, J.C., Wiebe, P.H., 1986. Particulate Matter Distributions, Chemistry and Flux in the Panama Basin - Response to Environmental Forcing. Progress in Oceanography 17 (1-2) 1-59.

Bishop, J.K.B., Wood, T.J., Davis, R.E., Sherman, J.T., 2004. Robotic observations of enhanced carbon biomass and export at 55 degrees S during SOFeX. Science 304 (5669) 417-420.

Bruland, K.W., Donat, J.R., Hutchins, D.A., 1991. Interactive Influences of Bioactive TraceMetals on Biological Production in Oceanic Waters. Limnology and Oceanography 36 (8) $1555-1577$.

Buesseler, K.O., Andrews, J.E., Pike, S.M., Charette, M.A., 2004. The effects of iron fertilization on carbon sequestration in the Southern Ocean. Science 304 (5669) 414-417.

Buesseler, K.O., Ball, L., Andrews, J., Cochran, J.K., Hirschberg, D.J., Bacon, M.P., Fleer, A., Brzezinski, M., 2001. Upper ocean export of particulate organic carbon and biogenic silica in the Southern Ocean along 170 degrees W. Deep-Sea Research Part Ii-Topical Studies in Oceanography 48 (19-20) 4275-4297.

Buesseler, K.O., Barber, R.T., Dickson, M.L., Hiscock, M.R., Moore, J.K., Sambrotto, R., 2003. The effect of marginal ice-edge dynamics on production and export in the Southern Ocean along 170 degrees W. Deep-Sea Research Part Ii-Topical Studies in Oceanography $50(3-4) 579-603$.

Burd, A., Jackson, G.A., Lampitt, R.S., Follows, M.J., 2002. Shining a Light on the Ocean's Twilight Zone. EOS, Transactions, American Geophysical Union 83 (49) 573.

Cardinal, D., Savoye, N., Trull, T.W., Andre, L., Kopczynska, E.E., Dehairs, F., 2005. Variations of carbon remineralisation in the Southern Ocean illustrated by the Baxs proxy. Deep Sea Research Part I: Oceanographic Research Papers 52 (2) 355-370.

Coale, K.H., Johnson, K.S., Chavez, F.P., Buesseler, K.O., Barber, R.T., Brzezinski, M.A., Cochlan, W.P., Millero, F.J., Falkowski, P.G., Bauer, J.E., Wanninkhof, R.H., Kudela, R.M., Altabet, M.A., Hales, B.E., Takahashi, T., Landry, M.R., Bidigare, R.R., Wang, X.J., Chase, Z., Strutton, P.G., Friederich, G.E., Gorbunov, M.Y., Lance, V.P., Hilting, A.K., Hiscock, M.R., Demarest, M., Hiscock, W.T., Sullivan, K.F., Tanner, S.J., Gordon, R.M., Hunter, C.N., Elrod, V.A., Fitzwater, S.E., Jones, J.L., Tozzi, S., Koblizek, M., Roberts, A.E., Herndon, J., Brewster, J., Ladizinsky, N., Smith, G., Cooper, D., Timothy, D., Brown, S.L., Selph, K.E., Sheridan, C.C., Twining, B.S., Johnson, Z.I., 2004. Southern ocean iron enrichment experiment: Carbon cycling in high- and low-Si waters. Science 304 (5669) 408-414.

Dunne, J.P., Armstrong, R.A., Gnanadesikan, A., Sarmiento, J.L., 2005. Empirical and mechanistic models for the particle export ratio. Global Biogeochemical Cycles 19 (4). 
Eppley, R.W., Peterson, B.J., 1979. Particulate organic matter flux and planktonic new production in the deep ocean. Nature 282 677-680.

François, R., Honjo, S., Krishfield, R., Manganini, S., 2002. Factors controlling the flux of organic carbon to the bathypelagic zone of the ocean. Global Biogeochemical Cycles 16 (4) 1087-1106.

Green, S.E., Sambrotto, R.N., 2006. Net community production in terms of C, N, P and Si in the Antarctic Circumpolar Current and its influence on regional water mass characteristics. Deep-Sea Research Part I-Oceanographic Research Papers 53 (1) 111-135.

Hedges, J.I., Baldock, J.A., Gelinas, Y., Lee, C., Peterson, M.L., Wakeham, S.G., 2002. The biochemical and elemental compositions of marine plankton: A NMR perspective. Marine Chemistry 78 (1) 47-63.

Ho, T.Y., Quigg, A., Finkel, Z.V., Milligan, A.J., Wyman, K., Falkowski, P.G., Morel, F.M.M., 2003. The elemental composition of some marine phytoplankton. Journal of Phycology 39 (6) 1145-1159.

Honjo, S., Francois, R., Manganini, S., Dymond, J., Collier, R., 2000. Particle fluxes to the interior of the Southern Ocean in the Western Pacific sector along 170 degrees W. DeepSea Research Part Ii-Topical Studies in Oceanography 47 (15-16) 3521-3548.

Hurd, D.C., Theyer, F., 1977. Changes in Physical and Chemical Properties of Biogenic Silica from Central Equatorial Pacific .2. Refractive-Index, Density, and Water-Content of Acid-Cleaned Samples. American Journal of Science 277 (9) 1168-1202.

Klaas, C., Archer, D.E., 2002. Association of sinking organic matter with various types of mineral ballast in the deep sea: Implications for the rain ratio. Global Biogeochemical Cycles 16 (4) 1116-1129.

Laws, E.A., Falkowski, P.G., Smith, W.O., Ducklow, H., Mccarthy, J.J., 2000. Temperature effects on export production in the open ocean. Global Biogeochemical Cycles 14 (4) 1231-1246.

Lutz, M., Dunbar, R., Caldeira, K., 2002. Regional variability in the vertical flux of particulate organic carbon in the ocean interior. Global Biogeochemical Cycles 16 (3).

Martin, J.H., Knauer, G.A., 1973. Elemental Composition of Plankton. Geochimica Et Cosmochimica Acta 37 (7) 1639-1653.

Martin, J.H., Knauer, G.A., Karl, D.M., Broenkow, W.W., 1987. Vertex - Carbon Cycling in the Northeast Pacific. Deep-Sea Research Part a-Oceanographic Research Papers 34 (2) 267285.

Michaels, A.F., Silver, M.W., 1988. Primary production, sinking fluxes and the microbial food web. Deep Sea Research Part A. Oceanographic Research Papers 35 (4) 473-490.

Millero, F.J., Poisson, A., 1981. International one-atmosphere equation of state of seawater. Deep Sea Research Part A. Oceanographic Research Papers 28 (6) 625-629.

Moore, J.K., Abbott, M.R., 2000. Phytoplankton chlorophyll distributions and primary production in the Southern Ocean. Journal of Geophysical Research-Oceans 105 (C12) 28709-28722.

Mortlock, R.A., Froelich, P.N., 1989. A Simple Method for the Rapid-Determination of Biogenic Opal in Pelagic Marine-Sediments. Deep-Sea Research Part a-Oceanographic Research Papers 36 (9) 1415-1426.

Pilson, M.E. 1998. An introduction to the chemistry of the sea. Prentice-Hall. 
Rubin, S.I., 2003. Carbon and nutrient cycling in the upper water column across the Polar Frontal Zone and Antarctic Circumpolar Current along 170 degrees W. Global Biogeochemical Cycles 17 (3).

Schiebel, R., 2002. Planktic foraminiferal sedimentation and the marine calcite budget. Global Biogeochemical Cycles 16 (4).

Trull, T.W., Bray, S.G., Manganini, S.J., Honjo, S., Francois, R., 2001. Moored sediment trap measurements of carbon export in the Subantarctic and Polar Frontal Zones of the Southern Ocean, south of Australia. Journal of Geophysical Research-Oceans 106 (C12) 31489-31509.

Volk, T., Hoffert, M.I., 1985. Ocean carbon pumps: Analysis of relative strengths and efficiencies in ocean-driven atmospheric $\mathrm{CO}_{2}$ changes. Geophysical Monographs 32 99110.

Young, J.R., 1994. Functions of coccoliths. In: A. Winter and W. G. Siesser [Eds.], Coccolithophores. Cambridge University Press, Cambridge, UK, pp. 63-82. 